\title{
EFFECT OF WATER CONTENT AND DENSITY ON STRENGTH AND DEFORMATION BEHAVIOR OF CLAY SOILS
}

A thesis submitted to the

Kent State University Graduate College

in partial fulfillment of the requirements

for the degree of Master of Science

By

John Paul Malizia

May 2016 
Thesis written by

John Paul Malizia

B.S., Edinboro University, 2013

M.S., Kent State University, 2016

Approved by

\begin{abstract}
Abdul Shakoor, Ph. D., Advisor:
Daniel Holm, Ph.D., Chair, Department of Geology
\end{abstract}

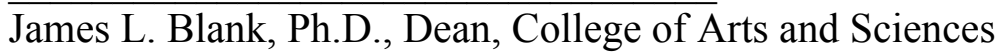




\section{TABLE OF CONTENTS}

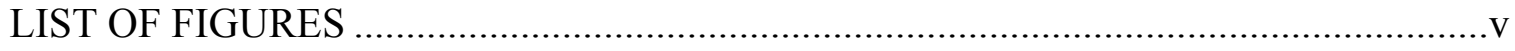

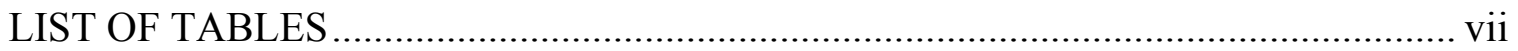

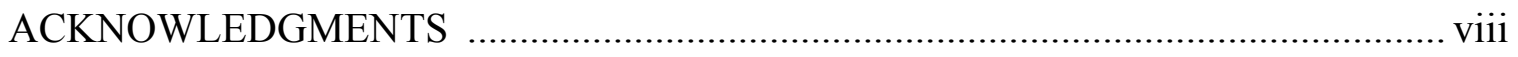

ABSTRACT

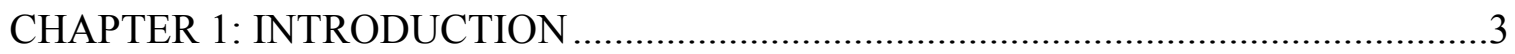

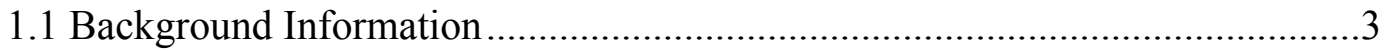

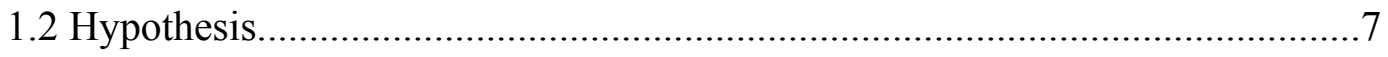

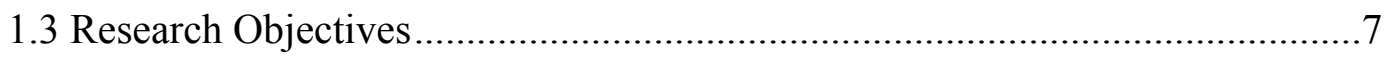

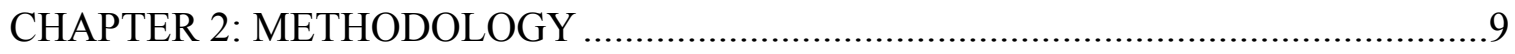

2.1 Sampling and Sample Preparation ............................................................

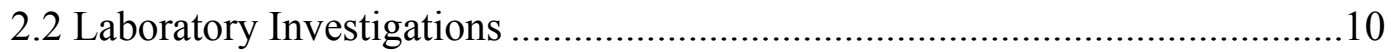

2.2.1 Grain Size Analysis.......................................................................10

2.2.2 X-Ray Diffraction Analysis ..............................................................11

2.2.3 Atterberg Limits Test...................................................................11

2.2.4 Compaction Test ...........................................................................11

2.2.5 Unconfined Compression Test........................................................12

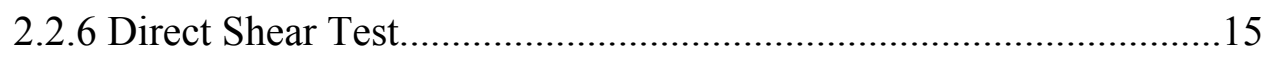

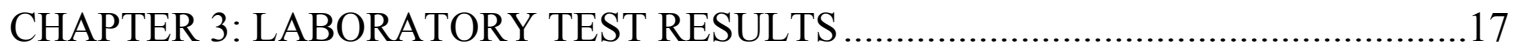

3.1 Grain Size Analysis Results...................................................................... 


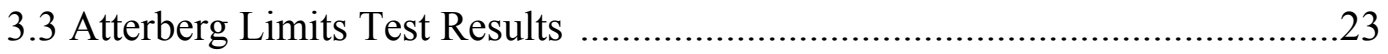

3.4 Compaction Test Results ..................................................................24

3.5 Unconfined Compression Test Results ................................................28

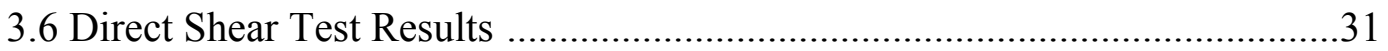

CHAPTER 4: QUANTIFYING THE TRANSITION WATER CONTENT BETWEEN BRITTLE AND PLASTIC BEHAVIORS ..........................................36

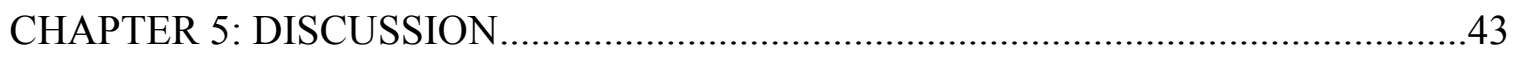

CHAPTER 6: CONCLUSIONS AND RECOMMENDATIONS .................................46

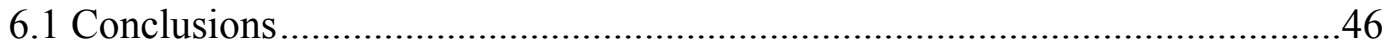

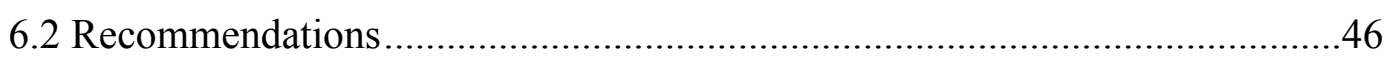

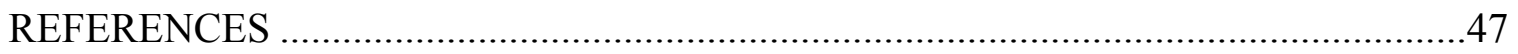

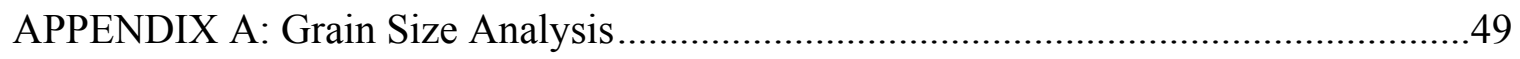

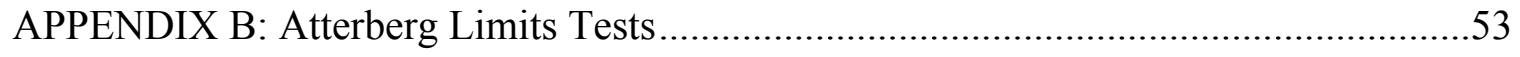

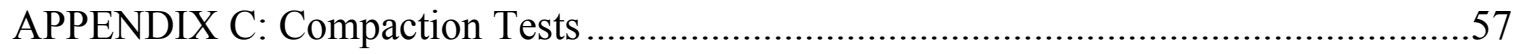

APPENDIX D: Unconfined Compression Tests ......................................................61

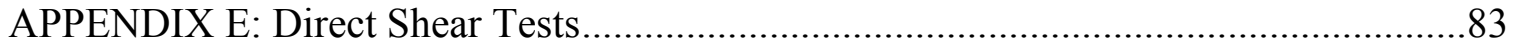




\section{LIST OF FIGURES}

Page

Figure 1.1: Casagrande plasticity chart for classification of fine-grained soils according to the USCS (modified from Scott, 2000).

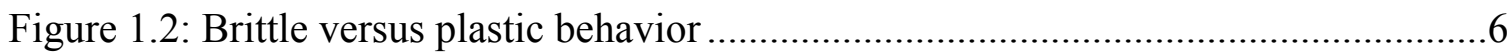

Figure 1.3: Compaction curves of a soil showing the relationship between water content and dry density for two different compactive efforts (After Holtz et al., 2011).

Figure 2.1: Unconfined compression machine

Figure 2.2: Example of stress-strain relationship for brittle and plastic deformation behaviors

Figure 3.1: Grain Size Distribution for the low plasticity clay......................................18

Figure 3.2: Grain Size Distribution for the medium plasticity clay...............................18

Figure 3.3: Grain Size Distribution for the high plasticity clay ...................................18

Figure 3.4: X-ray diffraction analysis for the low plasticity clay ..................................20

Figure 3.5: X-ray diffraction analysis for the medium plasticity clay ............................21

Figure 3.6: X-ray diffraction analysis for the high plasticity clay ................................22

Figure 3.7: A plot of Atterberg limits of the three samples on the Casagrande plasticity chart.

Figure 3.8: Compaction curve for the low plasticity clay ..........................................26

Figure 3.9: Compaction curve for the medium plasticity clay ......................................27

Figure 3.10: Compaction curve for the high plasticity clay......................................28

Figure 3.11: Relationship between unconfined compressive strength and compaction water content for the low plasticity clay 
Figure 3.12: Relationship between unconfined compressive strength and compaction water content for the medium plasticity clay....

Figure 3.13: Relationship between unconfined compressive strength and compaction water content for the high plasticity clay ...............................................30

Figure 3.14: Relationship between friction angle and compaction water content for the low plasticity clay

Figure 3.15: Relationship between friction angle and compaction water content for the medium plasticity clay ......

Figure 3.16: Relationship between friction angle and compaction water content for the high plasticity clay

Figure 3.17: Relationship between cohesion and compaction water content for the low plasticity clay .34

Figure 3.18: Relationship between cohesion and compaction water content for the medium plasticity clay

Figure 3.19: Relationship between cohesion and compaction water content for the high plasticity clay .35

Figure 4.1: Range of the low plasticity clay samples failed under unconfined compression .36

Figure 4.2: Range of the medium plasticity clay samples failed under unconfined compression

Figure 4.3: Range of the high plasticity clay samples failed under unconfined compression

Figure 4.4: Stress-strain curves for the low plasticity clay .38

Figure 4.5: Stress-strain curves for the medium plasticity clay. 39

Figure 4.6: Stress-strain curves for the high plasticity clay..... 40

Figure 5.1: Plot of Plasticity Index versus average transition water content. .45 


\section{LIST OF TABLES}

Page

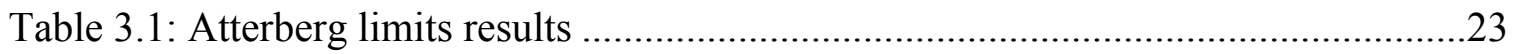

Table 3.2: Cohesion and friction angle values for each sample as determined from the Mohr envelopes ........................................................................ 32 


\section{ACKNOWLEGMENTS}

I would first like to thank my advisor, Dr. Abdul Shakoor, for his tolerance, advice, and expert guidance throughout my project. You have taught me so much. Thank you.

I would also like to thank my committee members, Dr. Daniel Holm and Dr. Neil Wells, for keeping me on track towards my goal and finishing my degree.

I want to extend my deepest gratitude to my classmates Stuart Baker and Sebastian Dirringer, for helping, inspiring, and supporting me through grad school to achieve this milestone.

I am deeply grateful for my siblings, Annie, Joe, Tom, and Mike, for urging me to further my education.

I would like to acknowledge my parents, Paul and Beth, for their guidance and support throughout all of my upbringing, teaching me to apply myself, and to always do my best.

Lastly, I would like to thank my wife, Karen Leigh, for keeping me focused to finish my studies, supporting and following me wherever I have had to go, and for putting up with me along the way. I cannot thank you enough! 


\begin{abstract}
Clays are used widely in sanitary landfills, embankment dams, highway embankments, hydraulic barriers, and foundations. In most of these applications, clays are compacted at maximum dry density (MDD) and optimum water content (OWC). Density and water content have a profound effect on the strength and deformation behavior of compacted clays. However, this effect has not been quantified in detail, especially the water content at which transition from brittle to plastic behavior occurs for low, medium, and high plasticity clays. The objective of this research was to investigate the effect of varying water content and density on the strength and deformation behavior of low, medium, and high plasticity clays, and to quantify the transition water content between brittle and plastic behavior for each type of clay.

Initially, six samples each of low, medium, and high plasticity clays were compacted, three on the dry side and three on the wet side of OWC, to establish their compaction curves. The compacted samples were failed axially under unconfined compression and were visually inspected to determine the water content at which transition occurred between brittle and plastic deformation. Additionally, three samples of each type of clay were compacted at different water contents and failed using the direct shear test. The stress-strain curves from both tests were used to determine the transition water content between brittle and plastic behaviors.

The MDD values for low, medium, and high plasticity clays were found to be $102.5 \mathrm{lb} / \mathrm{ft}^{3}\left(1.64 \mathrm{Mg} / \mathrm{m}^{3}\right), 95 \mathrm{lb} / \mathrm{ft}^{3}\left(1.52 \mathrm{Mg} / \mathrm{m}^{3}\right)$, and $89.5 \mathrm{lb} / \mathrm{ft}^{3}\left(1.43 \mathrm{Mg} / \mathrm{m}^{3}\right)$, with the
\end{abstract}


corresponding OWC values of $18 \%, 25 \%$, and $27 \%$, respectively. The compressive strength values for the low, medium, and high plasticity clays at MDD and OWC were 54 psi (344.8 kPa), 59 psi (413.8 kPa), and 60 psi (420.7 kPa), respectively. The unconfined compressive strength first increased and then decreased with increasing water content, with the change in trend occurring within $5 \%$ of OWC for each type of clay. The high plasticity clay had the highest cohesion while the low plasticity clay had the highest friction angle. The transition between brittle and plastic behavior for the low, medium, and high plasticity clays occurred between $19-20 \%, 27-29 \%$, and $30-32 \%$ water content, respectively.

This study was aimed at determining the transition water content as it relates to both brittle and plastic deformation. Earthquakes can cause failure of embankment dams in the form of cracking due to displacements or differential settlements from the vibrations. To prevent such failures from occurring, a homogenous embankment dam consisting of low plasticity clay (CL) or the clay core of a zoned embankment dam, must be compacted so that the clay material behaves more like a plastic material, i.e. deforms without a well developed failure plane. This study shows that, to ensure structural integrity of embankment dams in seismically active areas, the clay should not only be compacted wet of the OWC, but also on the wet side of the transition water content marking the boundary between brittle and plastic deformations. 


\section{CHAPTER 1}

\section{INTRODUCTION}

\subsection{Background Information}

Clays are fine-grained soils with more than 50\% particles passing the \#200 sieve $(0.074 \mathrm{~mm})$ (Mitchell and Soga, 2005). Current grain size classifications place the boundary between silt and clay either at $0.005 \mathrm{~mm}$ or at $0.002 \mathrm{~mm}$ (Mitchell and Soga, 2005, Hubert et al., 2009; Holtz et al., 2011). According to the American Society for Testing and Materials (ASTM) classification, clay soils have particles smaller than 0.002 mm (ASTM, 2010). The Unified Soil Classification System (USCS), developed by Casagrande (1948), classifies clays on the basis of Atterberg limits, which indicate plasticity characteristics of the soil, not on the basis of particle size (Holtz et al., 2011). This is because Casagrande (1948) found that the engineering behavior of clay soils depended on their plasticity characteristics rather than particle size. Atterberg limits (liquid limit, plastic limit, plasticity index) are water contents at which marked changes occur in the engineering behavior of fine-grained soils. Liquid limit (LL) is the minimum water content at which a soil behaves as a viscous liquid, plastic limit (PL) is the minimum water content at which a soil behaves as a plastic material, and plasticity index (PI) is the numerical difference between LL and PL. The PI indicates the range of water content over which a soil behaves as a plastic material. The Casagrande plasticity chart (Figure 1.1) is used to differentiate between silts and clays, with silts plotting below the A-line and clays plotting above the A-line (Casagrande, 1948; Wesley 2003; Mitchell and 
Soga, 2005; Holtz et al., 2011). Based on the liquid limit values, clays are further divided into low plasticity $(\mathrm{LL}<50)$ and high plasticity (LL > 50) clays (Casagrande, 1948; Wesley, 2003; Mitchell and Soga, 2005; Holtz et al., 2011).

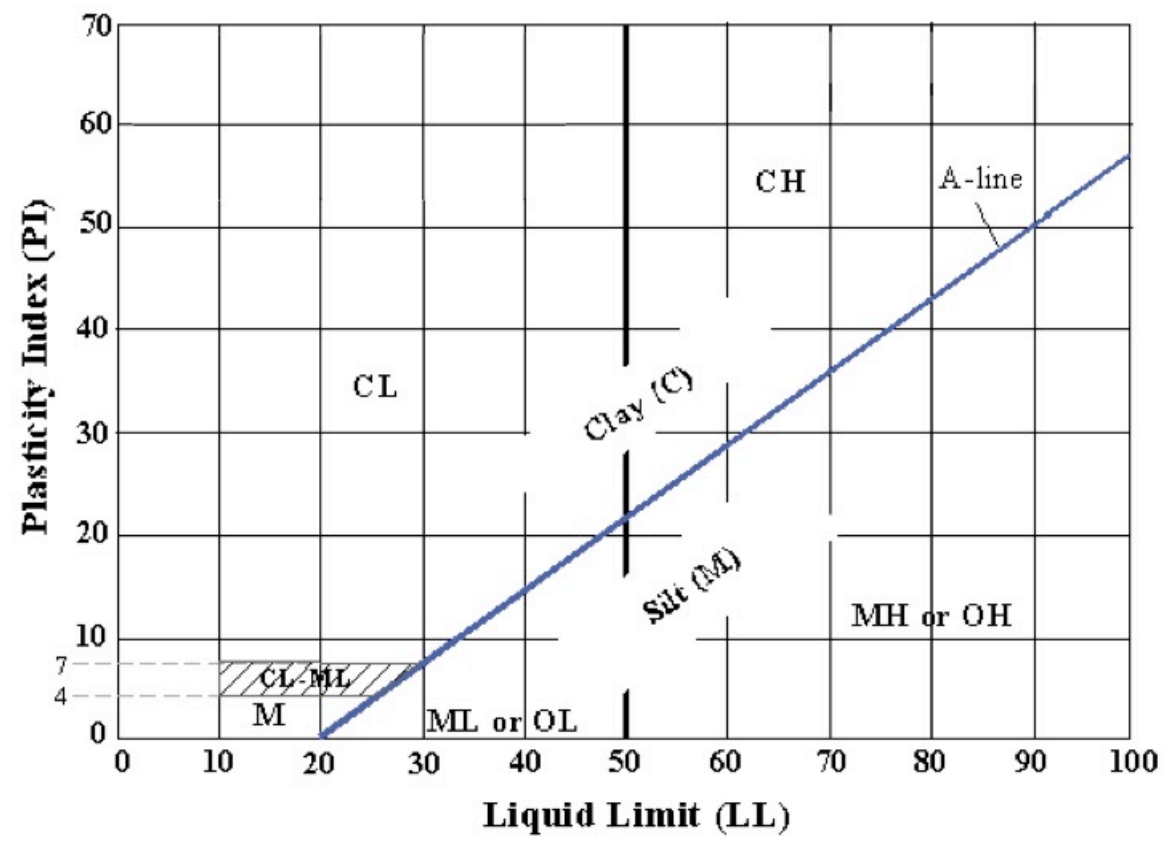

Figure 1.1 Casagrande plasticity chart for classification of fine-grained soils according to the USCS (modified from Scott, 2000).

Clay soils are extensively used in construction of structures such as liners for sanitary landfills, embankment dams, highway embankments, general hydraulic barriers, and as foundation material. In most of these applications, clay soils are compacted at maximum dry density (MDD) and optimum water content (OWC) (Das, 1998; Holtz et al., 2011). Water content is the ratio of the mass of water to the mass of solids, expressed as a percentage, in a given volume of soil (Mitchell and Soga, 2005; Holtz et al., 2011). The optimum water content is the water content at which maximum dry density is 
achieved. In all of the construction applications of clay soils stated above, their engineering properties and deformation characteristics, such as unconfined compressive strength, shear strength, compressibility, and brittle versus plastic behavior, depend on their density and water content, either present naturally or as a result of compaction (Spangler and Handy, 1973; Voight, 1973; Wang and Huang 1984; Blotz et al., 1998; AlShayea, 2001; Wesley, 2003; Mitchell and Soga, 2005; Al-Zoubi, 2008; Jesmani et al., 2008; Holtz et al., 2011; Kalkan, 2011; Rao et al., 2011; Mishra et al., 2012). Depending upon the water content of a compacted clay soil, it can behave either as a brittle material or a plastic material under the application of stresses (Spangler and Handy, 1973; Mitchell and Soga, 2005; Holtz et al., 2011). Figure 1.2 shows how two samples of a clay soil, compacted at different water contents, behave differently when subjected to unconfined compression - one failing as a brittle material (right) and the other as a plastic material (left). Whether a clay soil behaves as a brittle or a plastic material is of great practical significance in projects where clay is used as a hydraulic barrier such as sanitary landfills, embankment dams, and foundations. This is because brittle deformation of hydraulic barriers, in the form of fracturing, can lead to serious problems of leakage and erosion (Mitchell and Soga, 2005). The water content at which transition from brittle to plastic behavior occurs is anticipated to depend on the type of clay, i.e. low plasticity, medium plasticity, and high plasticity, which, in turn, depends on the amount of clay size particles and the types of clay minerals (Mitchell and Soga, 2005; Holtz et al., 2011). 


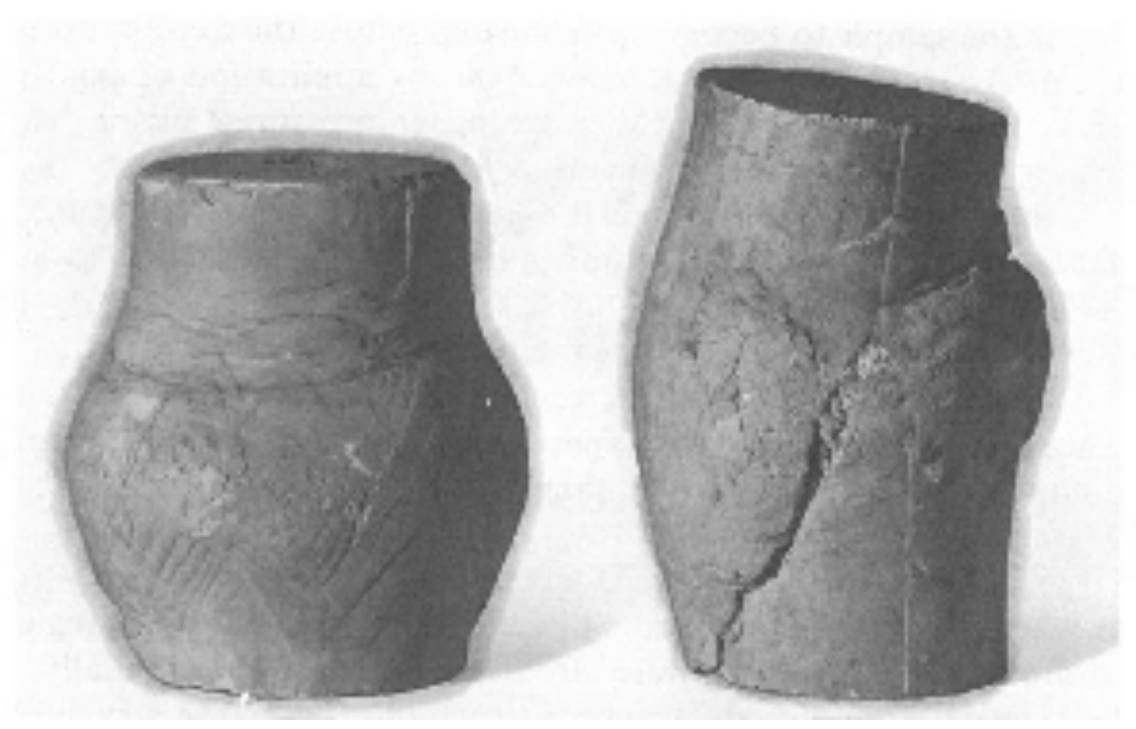

Figure 1.2: Plastic (left) versus brittle (right) behavior of clay samples under compression (after Spangler and Handy, 1973).

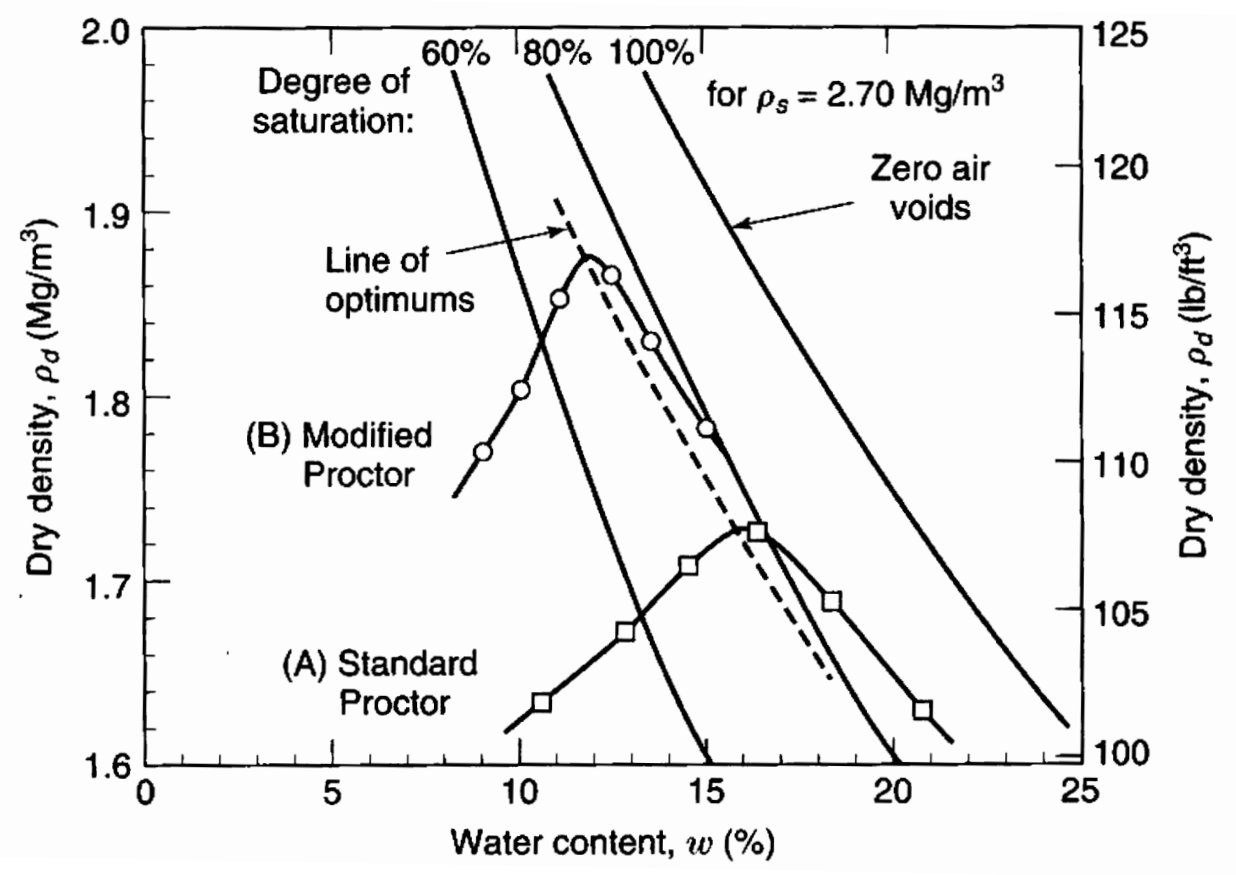

Figure 1.3: Compaction curves of a soil showing the relationship between water content and dry density for two different compactive efforts (After Holtz et al., 2011). 
Figure 1.3 shows the compaction curves for a soil at two different compactive efforts. It is clear from the figure that density of a compacted soil is a function of compaction water content. Generally, on the dry side of the optimum water content, clay soils are known to behave as a brittle material whereas wet of the optimum content they behave as a plastic material (Hoek and Brown, 1980; Mitchell and Soga, 2005; Holtz et al., 2011).

\subsection{Hypothesis}

The above discussion shows that density and water content have a profound effect on strength and deformation behavior of compacted clay soils. Holtz et al. (2011) have several figures showing the effect of density and water content in the section on "Properties of Compacted Cohesive Soils". However, the effect of water content and density on the strength and deformation of clay soils has not been quantified in detail, especially the water content at which transition from brittle to plastic behavior occurs for low plasticity, medium plasticity, and high plasticity clays. The hypothesis for this research was that the transition between brittle and plastic behavior of compacted clays would occur at a water content between $2-3 \%$ of the optimum water content.

\section{$\underline{1.3 \text { Research Objectives }}$}

The objectives of this research were:

1. To investigate the effect of varying density and water content on strength behavior of a low plasticity clay, a medium plasticity clay, and a high plasticity clay.

2. To investigate the effect of varying density and water content on deformation 
behavior (brittle vs. plastic) of a low plasticity clay, a medium plasticity clay, and a high plasticity clay.

3. To investigate the water content at which the transition from brittle to plastic behavior occurs for the three types of clay. 


\section{CHAPTER 2}

\section{METHODOLOGY}

\subsection{Sampling and Sample Preparation}

Six $100 \mathrm{lb}(45.5 \mathrm{~kg})$ samples of a clay soil were collected from the head scarp of a landslide along the Chagrin River Road, near the western border of Chagrin Valley Parkway. Three $1000 \mathrm{~g}$ samples of the clay soil were weighed in the wet state, oven dried for 24 hours at $105^{\circ} \mathrm{C}$, and weighed again in the dry state to determine the natural water content of the clay soil. The test showed that the clay had a natural water content of $30 \%$. The rest of the clay soil was oven dried for 24 hours, placed in large plastic bags, and stored in airtight five-gallon buckets for laboratory testing. For other laboratory tests, the Los Angeles (L.A.) Abrasion equipment, consisting of a large-size steel drum and 2inch $(5.1 \mathrm{~cm})$ diameter steel balls, was used to pulverize the clay lumps into fine particles. The clay was placed in the drum, along with 11 steel balls, and the gauge on the equipment was set to rotate the drum for 500 rotations at a rate of 25 rotations per minute. This procedure was repeated twice to ensure complete pulverization. The pulverized clay material was sieved through $\# 40(0.425 \mathrm{~mm})$ sieve.

The Atterberg limits test results from previous research (Kroenke, 1996; Wesley, 2003) indicated that the sampled clay was a low plasticity clay (CL). In order to prepare the medium and high plasticity $(\mathrm{CH})$ clay samples, four $100 \mathrm{lb}(45.5 \mathrm{~kg})$ samples of low plasticity clay were each mixed with $20 \%$ and $40 \%$ commercial bentonite by weight. The amount of bentonite to be added to obtain the desired clay type was determined by trial 
and error until the Atterberg limit tests revealed that the mixtures had the appropriate plasticity characteristics.

\subsection{Laboratory Investigations}

Laboratory tests were performed to determine grain size distribution, clay mineralogy, Atterberg limits, compaction characteristics, unconfined compressive strength, and shear strength parameters for the three types of clay. All laboratory tests were performed according to the standardized procedures by the American Society for Testing and Materials (ASTM), where applicable.

\subsubsection{Grain Size Analysis}

The purpose of this analysis was to determine the grain size distribution of each of the three types of clay (low plasticity, medium plasticity, and high plasticity). Clay of low plasticity (the basic clay used in this study) can contain a significant amount of silt. Therefore, it was considered important to see how the amount of clay-size material $(0.005 \mathrm{~mm}$ or $0.002 \mathrm{~mm})$ influenced the engineering properties (compaction characteristics, compressive strength, and shear strength parameters), stress-strain behavior, and the water content at which transition from brittle to plastic behavior was observed. The samples for the test were prepared by sieving each clay type through \#200 sieve $(0.074 \mathrm{~mm})$. A Malvern Mastersizer 2000 was used for determining the grain size distribution of the material passing the \#200 sieve. The Malvern Mastersizer 2000 uses an optical bench to capture the scattering pattern of light from a prepared sample through the use of the Fraunhofer model and Mie theory. The optical bench collects light, or takes "snapshots" of light, scattering from a range of angles from the samples passing 
through the beam at a certain time. The equipment takes roughly 2000 snaps for each measurement and averages them over time. This calculates and determines the sizes of the particles (Malvern Instruments Ltd., 2007). The computer software accompanying the Mastersizer automatically plots the grain size distribution curve for the sample tested. The results of grain size analysis are included in Appendix A.

\subsubsection{X-Ray Diffraction Analysis}

X-ray diffraction analysis was performed on each of the three types of un-oriented powdered clay used in this study, using glass mounted slides. The purpose of the analysis was to characterize the three types of clay in terms clay mineralogy and to investigate the effect of clay mineralogy on engineering properties, stress-strain behavior, and the transition water content. The analysis was performed using a Rigaku L03702N XRD. The scans ranged from 3 to 70 degrees and had a measurement time of two seconds per 0.02 degrees two-theta step. After completing the x-ray scans, JADE XRD software was used to identify the peaks and the corresponding clay minerals.

\subsubsection{Atterberg Limits Test}

The liquid limit (LL) and plastic limit (PL) were determined for the three clay types using ASTM method D4318 (ASTM, 2010). Appendix B provides the Atterberg limits test data for the individual samples. The plasticity index (PI) was determined as the arithmetic difference between the liquid limit and the plastic limit.

\section{$\underline{\text { 2.2.4 Compaction Test }}$}

The compaction test was performed to establish the compaction curves, showing the relationship between water content and dry density, for the three types of clay. The 
test was performed following ASTM procedure D698 (ASTM, 2010). Initially, six samples of each clay soil, each weighing $2100 \mathrm{~g}$, were prepared at varying water contents. The low plasticity clay samples were prepared with $8 \%, 12 \%, 16 \%, 20 \%, 24 \%$, and $28 \%$ water content, by weight. Six samples of medium plasticity clay were prepared by adding $14 \%, 19 \%, 23 \%, 27 \%, 29 \%$, and $31 \%$ water, by weight. For the high plasticity clay, $12 \%, 16 \%, 20 \%, 24 \%, 28 \%$, and $32 \%$ water, by weight, was added, respectively. Each sample was thoroughly mixed to achieve uniform distribution of water and was placed in plastic bags to allow the soil to cure for 24 hours. The cured samples were used for the compaction tests. After establishing the initial compaction curves, additional samples were prepared with other water contents, to further refine the compaction curves. Appendix C provides the results of the compaction tests.

\subsubsection{Unconfined Compression Test}

Unconfined compression tests were performed on the compacted samples of each of the three types of clay with their compaction water contents as stated in Section 2.2.4. The test was conducted in accordance with the procedure outlined in ASTM D2166 (ASTM, 2010). Each sample was tested immediately after its bulk density had been determined. A gauge, capable of reading to an accuracy of 0.0001 inch $(0.00252 \mathrm{~mm})$, was placed between the loading plates (Figure 2.1) to measure the decrease in sample length upon loading. The dial gauge readings were used to compute longitudinal strain (ratio of change in length to initial length, expressed as a percentage) corresponding to different stress values. The force at the failure of the sample was divided by the crosssectional area of the sample to determine compressive strength. For samples that 
deformed plastically during loading, $15 \%$ strain was originally chosen to represent the failure, however, the samples showed no increase in stress for an extended period of time before $15 \%$ strain. Therefore, $10 \%$ strain was chosen to represent the failure of the samples that deformed plastically during loading. This issue will be discussed later in Chapter 4.

Stress-strain curves were constructed after completing the unconfined compression test on each sample. The results from the unconfined compression test were used to evaluate the stress-strain behaviors including the transition boundary between brittle and plastic behavior of the three types of clays. Stress-strain curves for clays exhibiting brittle behavior are steeper and pass through a peak, whereas curves for clays that deform plastically are flatter and do not pass through a peak (Figure 2.2). Photographs of failed samples were taken to illustrate the brittle versus plastic modes of failure and deformation behavior at varying water contents (Appendix D). 


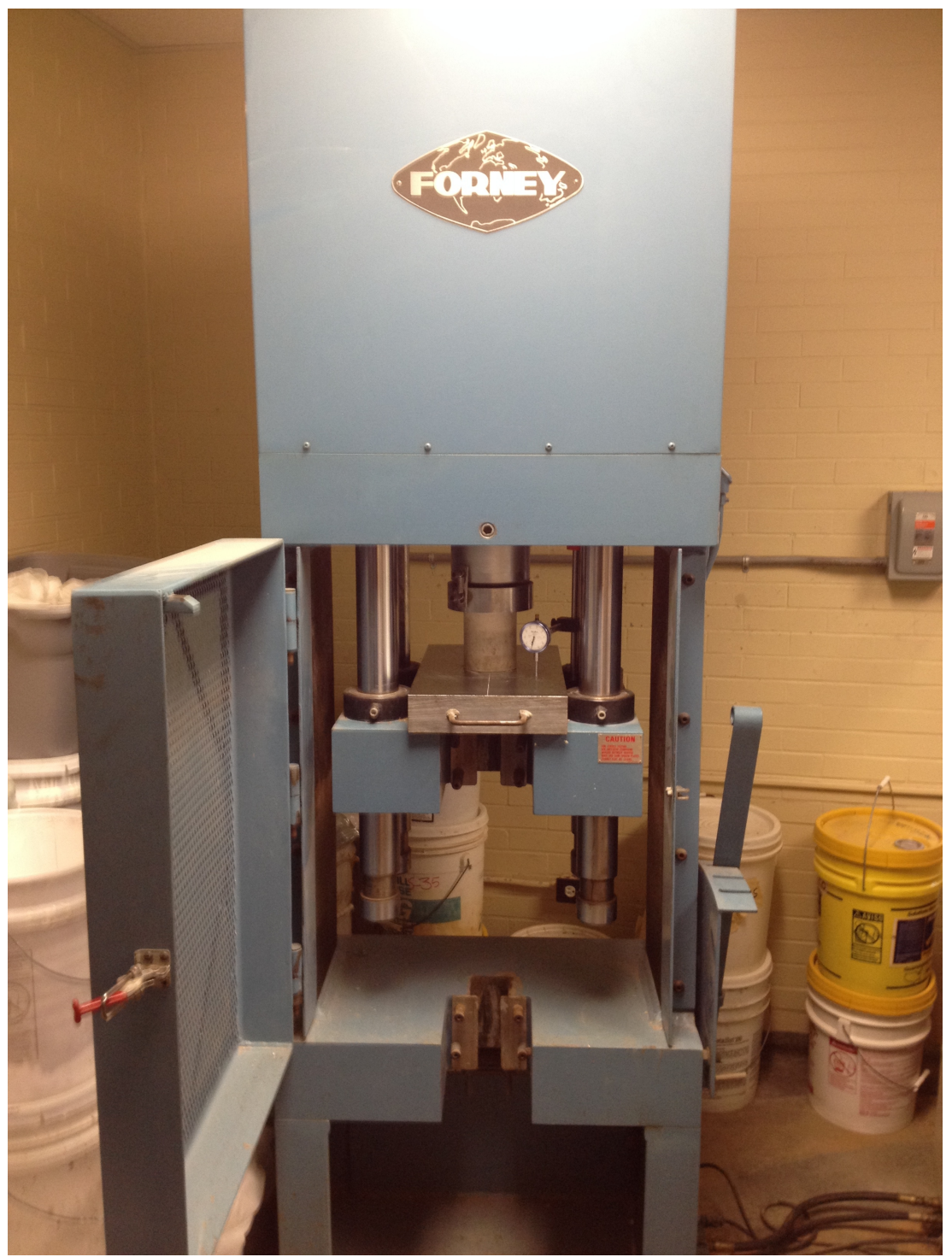

Figure 2.1: Unconfined compression test machine. Notice the sample between the loading plates and the gauge set up. 


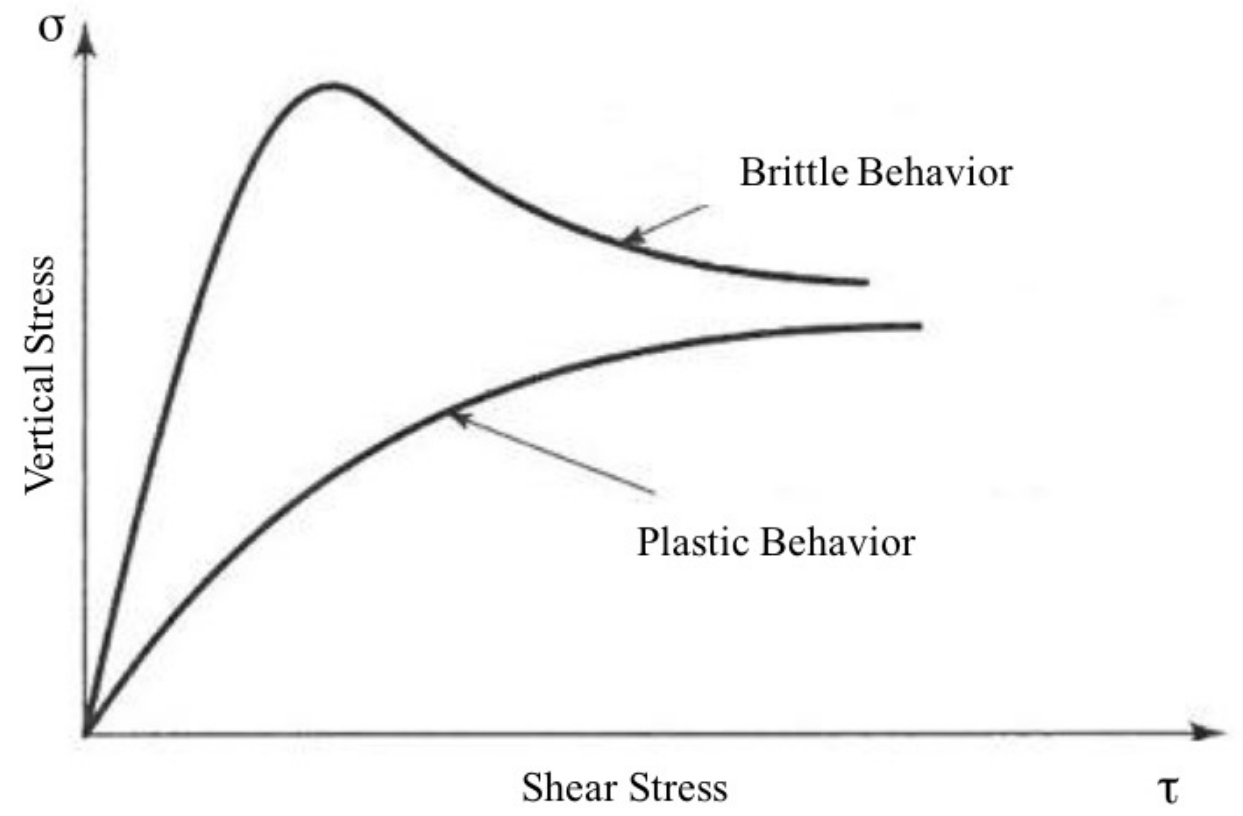

Figure 2.2: Example of stress-strain curves for brittle and plastic deformation behaviors.

\subsubsection{Direct Shear Test}

Three samples of each clay soil were prepared, one on the dry side of the optimum water content, one on the wet side of the optimum water content, and one close to the transition water content between brittle/plastic behavior, as indicated by the compression test results. Each was tested for strength parameters (cohesion and friction) using the direct shear test as specified in ASTM method D3080 (ASTM, 2010). A fourth sample for each of the medium and high plasticity clays was added to further refine the transition between brittle and plastic deformation behaviors. The samples for the direct shear test were compacted in the same manner as samples for the compaction test (ASTM method D698; ASTM 2010). Each compacted sample was cut into three nearly equal 
portions, perpendicular to the longitudinal axis. Each portion was then further cut to fit in the shear box (2" x 2" x 3/4" i.e. $5.1 \mathrm{~cm}$ x $5.1 \mathrm{~cm}$ x $1.9 \mathrm{~cm})$ and was tested in direct shear. Normal loads of $25 \mathrm{lb}(11.4 \mathrm{~kg}), 50 \mathrm{lb}(22.7 \mathrm{~kg})$, and $75 \mathrm{lb}(34.1 \mathrm{~kg})$ were used to perform the three trials of direct shear test on a sample with specific water content.

Stress-strain curves were constructed from the initial data. The stress-strain curves were used to establish the Mohr envelopes in each clay type. Cohesion and friction angle values were read from the Mohr envelopes. Appendix E provides the direct shear test results for the individual samples. 


\section{CHAPTER 3}

\section{LABORATORY TEST RESULTS}

\subsection{Grain Size Analysis Results}

Figures 3.1, 3.2, and 3.3 show the results of grain size analysis, as determined by the Malvern Mastersizer, for the low, medium, and high plasticity clays, respectively. The results indicate that the three clays well sorted, showing nearly log normal distributions, except for a small fraction of sand in the low and medium plasticity clays, and 5 microns $(0.005 \mathrm{~mm})$ being the most abundant particle size. Since $20 \%$ and $40 \%$ bentonite was added to create medium plasticity and high plasticity clay samples and since the bentonite is extremely fine grained, one would have expected the abundant particle size to decrease with increasing percentage of bentonite. However, the bentonite may have expanded with the addition of water and skewed the results. In spite of this limitation, the results confirm the clayey nature of the samples tested as most soil classifications define clays as soils with particle sizes smaller than 5 microns $(0.005 \mathrm{~mm})$. 


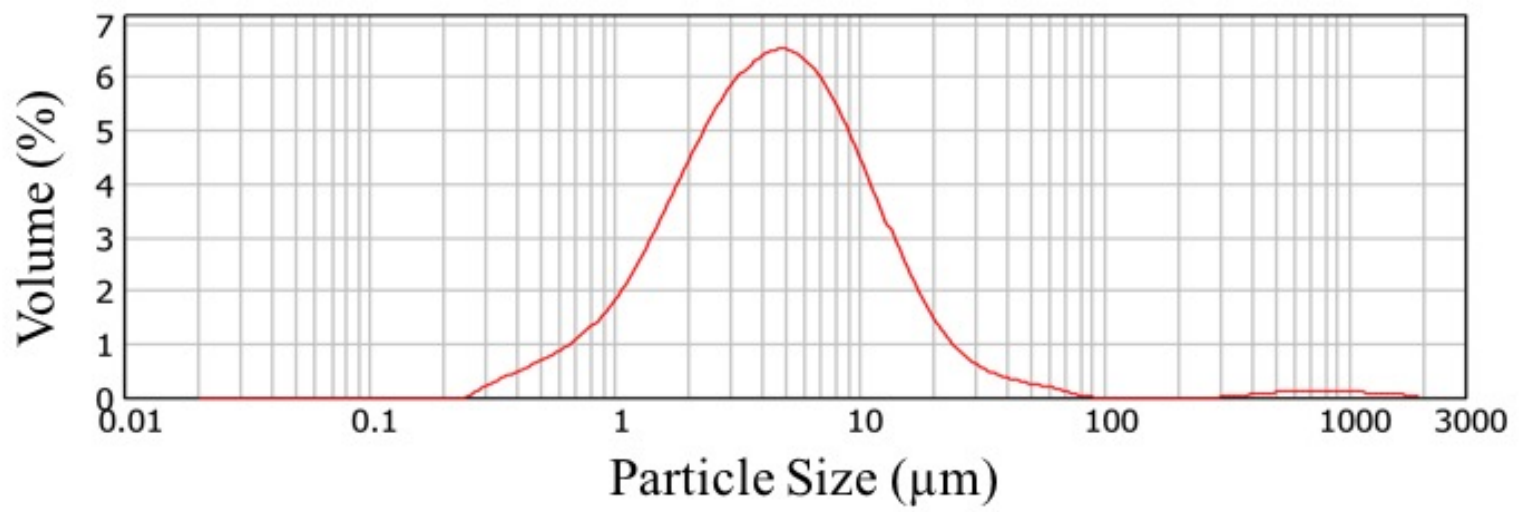

Figure 3.1: Grain size distribution for the low plasticity clay.

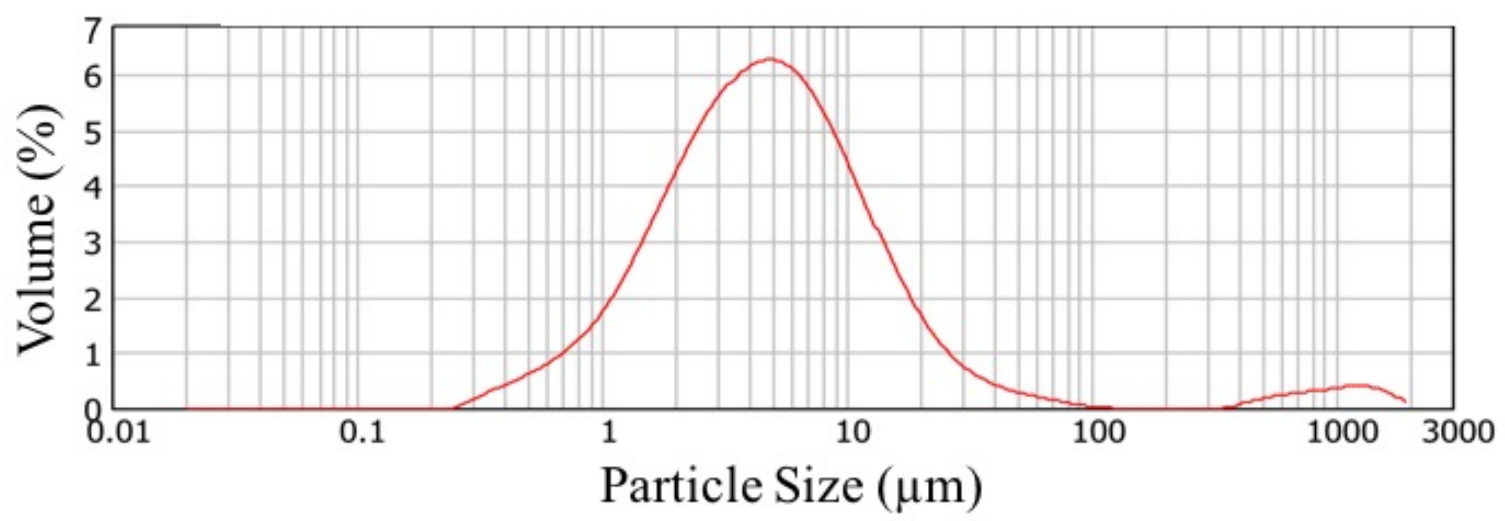

Figure 3.2: Grain size distribution for the medium plasticity clay.

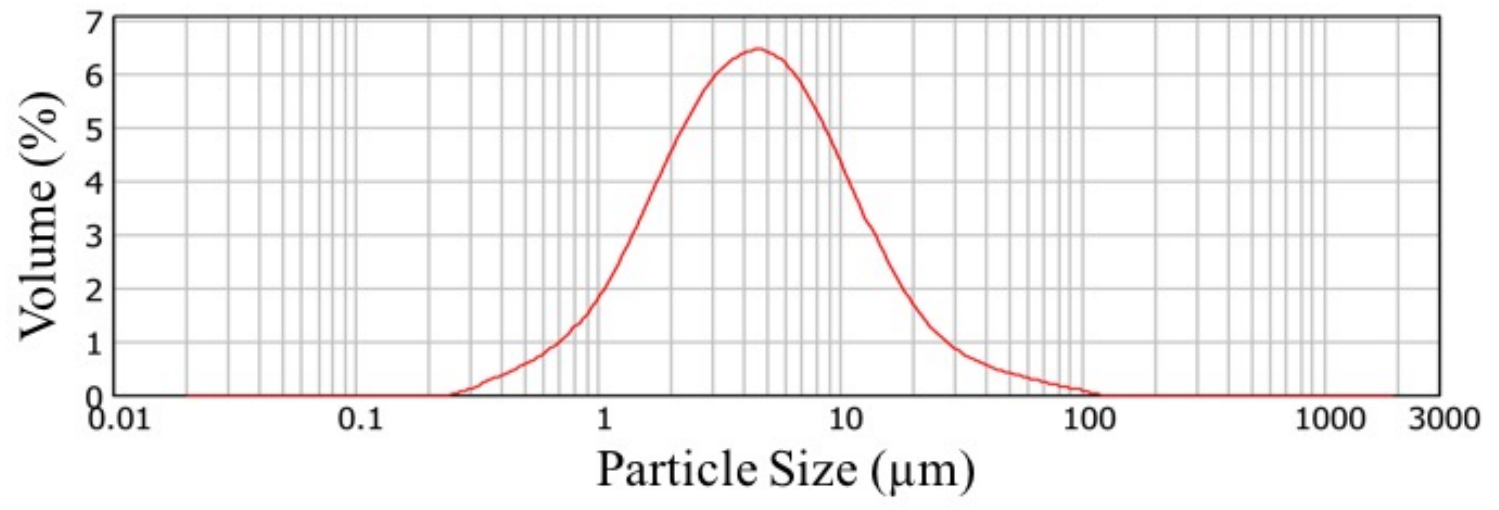

Figure 3.3: Grain size distribution for the high plasticity clay. 


\section{$\underline{3.2 \mathrm{X}-\text { Ray Diffraction Analysis Results }}$}

The results of the X-ray diffraction analysis for the low, medium, and high plasticity clays are shown in Figures 3.4, 3.5, and 3.6, respectively. The analysis indicates that all three un-oriented clay samples contain quartz, illite, and kaolinite as the primary minerals present, with smectite and chlorite as the secondary minerals. The major spike in the uppermost diffractogram in each figure shows the cumulative effect of all the minerals present in the sample. Upon closer examination, there is an increase in the intensity between the low plasticity clay and the medium plasticity clay within the major spike of the diffractogram pertaining to quartz. This suggests that the amount of bentonite added to the medium and high plasticity clays does not make a significant difference in the diffractograms. The reason for this discrepancy is not clear. It is possible that the JADE XRD software did not function properly. 


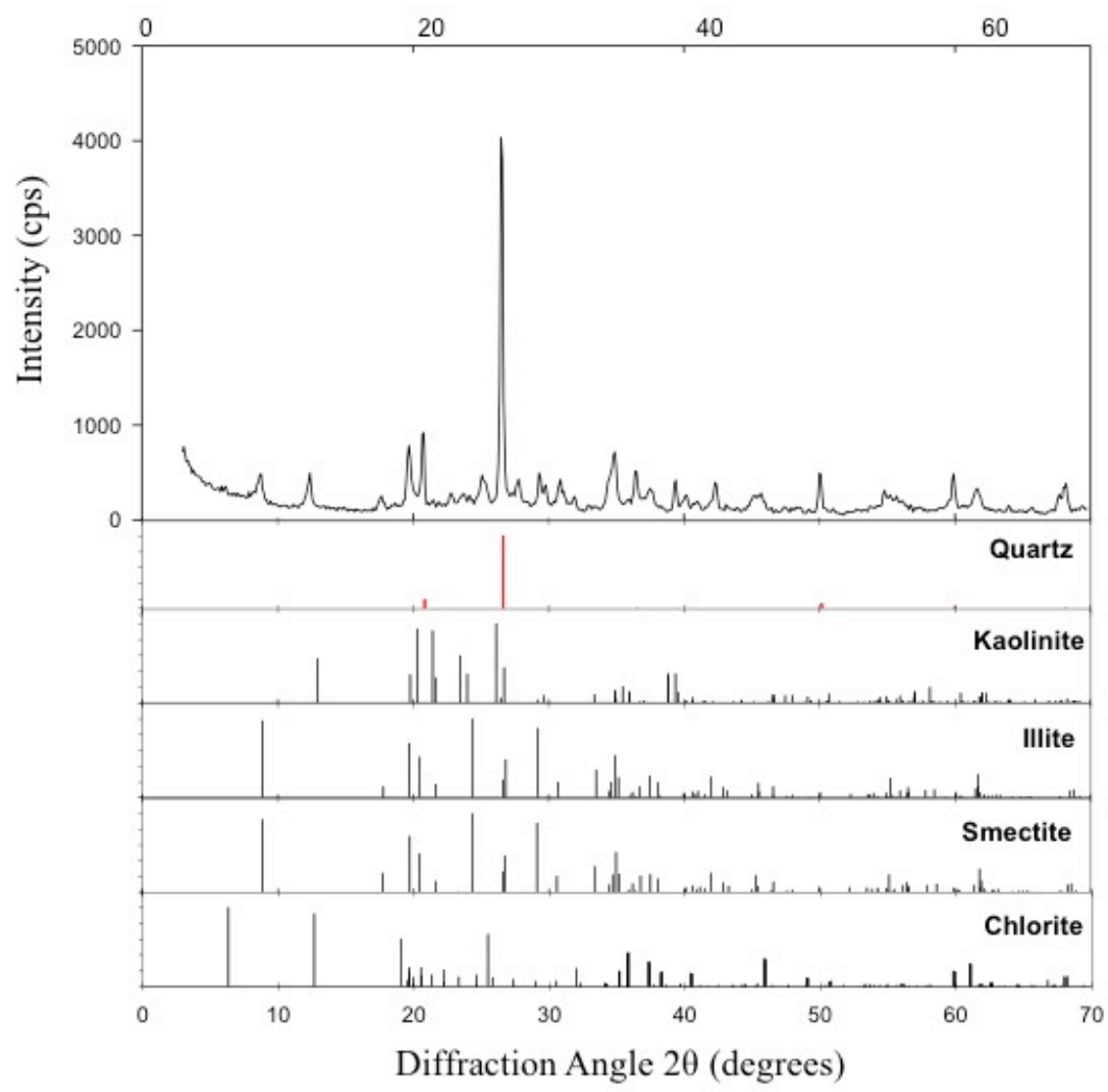

Figure 3.4: X-ray diffraction analysis results for the low plasticity clay. 


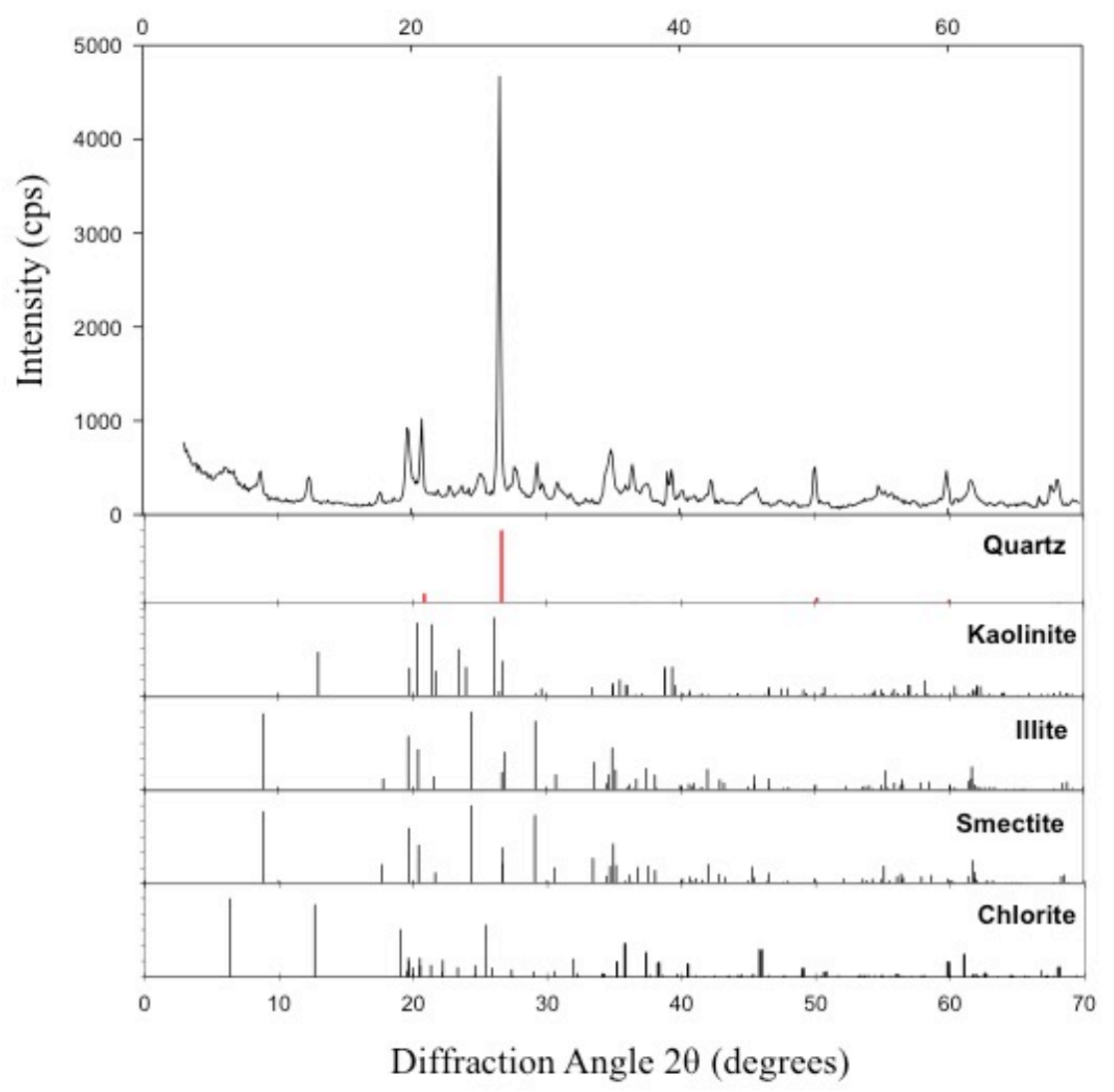

Figure 3.5: X-ray diffraction analysis results for medium plasticity clay. 


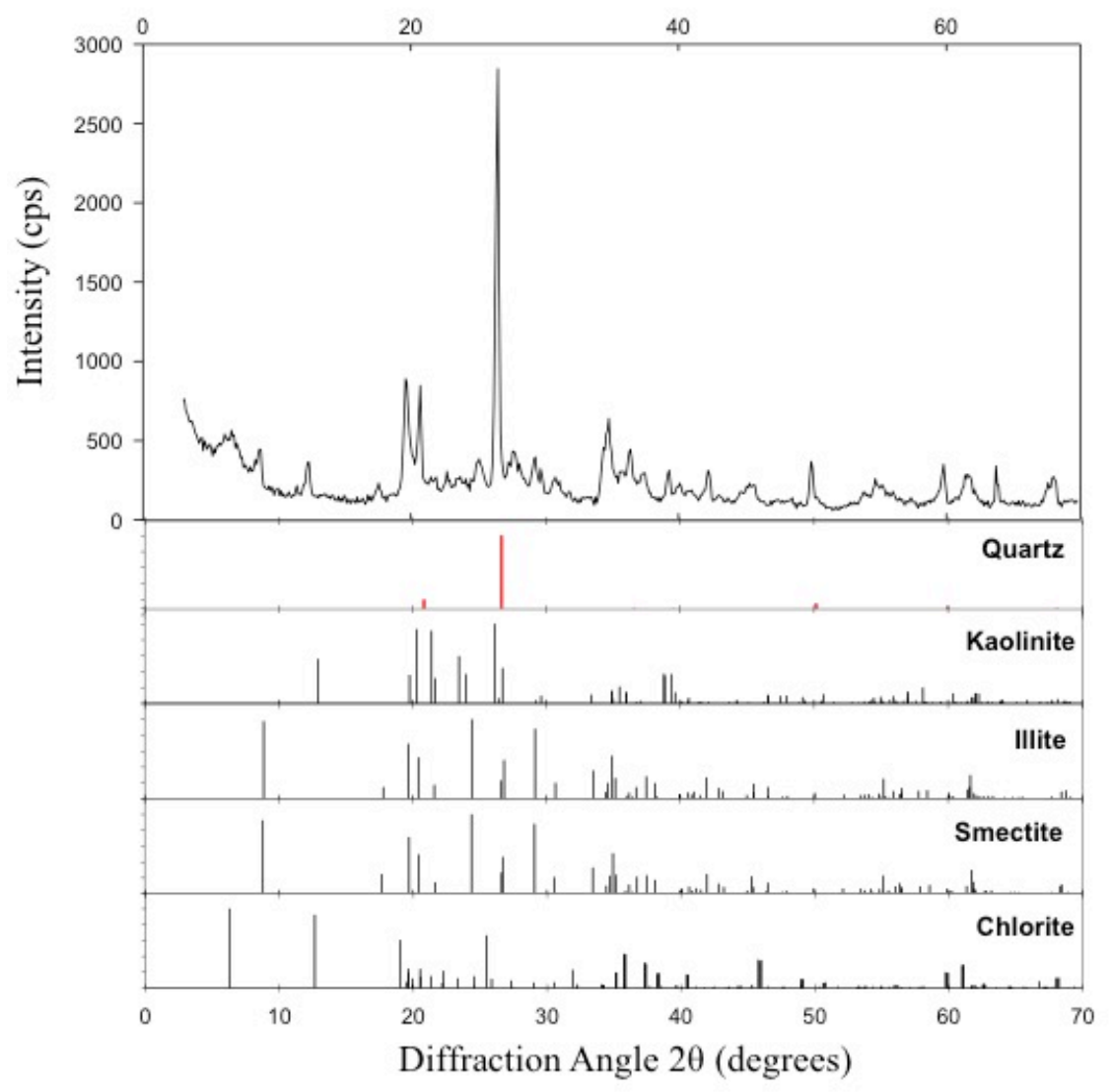

Figure 3.6: X-ray diffraction analysis for high plasticity clay. 


\section{$\underline{3.3 \text { Atterberg Limits Test Results }}$}

Table 3.1 shows the liquid limit (LL), plastic limit (PL), and plasticity index (PI) values for the three types of clay tested. Figure 3.7 shows the plots of LL and PI values for the three clays on the Casagrande plasticity chart. As can be seen from the figure, the three clays classify as CL or CH according to the USCS. The low plasticity clay (CL) plots to the left of LL value of 50 whereas the medium and high plasticity clays $(\mathrm{CH})$, containing $20 \%$ and $40 \%$ bentonite, respectively, plot to the right of LL value of 50 . Also, the PI value increases with increasing amount of bentonite, as expected. For each clay type, the average value of three tests was taken for each Atterberg limit test as shown in Table 3.1. For the high plasticity clay, I used two of the three PL values because two of the values matched while the third was significantly different and was considered an outlier.

Table 3.1: Atterberg limits test results.

\begin{tabular}{|c|c|c|c|}
\hline SAMPLE & Liquid Limit (LL) & Plastic Limit (PL) & Plasticity Index (PI) \\
\hline $\begin{array}{c}\text { Low Plasticity Clay } \\
\text { (CL) }\end{array}$ & 39 & 26 & 13 \\
\hline $\begin{array}{c}\text { Medium Plasticity } \\
\text { Clay (CH) }\end{array}$ & 66 & 32.6 & 33.4 \\
\hline $\begin{array}{c}\text { High Plasticity Clay } \\
(\mathrm{CH})\end{array}$ & 93 & 40 & 53 \\
\hline
\end{tabular}




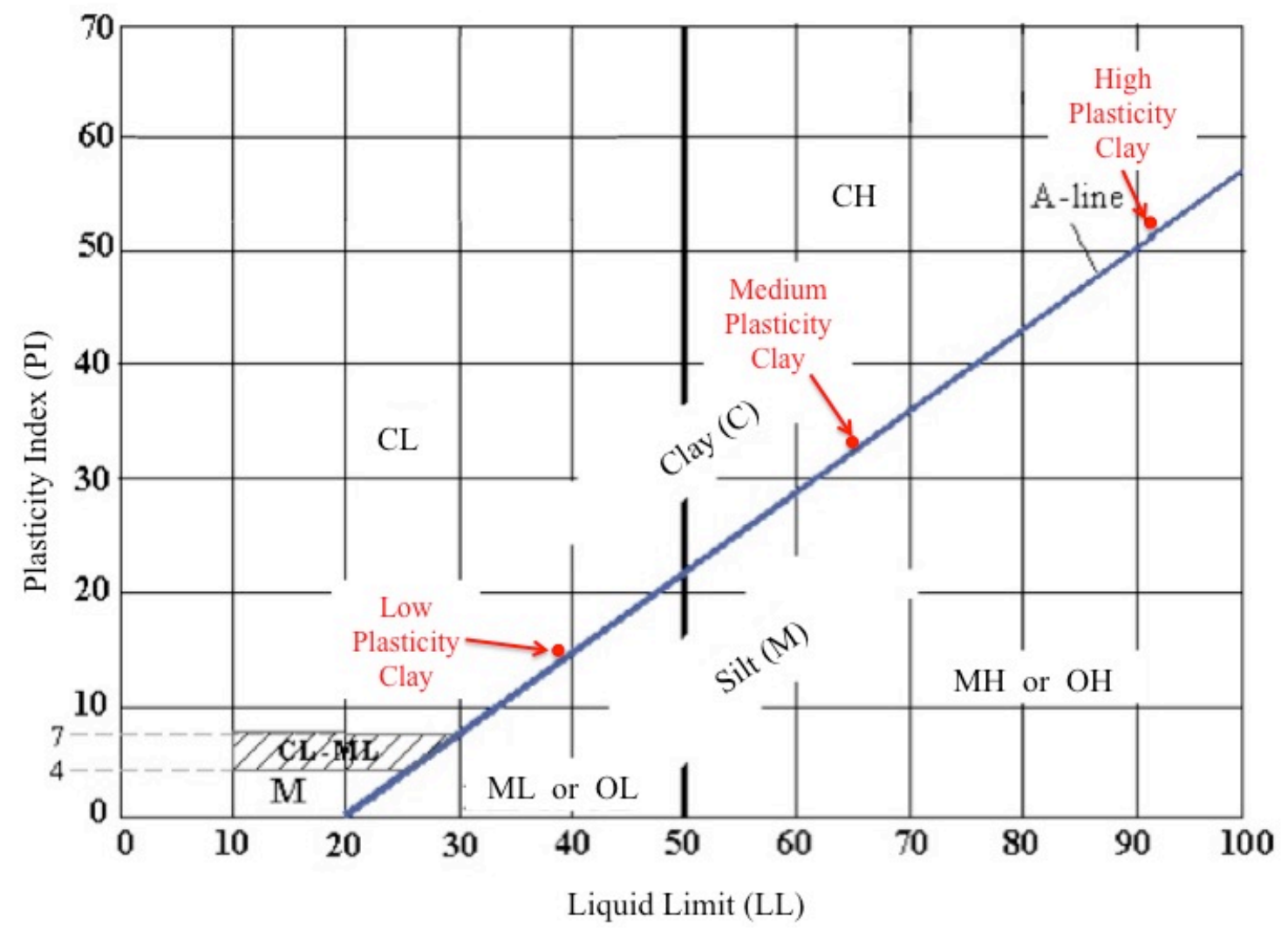

Figure 3.7: Casagrande chart showing the results of the Atterberg limit tests for the three clays.

\subsection{Compaction Test Results}

Figures 3.8, 3.9, and 3.10 show the compaction curves for the low, medium, and high plasticity clays, respectively. The maximum dry density (MDD) values for the low, medium, and high plasticity clays are $102.5 \mathrm{lb} / \mathrm{ft}^{3}\left(1.64 \mathrm{Mg} / \mathrm{m}^{3}\right), 95 \mathrm{lb} / \mathrm{ft}^{3}\left(1.52 \mathrm{Mg} / \mathrm{m}^{3}\right)$, and $89.5 \mathrm{lb} / \mathrm{ft}^{3}\left(1.43 \mathrm{Mg} / \mathrm{m}^{3}\right)$, respectively, and the corresponding optimum water content (OWC) values are $18 \%, 26 \%$, and $27 \%$. The blue points represent the original samples created to establish the compaction curve. Additional points (orange) were added to check the accuracy of the replicate samples used for compression testing. Note that the 
original curve was modified because of the additional data points from the replicate samples. The figures also show the relationship between dry density and water content for different degrees of soil saturation $(70 \%, 80 \%, 90 \%$, and $100 \%)$. It is obvious from a comparison of Figures 3.8, 3.9, and 3.10 that an increase in the plasticity of the clay, as indicated by the increasing plasticity index values (Table 3.1), results in a decrease in maximum dry density and an increase in optimum water content. This is because high plasticity clays are more cohesive, i.e. have stronger inter-particle bonds, and require more water to facilitate inter-particle movement to achieve MDD (Mitchel and Soga, 2005). Furthermore, stronger bonds are more difficult to break and, therefore high plasticity clays are more difficult to compact and that is why the MDD decrease as the water content increases (Holtz et al., 2011). 


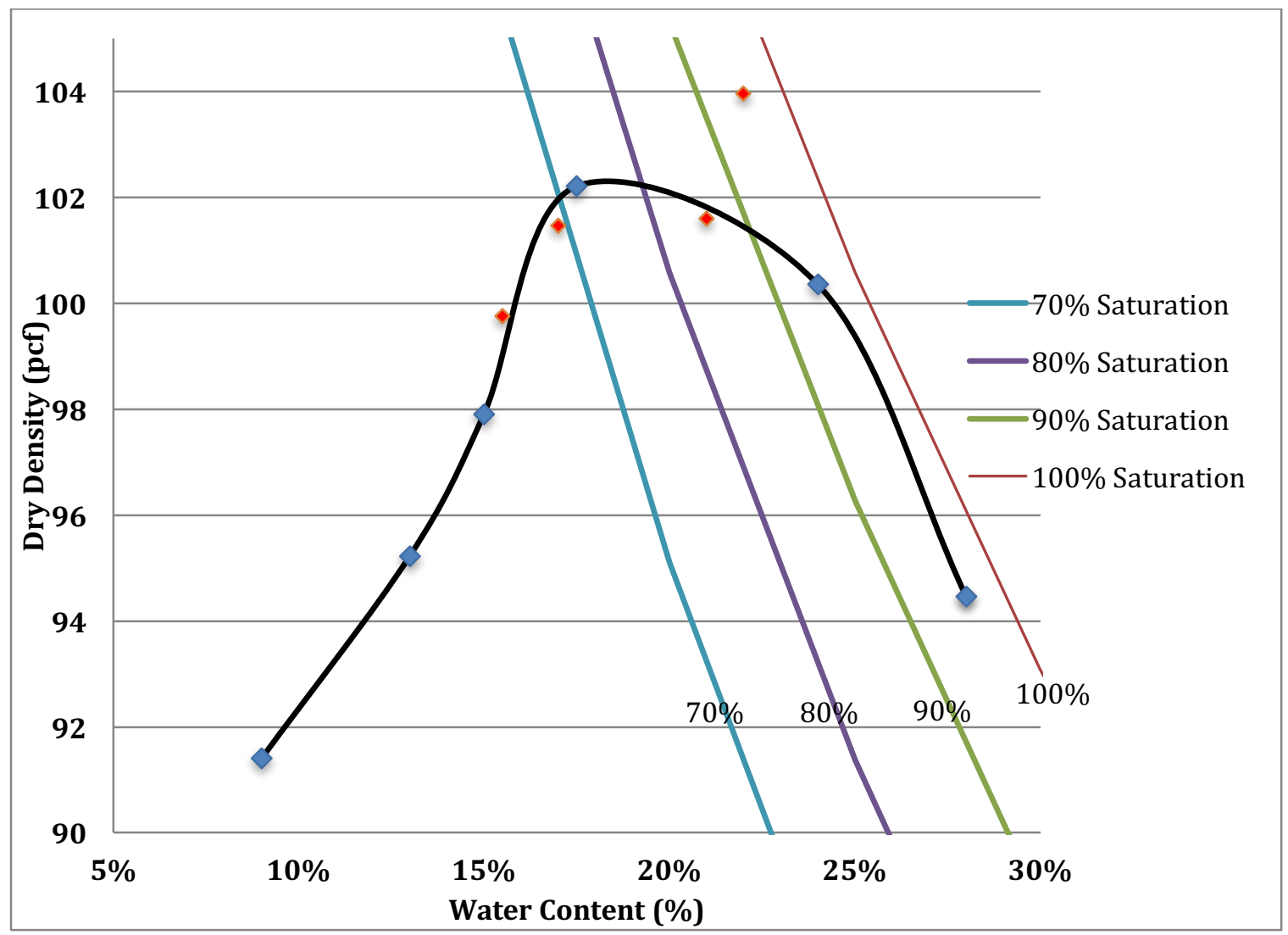

Figure 3.8: Compaction curve for the low plasticity clay. 


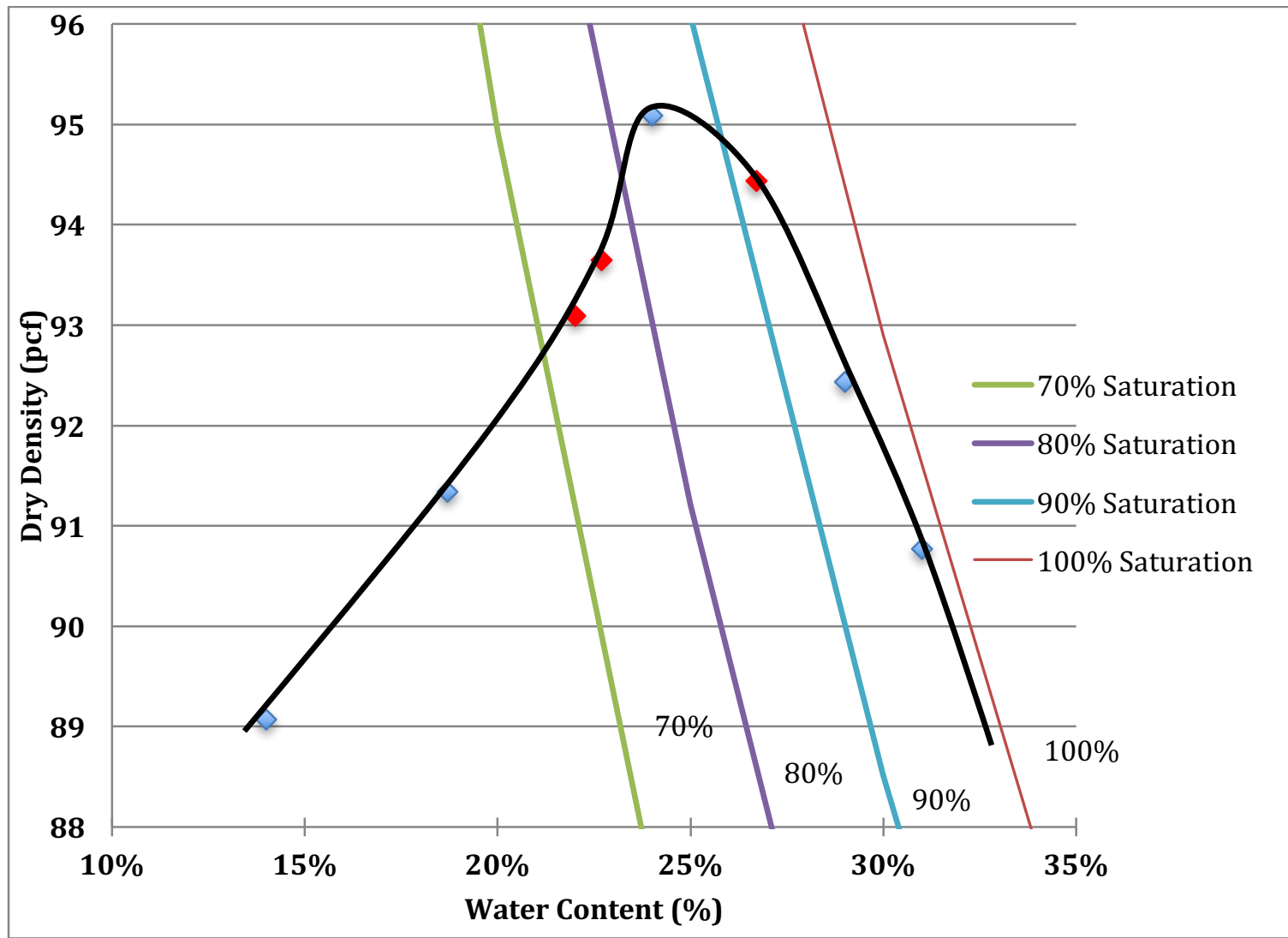

Figure 3.9: Compaction curve for the medium plasticity clay. 


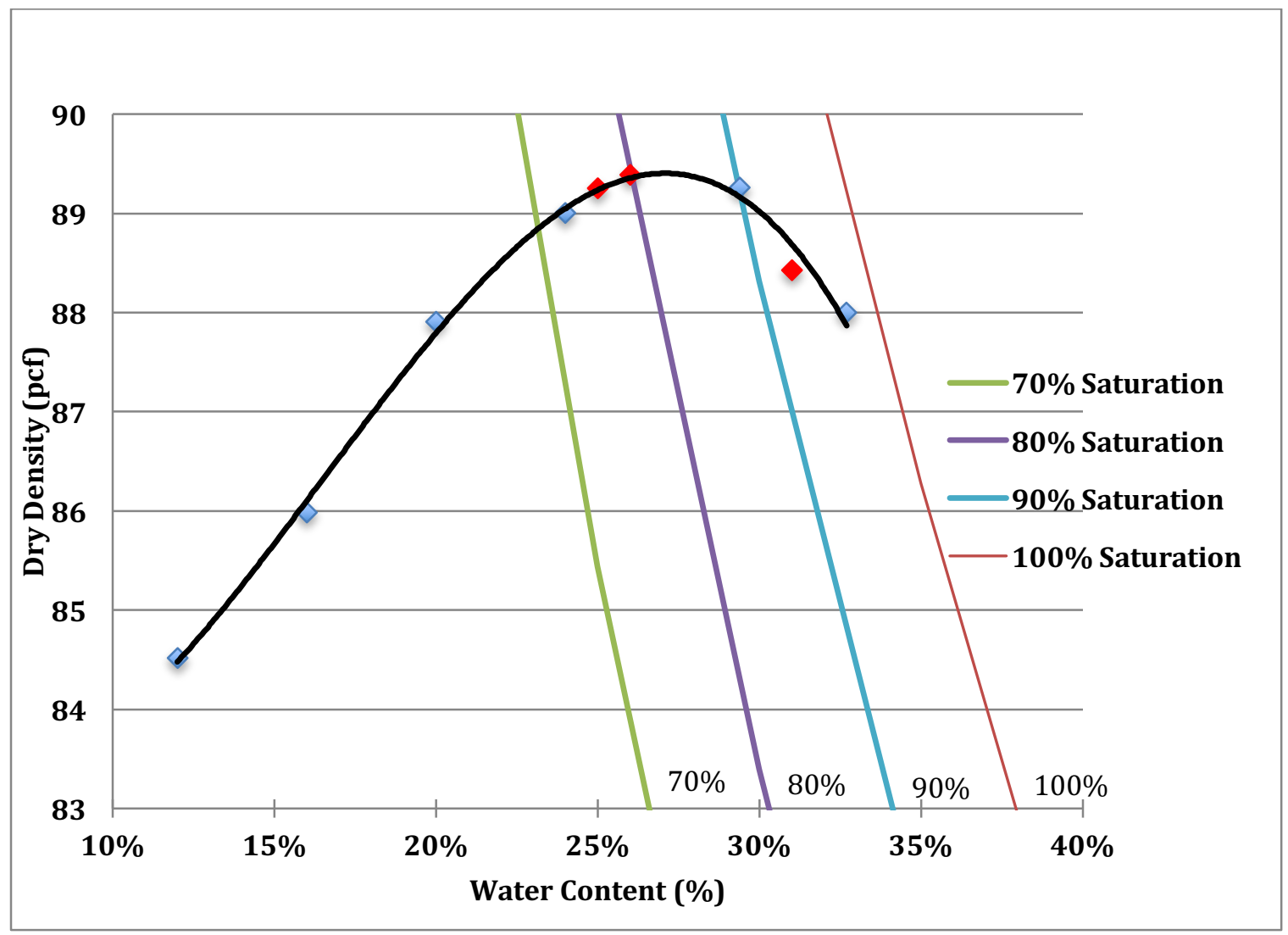

Figure 3.10: Compaction curve for the high plasticity clay.

\subsection{Unconfined Compression Test Results}

For the samples compacted at maximum dry density and optimum water content, the low, medium, and high plasticity clays have unconfined compressive strength values of 54 psi (344.8 $\mathrm{kPa}), 59 \mathrm{psi}(413.8 \mathrm{kPa})$, and 60psi $(420.7 \mathrm{kPa})$, respectively. The relationships between unconfined compressive strength and compaction water content for the low, medium, and high plasticity clays are shown in Figures 3.11, 3.12, and 3.13, respectively. The test data pertaining to these figures can be found in Appendix D. Figures 3.11 through 3.13 demonstrate that there is a marked increase in compressive strength from low plasticity clay to high plasticity clay, but the difference in strength values between 
medium and high plasticity clays is insignificant.

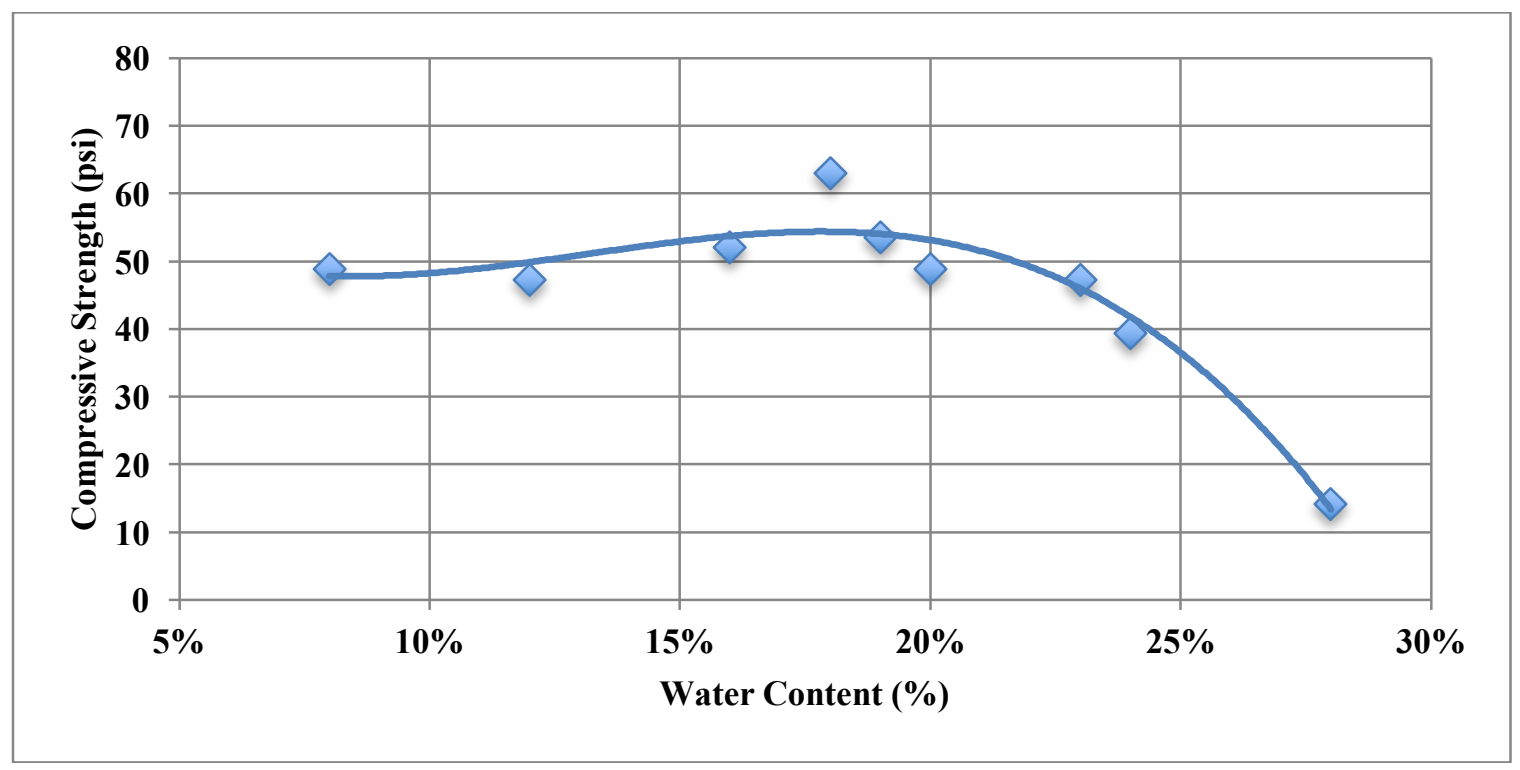

Figure 3.11: Relationship between unconfined compressive strength and compaction water content for the low plasticity clay. Note: $145 \mathrm{psi}=1 \mathrm{MPa}$

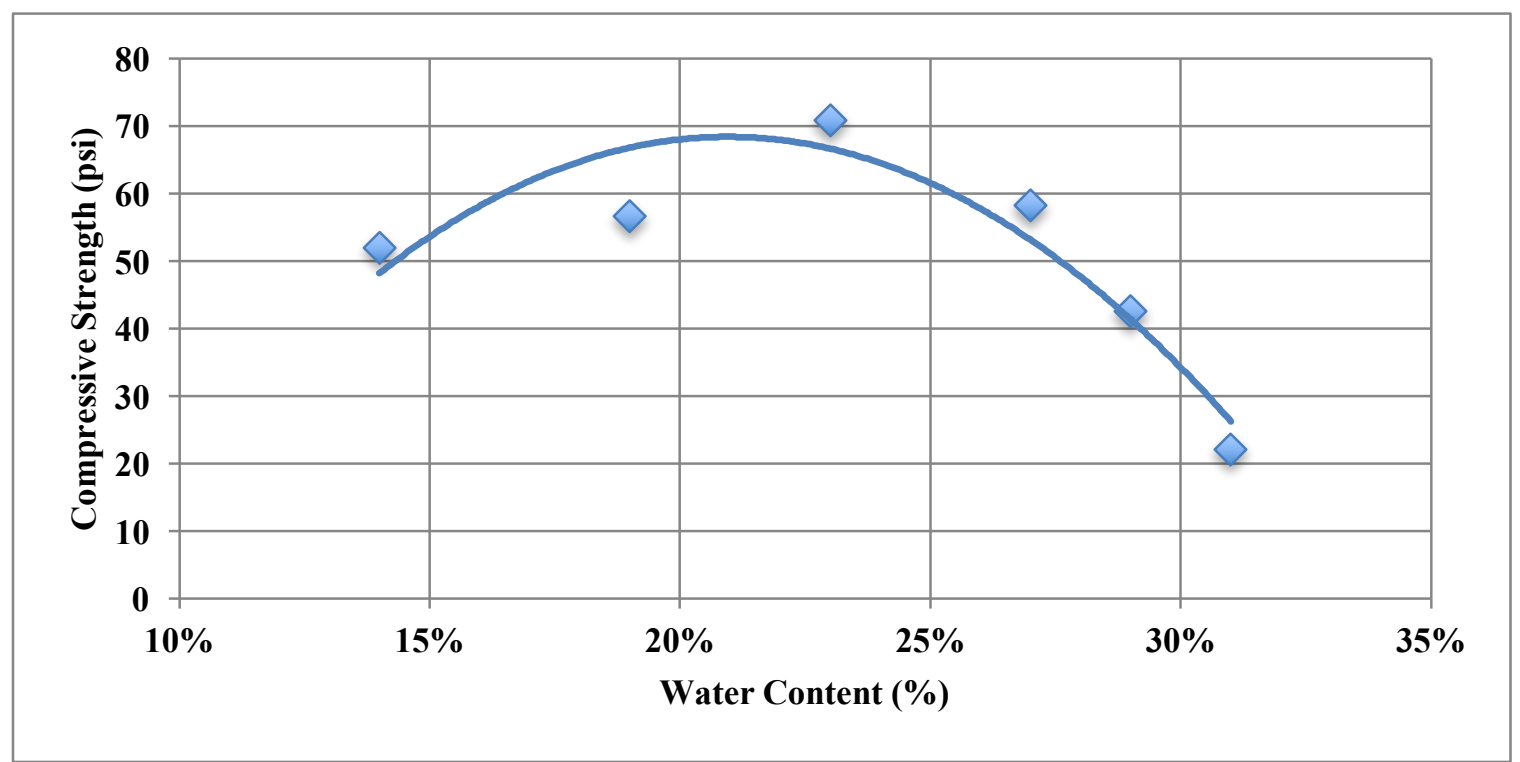

Figure 3.12: Relationship between unconfined compressive strength and compaction water content for the medium plasticity clay. Note: $145 \mathrm{psi}=1 \mathrm{MPa}$ 


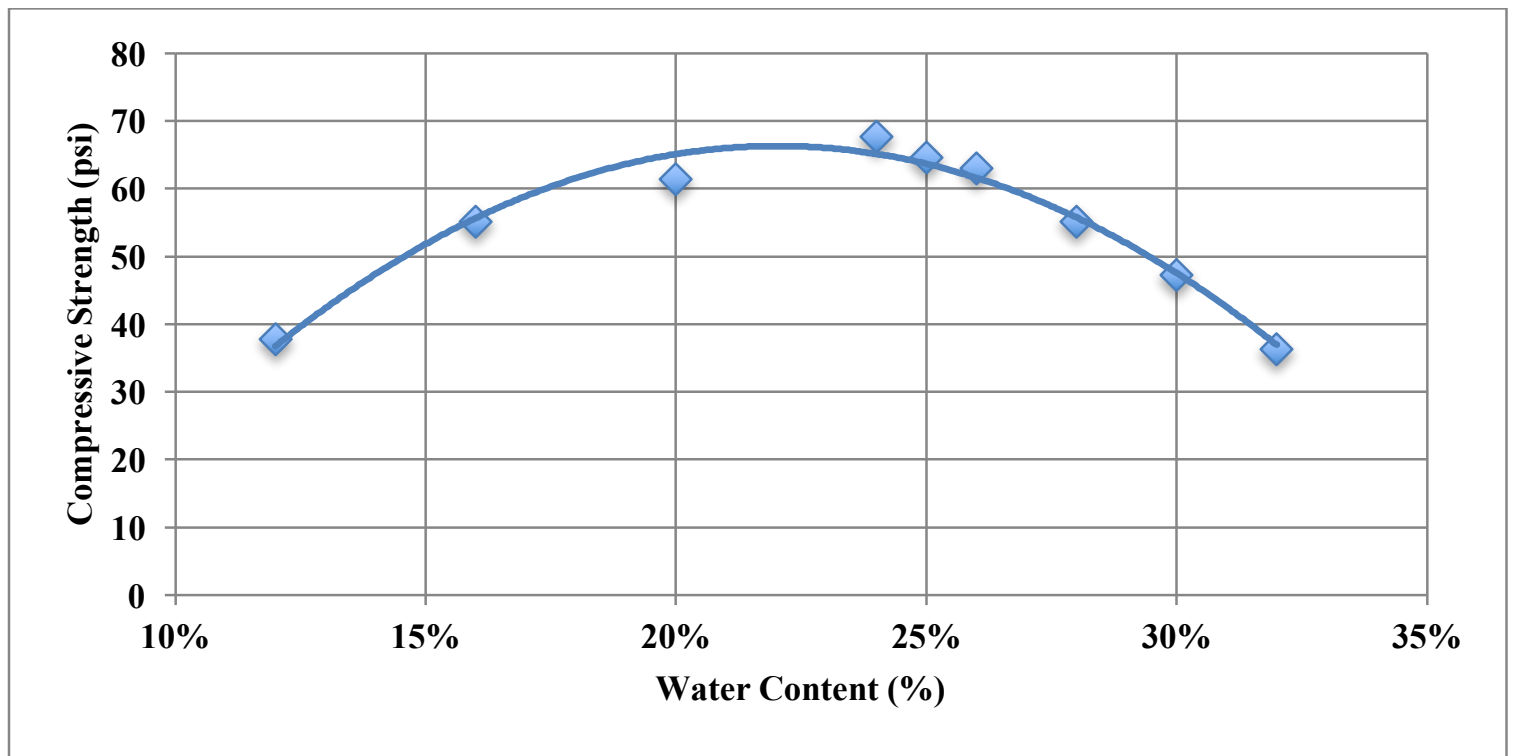

Figure 3.13: Relationship between unconfined compressive strength and compaction water content for the high plasticity clay. Note: $145 \mathrm{psi}=1 \mathrm{MPa}$.

This shows that compressive strength increases with increasing plasticity to a point and then levels off. Figures 3.11 through 3.13 also show that the unconfined compressive strength first increases and then decreases with increasing water content, with the transition occurring within $5 \%$ of for the optimum water content for each type of clay. The figures further show that the low, medium, and high plasticity clays attain their maximum compressive strength values of $63 \mathrm{psi}(434 \mathrm{kPa}), 71 \mathrm{psi}(489.5 \mathrm{kPa})$, and $68 \mathrm{psi}$ $(468.8 \mathrm{kPa})$ at compaction water contents of $18 \%, 23 \%$, and $24 \%$, respectively. It is important to note that the maximum unconfined compressive strength for the three types of clay does not occur at the optimum water content. Rather, it occurs on the dry side of the optimum water content for all three types of clay. This observation is of considerable practical importance and is supported by previous studies (Mitchell and Soga, 2005;

Holtz et al., 2011). 


\subsection{Direct Shear Test Results}

Appendix E provides the direct shear test data, stress-strain plots, and the Mohr envelopes for samples of the three clay types tested at varying water contents (on both sides of the transition water content as indicated by the unconfined compression tests). Table 3.2 displays the cohesion and friction angle values for each sample as determined from the Mohr envelopes. As can be seen from Table 3.2, the high plasticity clay exhibits the highest cohesion while the low plasticity clay exhibits the highest friction angle. Figures 3.14, 3.15, and 3.16 show the friction angle versus water content plots for the low, medium, and high plasticity clays, respectively. Note that for each type of clay, the friction angle generally decreases slightly with increasing water content. Plots showing the cohesion versus water content are shown in Figures 3.17, 3.18, and 3.19 for the three types of clay. The cohesion shows a weak, questionable, trend of increasing values with increasing water content for the low plasticity clay while the medium and high plasticity clays show a weak decreasing trend with increasing water content. In general, one would expect a decrease in friction angle and an increase in cohesion with increasing water content for the fine-grained soils. However, this is not the case in this study. This could be due to the non-uniform nature of the compacted samples and due to experimental errors. It is usually difficult to have a perfectly uniform distribution of water and uniform degree of compaction within a sample. Therefore, the cut portions of a given sample used for direct shear testing may not be exactly similar in nature. This is reflected by the scatter of data points in Figures 3.14 through 3.19. 
Table 3.2: Cohesion and friction angle values for each sample as determined from the Mohr envelopes.

\begin{tabular}{|c|c|c|c|}
\hline Clay Type & Water Content (\%) & Cohesion (psi) & Friction angle $\left(^{\circ}\right)$ \\
\hline \multirow{3}{*}{ Low Plasticity } & $18 \%$ & 12 & 37.2 \\
\cline { 2 - 4 } & $19 \%$ & 11.3 & 43.1 \\
\cline { 2 - 4 } & $20 \%$ & 13.5 & 33 \\
\hline \multirow{3}{*}{ Medium Plasticity } & $28 \%$ & 9.7 & 12 \\
\cline { 2 - 4 } & $29 \%$ & 7.4 & 11 \\
\cline { 2 - 4 } & $30 \%$ & 7.9 & 6.7 \\
\hline \multirow{3}{*}{ High Plasticity } & $31 \%$ & 7.7 & 12.5 \\
\cline { 2 - 4 } & $28 \%$ & 14 & 31.6 \\
\cline { 2 - 4 } & $29 \%$ & 13.3 & 34.2 \\
\cline { 2 - 4 } & $30 \%$ & 17.2 & 24.9 \\
\hline
\end{tabular}

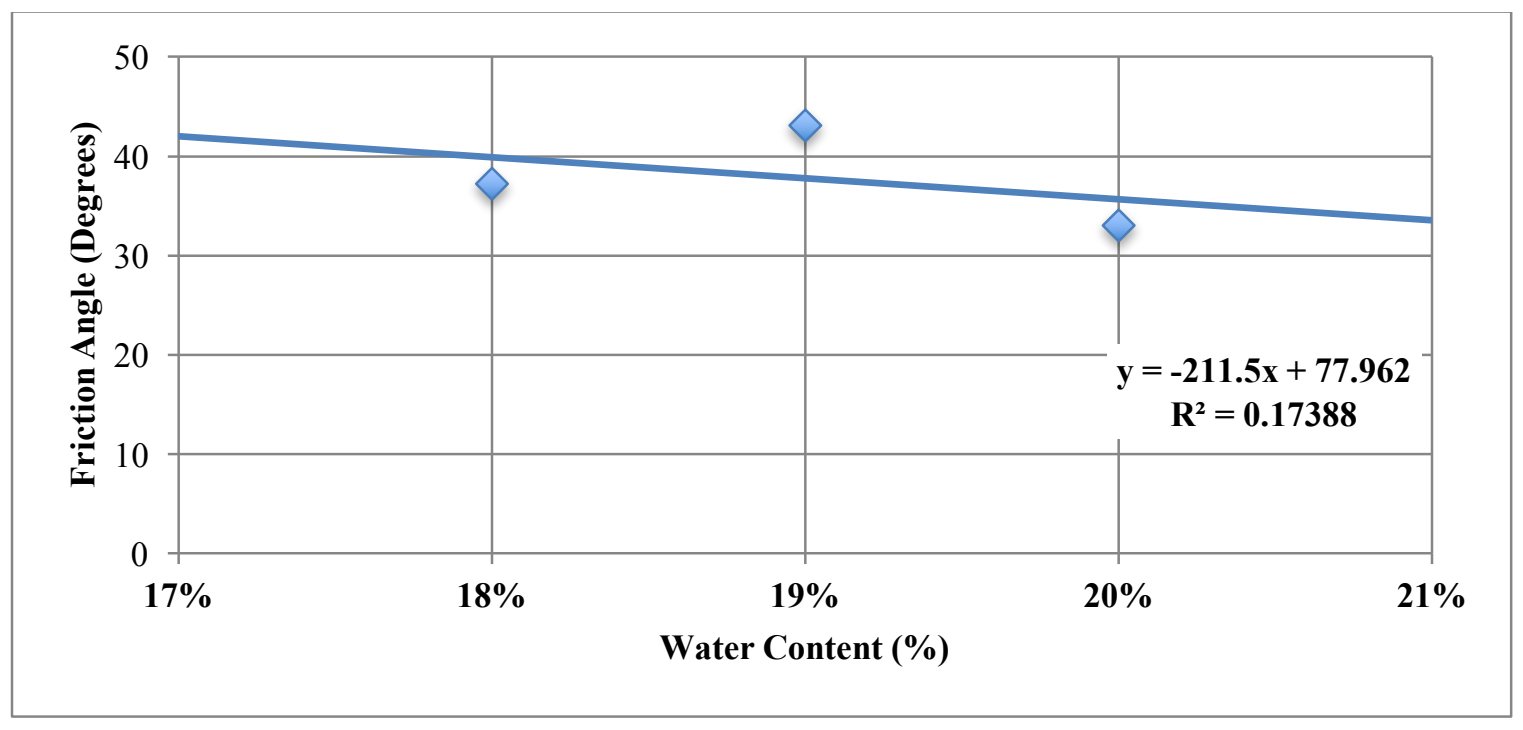

Figure 3.14: Relationship between friction angle and compaction water content for the low plasticity clay. 


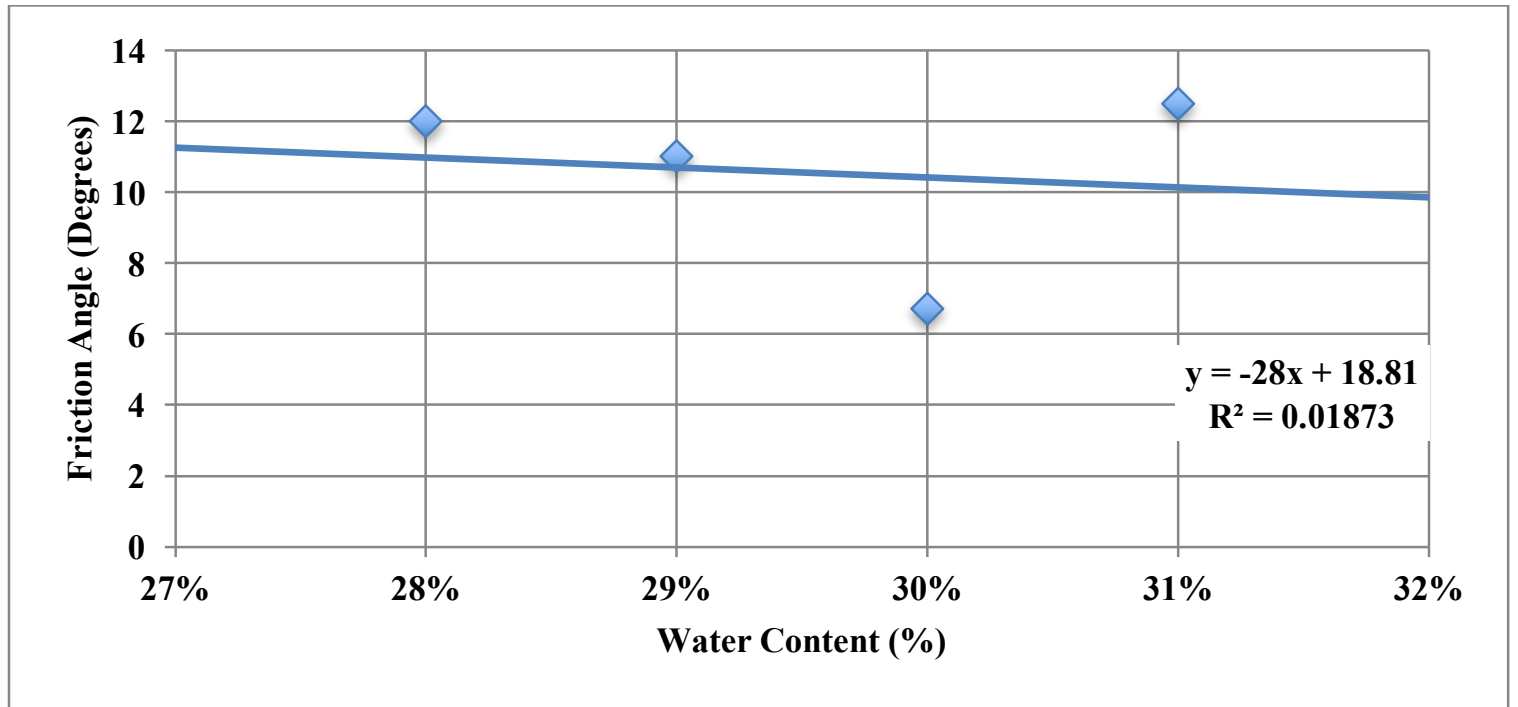

Figure 3.15: Relationship between friction angle and compaction water content for the medium plasticity clay.

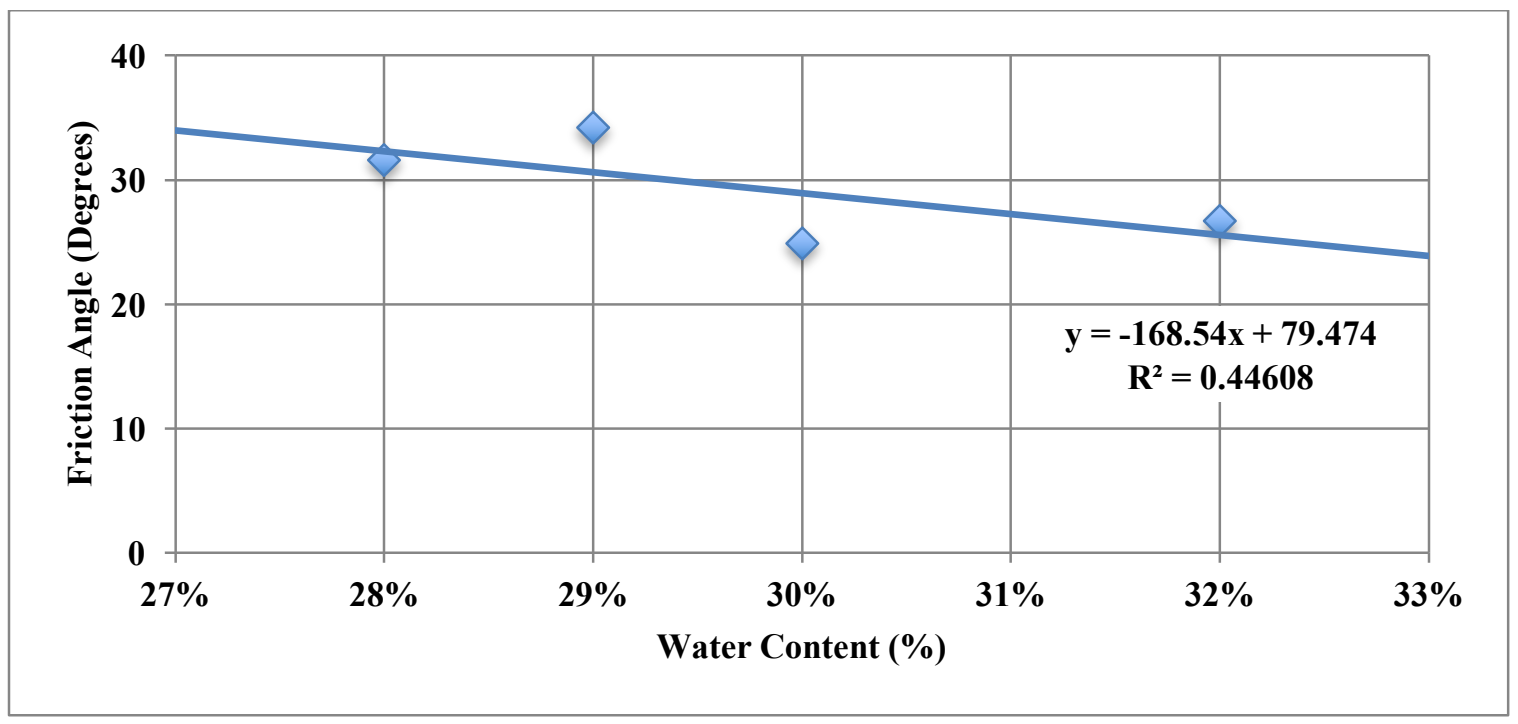

Figure 3.16: Relationship between friction angle and compaction water content for the high plasticity clay. 


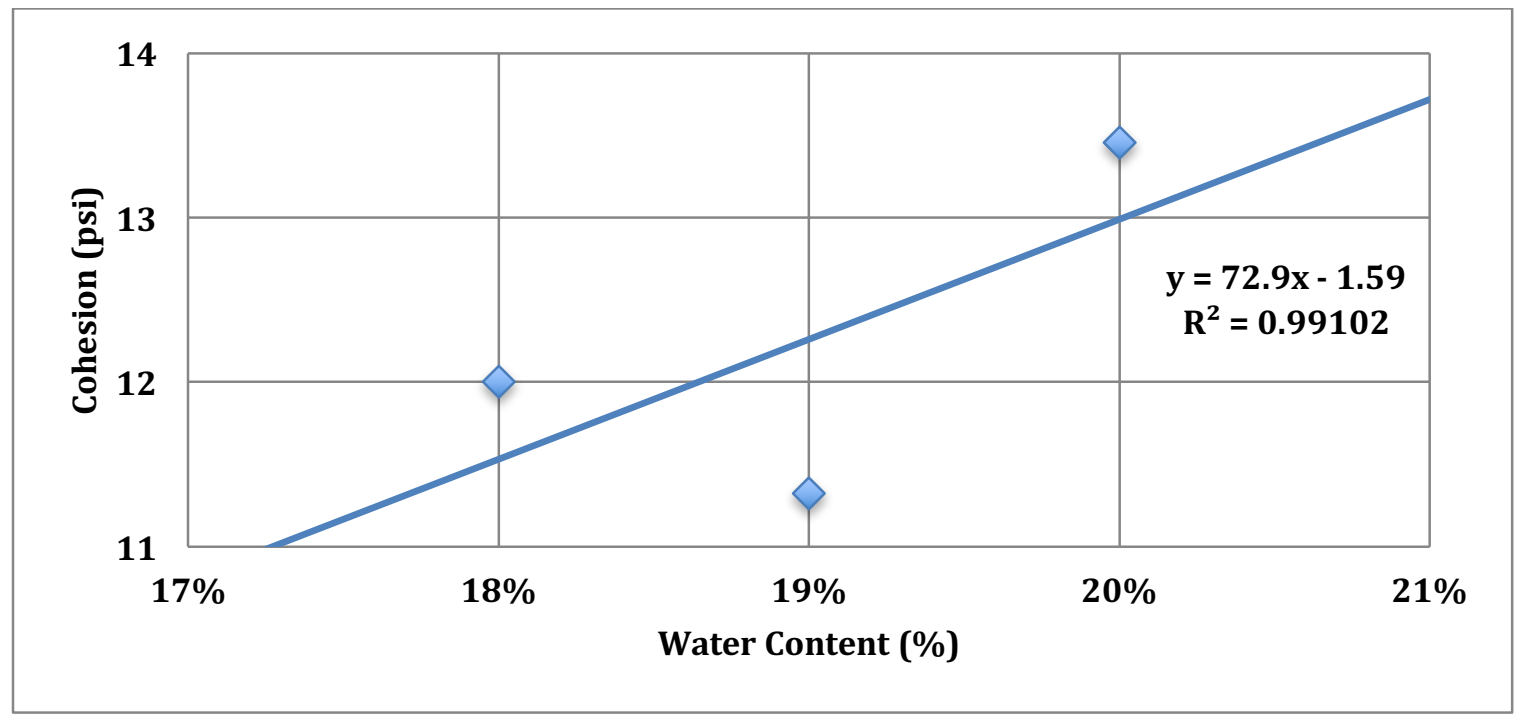

Figure 3.17: Relationship between cohesion and compaction water content for the low plasticity clay.

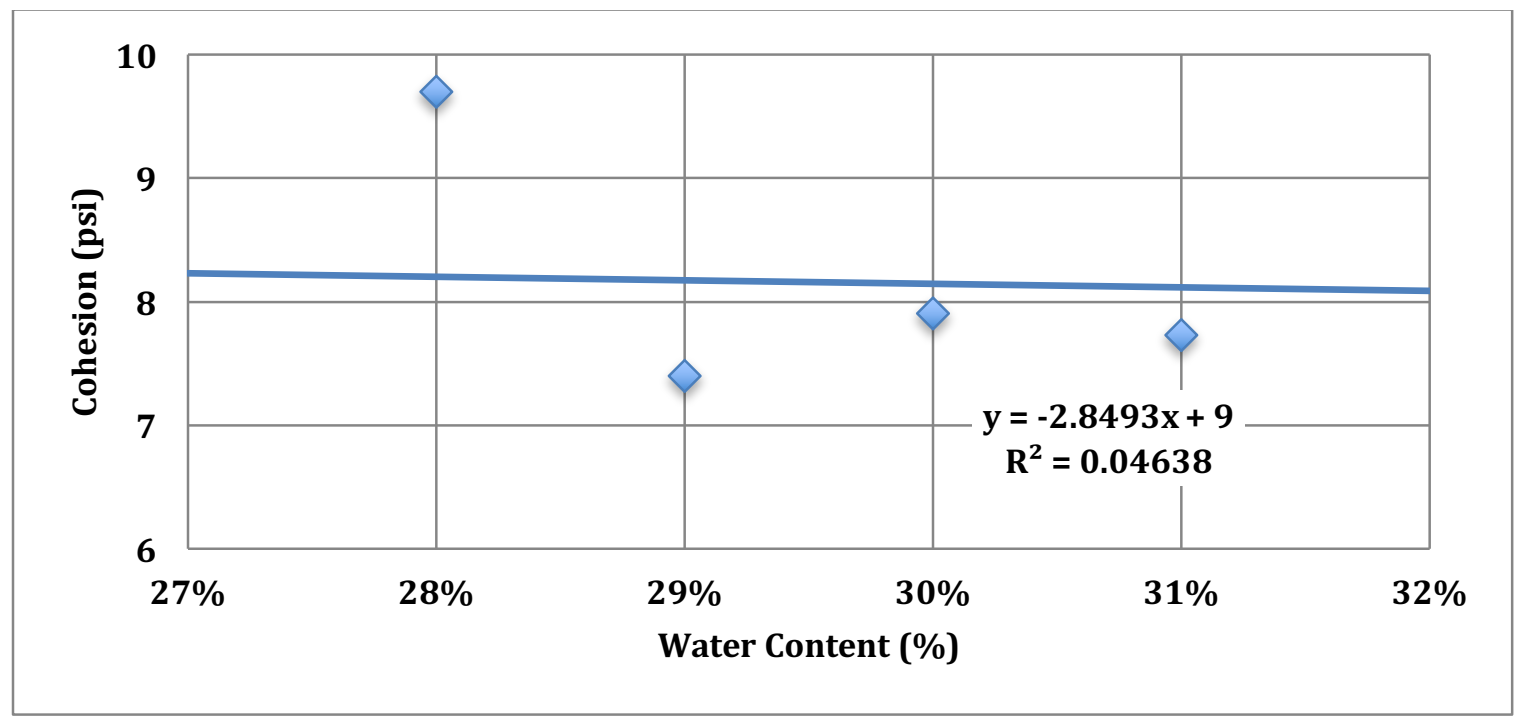

Figure 3.18: Relationship between cohesion and compaction water content for the medium plasticity clay. 


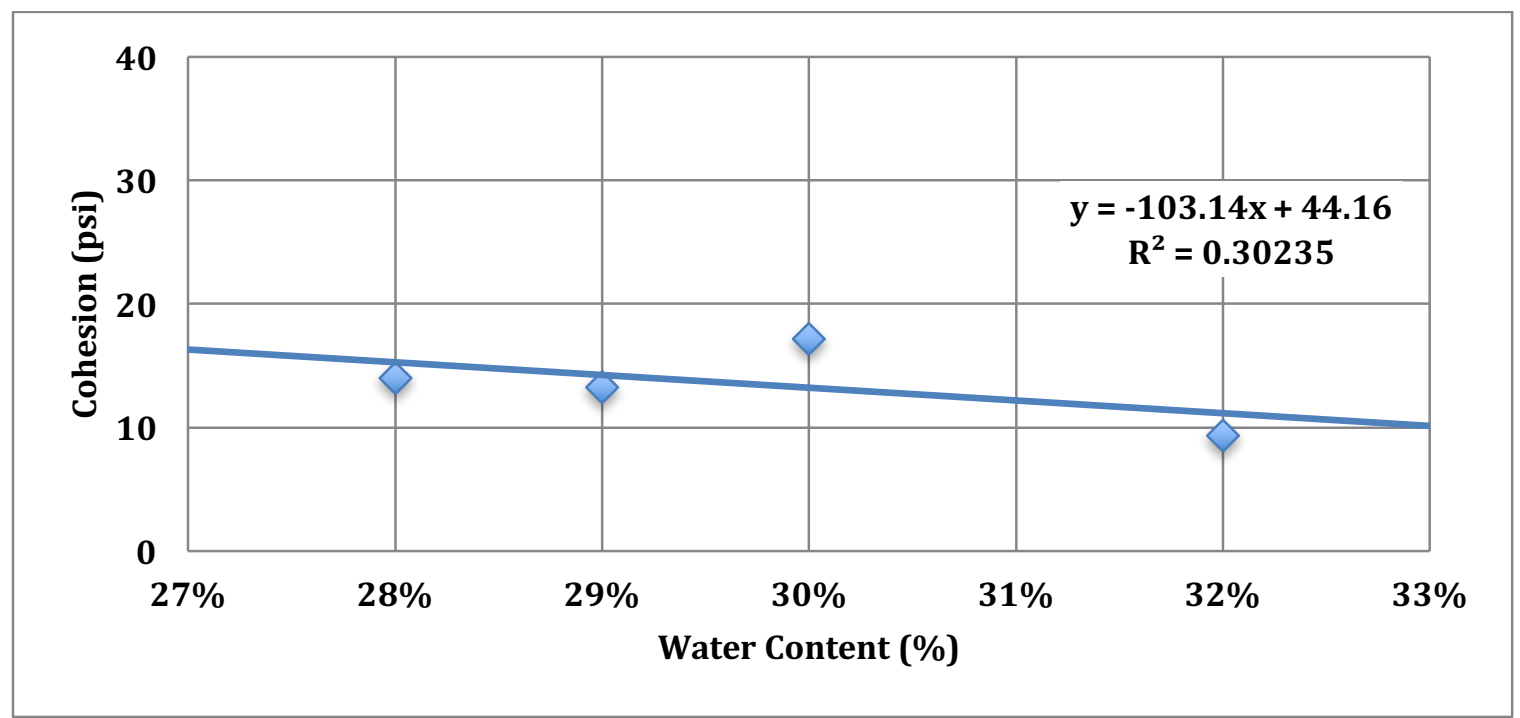

Figure 3.19: Relationship between cohesion and compaction water content for the high plasticity clay. 


\section{CHAPTER 4}

\section{QUANTIFYING THE TRANSITION WATER CONTENT BETWEEN BRITTLE AND PLASTIC BEHAVIORS}

The main purpose of this study was to investigate the transition water content between brittle and plastic deformation behaviors. To accomplish this, replicate samples of each of the three types of clay were compacted, both on the dry and wet sides of the optimum water content, and were tested in unconfined compression. Photographs of the failed samples are shown in Figures 4.1, 4.2, and 4.3, for the low, medium, and high plasticity clays, respectively and their corresponding stress-strain curves are displayed in Figures 4.4, 4.5, and 4.6.
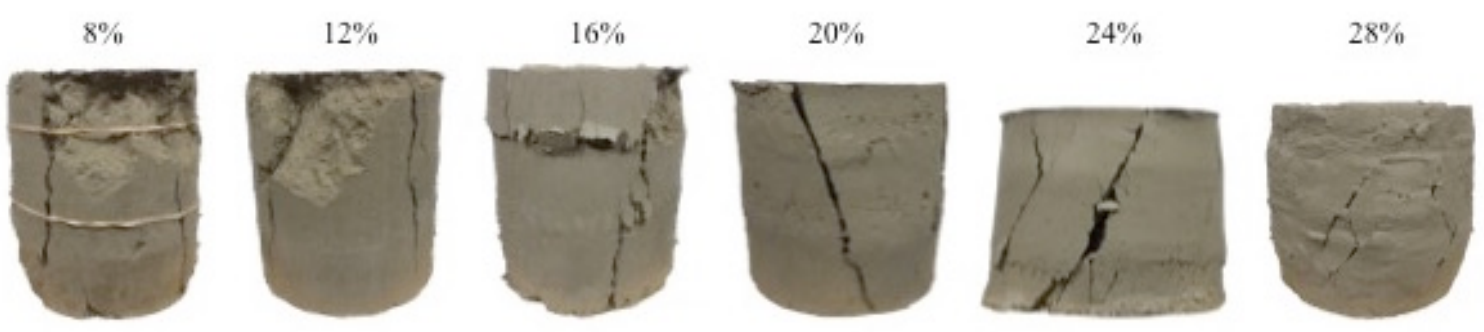

Figure 4.1: Low plasticity clay samples, ranging in compaction water content from $8 \%$ to $28 \%$, after failure under unconfined compression conditions. Notice the marked decrease in sample height during axial loading for samples containing more than $16 \%$ water content, indicating the initiation of the plastic mode of deformation. 

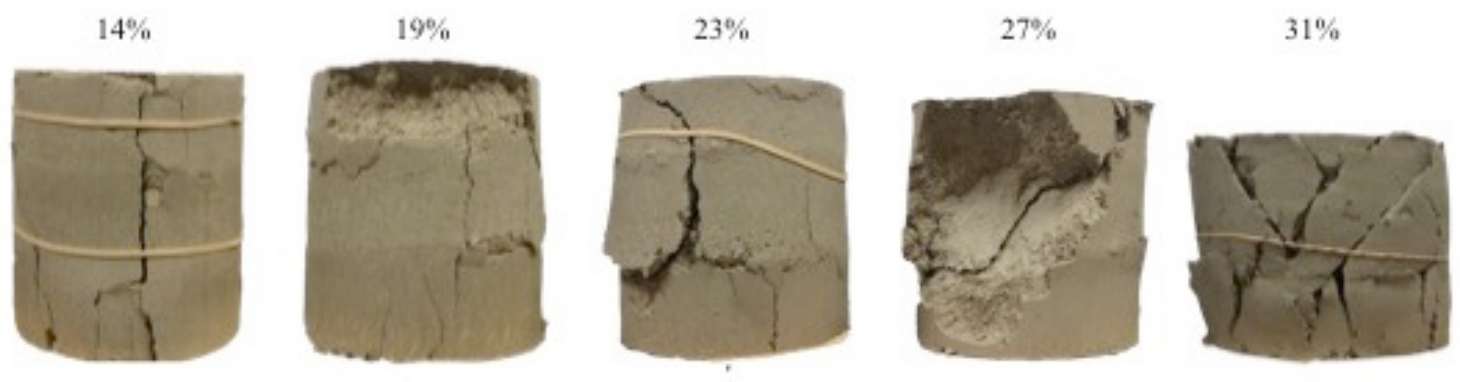

Figure 4.2: Medium plasticity clay samples, ranging in compaction water content from $14 \%$ to $31 \%$, after failure under unconfined compression conditions. Notice decrease in sample height, sample bulging, and the associated spalling, for samples containing $23 \%$, $27 \%$, and $31 \%$, all suggesting initiation of plastic mode of deformation.
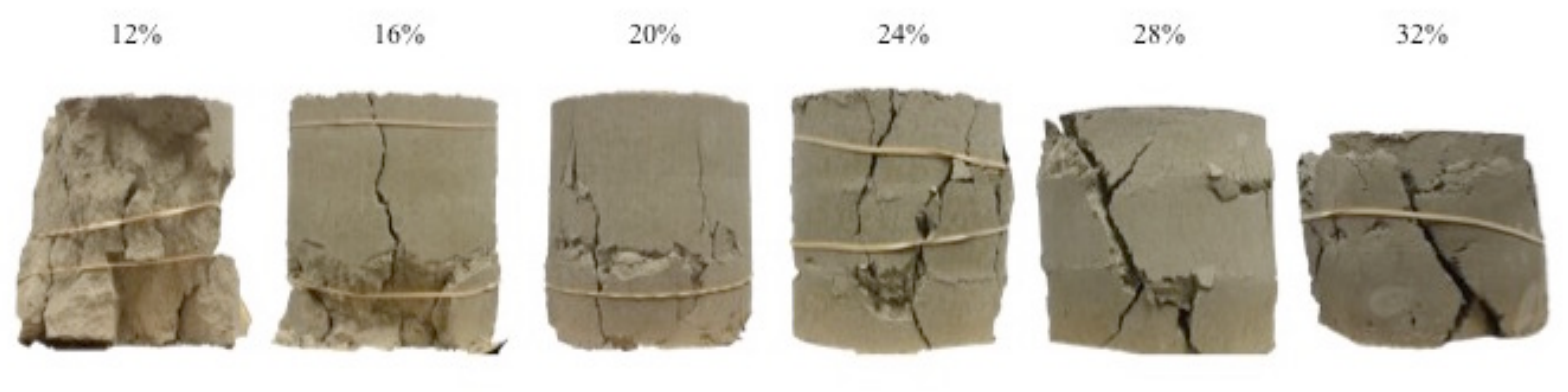

Figure 4.3: High plasticity clay samples, ranging in compaction water content from $12 \%$ to $32 \%$, after failure under unconfined compression conditions. Notice the increasing degree of bulging for samples containing $24 \%$ or higher water content. Also, notice a decrease in sample height after $24 \%$ water content and a marked decrease in sample height for sample containing $32 \%$ water content. A decrease in sample height suggests initiation of plastic deformation. 


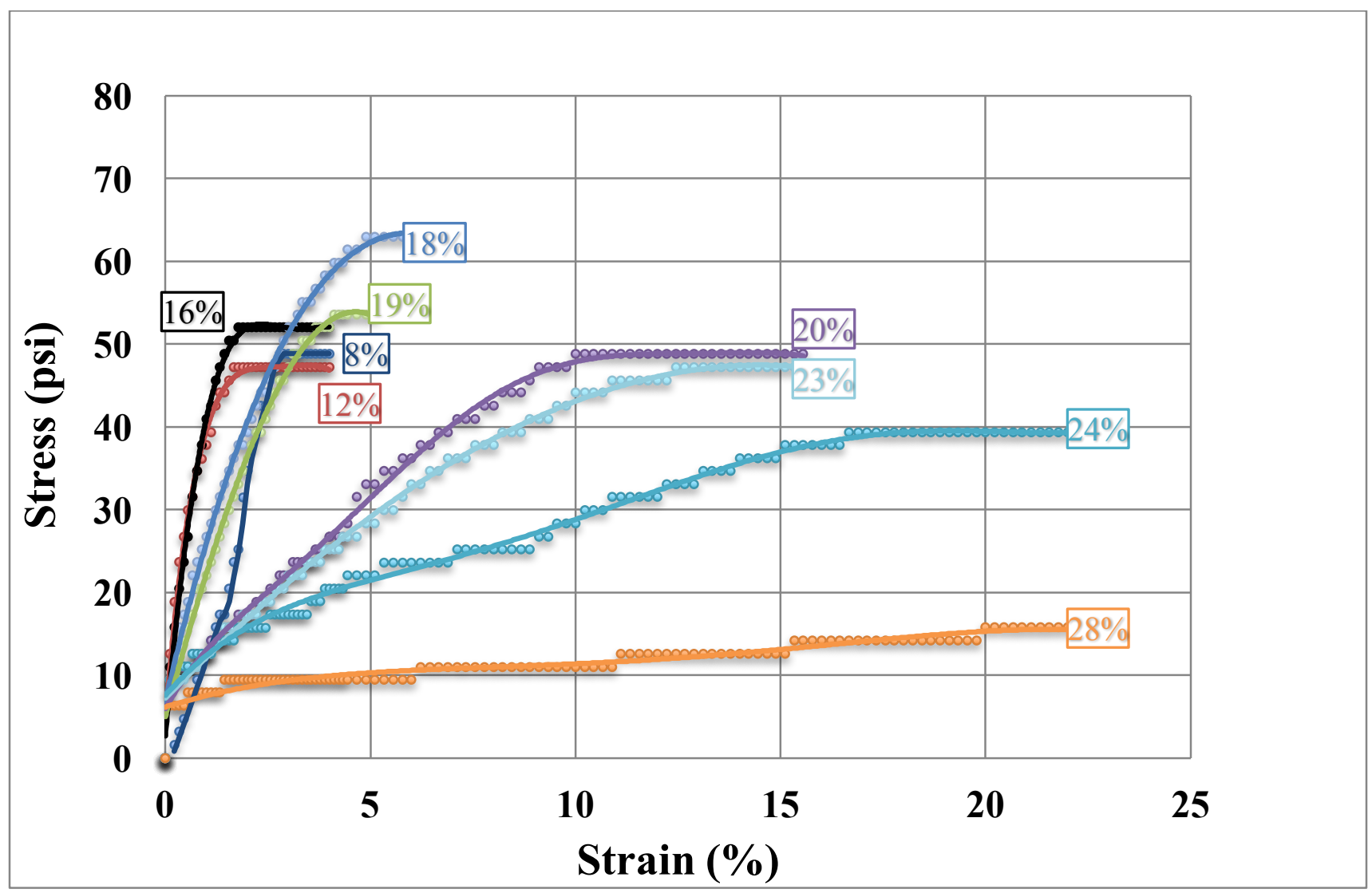

Figure 4.4: Stress-strain plots from unconfined compression tests on the low plasticity clay $(\mathrm{CL})$. 


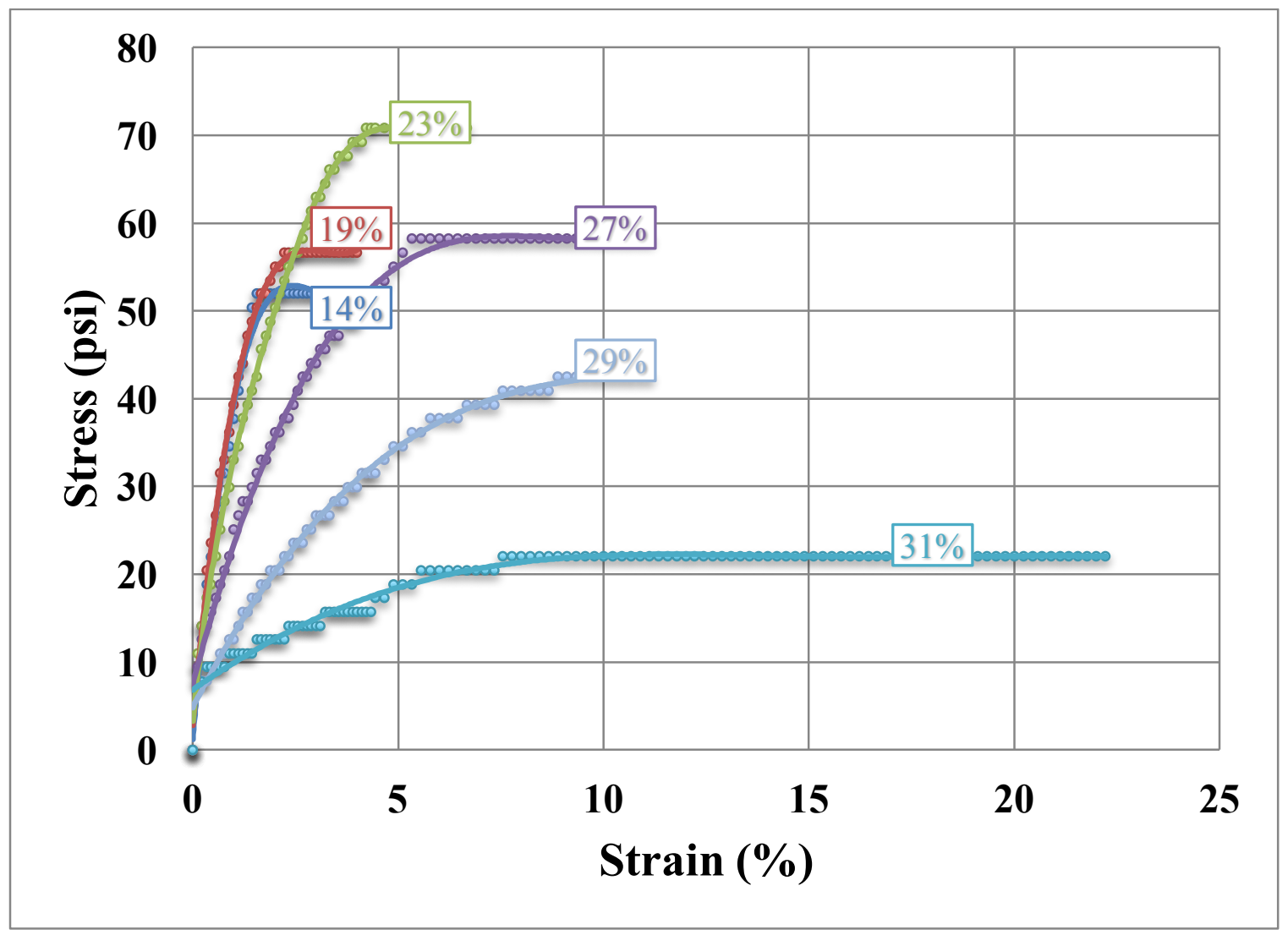

Figure 4.5: Stress-strain plots from unconfined compression tests on the medium plasticity clay (CL). 


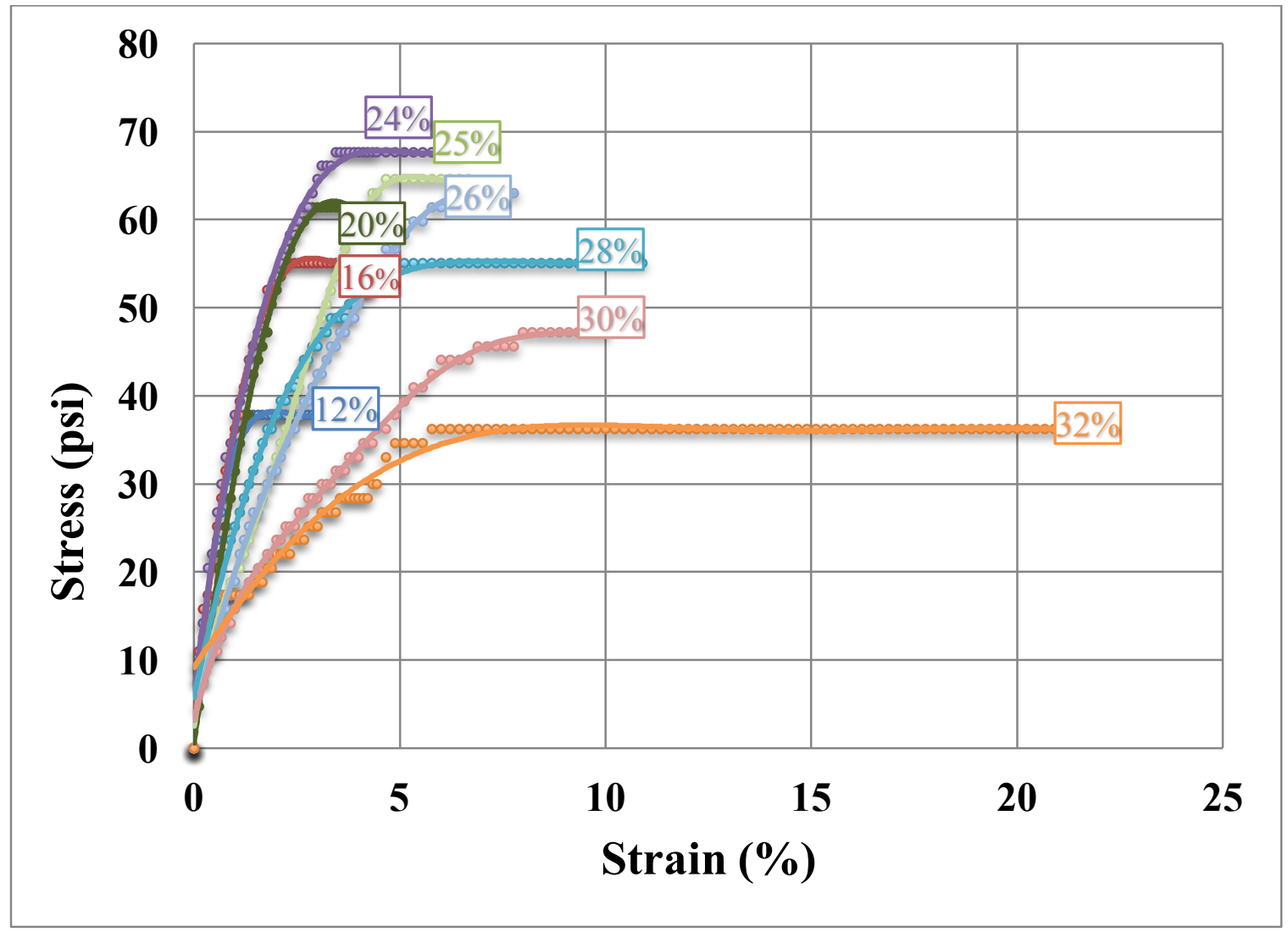

Figure 4.6: Stress-strain plots from unconfined compression tests on the high plasticity clay (CL).

In order to quantify the transition water content between brittle and plastic deformation behaviors, the samples were not only visually inspected for the type of failure, but the stress-strain curves from both the unconfined compression tests and the direct shear tests were carefully analyzed. Visually, the plastic deformation is indicated by decrease in sample height and by sample bulging (Figures 4.1 through 4.3 ). In terms of stress-strain plots, the transition between brittle and plastic behaviors for each type of clay is marked by a gap in the stress-strain plots for the two types of deformation (Figures 4.4 through 4.6). The gaps between 19\%-20\% water content plots for the low plasticity 
clay, between $27 \%-29 \%$ water content plots for the medium plasticity clay, and between $30 \%-32 \%$ water content plots for the high plasticity clay, represent where the transition between brittle deformation and plastic deformation most likely occurs. A visual inspection of the failed samples in Figures 4.1 through 4.3 does not clearly suggest if the samples failed plastically at $20 \%, 29 \%$, and $32 \%$ water contents, respectively. Therefore, the results of the stress-strain curves are considered to be more reliable than the visual observations. A closer examination of Figures 4.4, 4.5, and 4.6 reveals that the stressstrain curves for clays that failed in a brittle manner are grouped together while those for the samples that failed plastically are more spread out. This suggests that at water contents exceeding the transition water content, there is more variability in the strength and deformation behavior. Similar trends can be observed from stress-strain plots from the direct shear test, provided in Appendix D. The plots show that the low plasticity clay behaves as a brittle material at $19 \%$ water content and as a plastic material at $20 \%$ water content. The transition between the brittle and plastic modes of failure for the medium and high plasticity clays occurs between $27 \%-29 \%$ and $30 \%-32 \%$ water content, respectively.

Previous research has shown that failure can be considered to have occurred between 15\%-20\% strain for cohesive soils that fail plastically (Al-Shayea, 2001). However, in this study failure was observed to occur at $10 \%$ strain for all three clay types, and even less in case of some samples. As previously stated, the failure occurring at lower strain could be attributed to the compacted nature of the samples tested. Figures 4.4, 4.5 , and 4.6 clearly demonstrate that samples with increasing plasticity have overall 
higher compressive strengths and require higher water contents to display plastic deformation. 


\section{CHAPTER 5}

\section{DISCUSSION}

The effect of water content and density on the strength and deformation behaviors of clay soils is of great practical importance. The main purpose of this study was to find the transition water content between brittle and plastic deformation. Cracking of embankment dams due to differential settlement or due to displacements caused by earthquake vibrations is always a matter of major concern for designers of embankment dams (Newmark, 1965; Lee et al., 1988; Zomorodian and Moghadam, 2011). Therefore, it may be necessary to design a homogeneous embankment dam, made almost entirely of low plasticity clay (CL), or the clay core of a zoned embankment dam, so that the clay material behaves more like a plastic material, i.e. deforms without a well developed plane of failure, than a brittle material. This study shows that, to ensure structural integrity of embankment dams in seismically active areas, not only the clay should be compacted wet of the OWC, but also on the wet side of the transition water content marking the boundary between brittle and plastic deformations. However, the results of this study are based on three types of clay material prepared in the laboratory, which do not represent all variations within clay soils. Different low plasticity and high plasticity clays will exhibit different engineering behaviors depending upon the amount of clay-size material and the composition of clay minerals present. Thus, the results of this study pertain only to the clay types tested, not all clay soils. Additional research on a large variety of clay soils is needed to conclusively determine the transition water contents for different types 
of clay. Since plasticity index (PI) is a good indicator of the nature of a clay soil, a plot of plasticity index versus average transition water content (Figure 5.1) may provide a useful tool for predicting the water content at which clay soil should be compacted in case of embankment dams and levees. Figure 5.1 suggests that differences in the transition water contents for clays of different plasticity decrease as the PI increases.

It is important to note that although a clay soil compacted wet of the optimum water content is more flexible (i.e. more plastic), it has lower strength compared to the same soil compacted dry of the optimum water content (Holtz et al., 2011). Thus, a designer will need to consider the best comprise between strength and flexibility or will need to decide which of the two properties is more important in a given situation.

Compacting replicate samples for unconfined compression and direct shear tests revealed a variety of issues. Mixing the designated water content uniformly throughout a given sample was a very difficult task as, in case of low water-content samples, there was not enough water to allow uniform dissemination. On the other hand, some samples clumped up after mixing with water, preventing uniform mixing and compaction. This resulted in inconsistencies and scatter in the data. Additional studies are required to refine and validate the results of this study. Also conducting unconfined compression and direct shear tests on natural clays, with varying water contents, can provide additional data to refine the results of the present study, especially the relationship between PI and transition water content shown in Figure 5.1.

Unfortunately, very little research has been done on establishing the transition water content between brittle and plastic deformation of clay soils. Therefore, little is 
currently available for me to compare the results of my study.

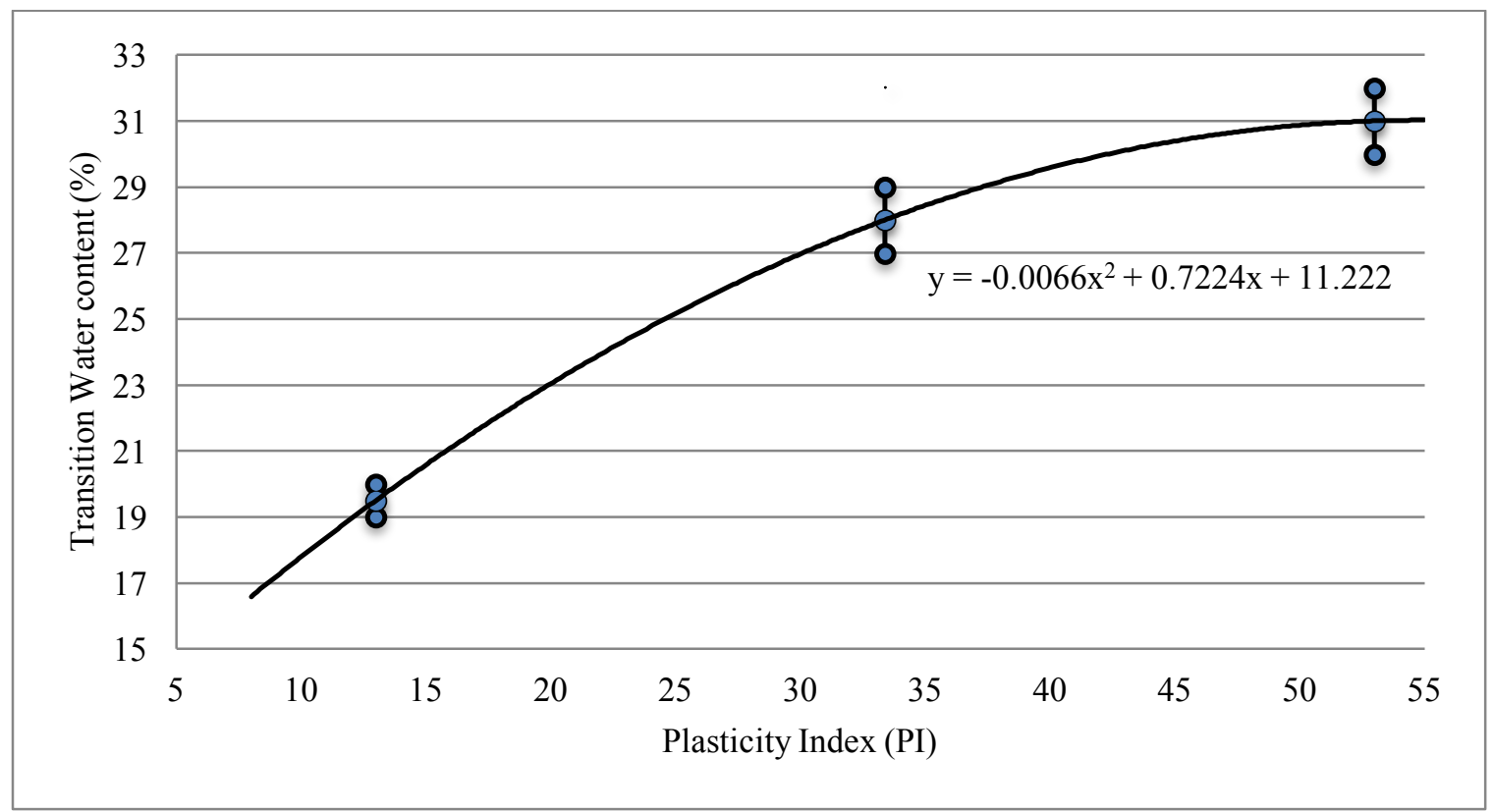

Figure 5.1: Plot of Plasticity Index versus average transition water content. Notice as PI increases, the range of the transition water content increases. 
CHAPTER 6

\section{CONCLUSIONS AND RECOMMENDATIONS}

\subsection{Conclusions}

The following conclusions can be drawn from this study:

1. The water content at which transition from brittle to plastic behavior occurs ranges from 19\%-20\% for low plasticity clay, $27 \%-29 \%$ for medium plasticity clay, and 30\%-32\% for the high plasticity clay, all of which are within $5 \%$ of the Optimum water content for each clay type.

2. The maximum compressive strength for the low, medium, and high plasticity clays occurs at $18 \%, 23 \%$, and $24 \%$ water content, respectively.

3. Friction angle decreases slightly with increasing water content and cohesion shows a weak, questionable increasing trend with increasing water content for the low plasticity clay while the medium and high plasticity clays display decreasing trends with increasing water content.

\subsection{Recommendations}

1. Additional research on a wide variety of clays, especially natural clays, should be conducted to refine and validate the results of this study.

2. A better procedure for preparing the replicate, compacted, samples should be developed. 


\section{REFERENCES}

Al-Shayea, N. A., 2001, The combined effect of clay and moisture content on the behavior of remolded unsaturated soils: Engineering Geology, 62(4), pp. 319-342.

Al-Zoubi, M. S., 2008, Swell characteristics of natural and treated compacted clays: Electronic Journal of Geotechnical Engineering, 13, 18 pages.

American Society for Testing and Materials [ASTM], 2010, Annual Book of Standards: Geosynthetics, Section 4, Construction, 4.08, Soil and Rock (I): D420_D4914; 4.09, Soil and Rock (II): D4943-latest;, West Conshohocken, PA.

Blotz, L.R., Benson, C.H., and Boutwell, G.P., 1998, Estimating optimum water content and maximum dry unit weight for compacted clays: Journal of Geotechnical and Geoenvironmental Engineering, 124(9), pp. 907-912.

Casagrande, A., 1948, Classification and identification of soils: Transactions, American Society of Civil Engineers: 113, pp. 901-930.

Das, Braja M., 1998, Principles of Geotechnical Engineering: International Thomson Publishing (ITP), New York, 712 pages.

Hoek, E. and Brown, E. T., 1980, Underground Excavations in Rock: The Institution of Mining and Metallurgy, London, U.K. 527 pages.

Holtz, R.D., Kovacs, W.D., and Sheahan, T.C., 2011, An Introduction to Geotechnical engineering: $2^{\text {nd }}$ edition. Pearson Education, Inc., Upper Saddle River, New Jersey, 853 pages.

Hubert, F., Caner, L., Meunier, A., and Lanson, B., 2009, Advances in characterization of soil clay mineralogy using X-ray diffraction: from decomposition to profile fitting: European Journal of Soil Science, 60(6), pp. 1093-1105.

Jesmani, M., Manesh, A. N., and Hoseini, S. M. R., 2008, Optimum water content and maximum dry unit weight of clayey gravels at different compactive efforts: Electronic Journal of Geotechnical Engineering, 13, Bundle L, 14 pages.

Kalkan, E., 2011, Impact of wetting-drying cycles on swelling behavior of clayey soils modified by silica fume: Applied Clay Science, 52(4), pp. 345-352. 
Kroenke, M. A., 1996, A Geotechnical Investigation of Three Landslide Complexes in the Moreland Hills Area, Cuyahoga County, Ohio. Unpublished M.S. Thesis, Department of Geology, Kent State University, Kent, OH, 44242, 164 pages.

Lee, F., Lo, K., and Lee, S., 1988, Tension Crack Development in Soils: Geotechnical. Engineering, 10.1061/(ASCE)0733-9410(1988)114:8(915), 915-929

Malvern Instruments Ltd., 2007, Malvern Mastersizer 2000 User Manual: Malvern Instruments Ltd., Enigma Business Park, Grovewood Road, Malvern, Worcestershire WR14 1XZ, United Kingdom, Manual 0384, Issue 1.0, 154 pages.

Mishra, A. K., Ohtsubo, M., Li, L. Y., and Higashi, T., 2012, Influence of various factors on the difference in the liquid limit values determined by Casagrande's and fall cone method: Environmental Earth Sciences, 65(1), pp. 21-27.

Mitchell, J. K. and Soga, K., 2005, Fundamentals of Soil Behavior, $3^{\text {rd }}$ Edition: John Wiley and Sons, 577 pages.

Newmark, N. M., 1965, Effects of earthquakes on dams and embankments: Geotechnique, 15(2), pp. 139-160.

Rao, B.H., Venkataramana, K., and Singh, D.N., 2011, Studies on the determination of swelling properties of soils from suction measurements: Canadian Geotechnical Journal, 48, pp. 375-387.

Scott, A.J., 2000, The physics of dirt: an introduction to soil mechanics: Physics Education, 35(1), pp. 58-63

Spangler, M. F. and Handy, R. L., 1973. Soil Engineering ( $3^{\text {rd }}$ Edition): Intest Educational Publishers, New York, NY, 748 p.

Voight, B., 1973, Correlation between Atterberg plasticity limits and residual shear strength of natural soils: Geotechnique, 23(2), pp. 265-267.

Wang, M.C. and Huang, C.C., 1984, Soil compaction and permeability prediction models: Journal of Environmental Engineering, 110(6), pp. 1063-1083.

Wesley, L.D., 2003, Residual strength of clays and correlations using the Atterberg limits: Géotechnique, 53(7), pp. 669-672.

Zomorodian, S. M. A. and Moghadam, M. J., 2011, Investigation of effective parameters on the embankment dam filter behavior in simultaneous cracking in the core and filter: Geotechnical and Geological Engineering, 29, pp. 637-644. 


\section{APPENDIX A}

GRAIN SIZE ANALYSIS DATA 
Table A-1: Low plasticity clay data showing the particle size in microns with the percent volume of the particle size.

\begin{tabular}{|c|c|c|c|c|c|c|c|c|c|c|c|}
\hline $\begin{array}{l}\text { Size } \\
(\mu \mathrm{m})\end{array}$ & $\begin{array}{c}\text { Volume } \\
(\%)\end{array}$ & $\begin{array}{l}\text { Size } \\
(\mu \mathrm{m})\end{array}$ & $\begin{array}{c}\text { Volume } \\
(\%)\end{array}$ & $\begin{array}{l}\text { Size } \\
(\mu \mathrm{m})\end{array}$ & $\begin{array}{c}\text { Volume } \\
(\%)\end{array}$ & $\begin{array}{l}\text { Size } \\
(\mu \mathrm{m})\end{array}$ & $\begin{array}{c}\text { Volume } \\
(\%)\end{array}$ & $\begin{array}{l}\text { Size } \\
(\mu \mathrm{m})\end{array}$ & $\begin{array}{c}\text { Volume } \\
(\%)\end{array}$ & $\begin{array}{l}\text { Size } \\
(\mu \mathrm{m})\end{array}$ & $\begin{array}{c}\text { Volum } \\
(\%)\end{array}$ \\
\hline 0.010 & & 0.105 & & 1.096 & & 11.482 & & 120.226 & & 1258.925 & \\
\hline 0.011 & 0.00 & 0.120 & 0.00 & 1.259 & 1.98 & 13.183 & 3.26 & 138.038 & 0.00 & 1445.440 & 0. \\
\hline 0.013 & 0.00 & 1.380 & 0.00 & 1.445 & 2.41 & 15.136 & 2.71 & 158.489 & 0.00 & 1659.587 & 0. \\
\hline 0.015 & 0.00 & 0.158 & 0.00 & 1.660 & 2.88 & 17.378 & 2.20 & 181.970 & 0.00 & 1905.461 & 0 . \\
\hline 0.017 & 0.00 & 0.182 & 0.00 & 1.905 & 3.38 & 19.953 & 1.74 & 208.930 & 0.00 & 2187.762 & 0.1 \\
\hline 0.020 & 0.00 & 0.209 & 0.00 & 2.188 & 3.86 & 22.909 & 1.35 & 239.883 & 0.00 & 2511.886 & 0.1 \\
\hline 0.023 & 0.00 & 0.240 & 0.00 & 2.512 & 4.33 & 26.303 & 1.04 & 275.423 & 0.00 & 2884.032 & 0.1 \\
\hline 0.026 & 0.00 & 0.275 & 0.02 & 2.884 & 4.74 & 30.200 & 0.79 & 316.228 & 0.00 & 3311.311 & 0.1 \\
\hline 0.030 & 0.00 & 0.316 & 0.13 & 3.311 & 5.10 & 34.674 & 0.60 & 363.078 & 0.00 & 3801.894 & 0.1 \\
\hline 0.035 & 0.00 & 0.363 & 0.25 & 3.802 & 5.37 & 39.811 & 0.46 & 416.869 & 0.04 & 4365.158 & 0.1 \\
\hline 0.040 & 0.00 & 0.417 & 0.35 & 4.365 & 5.56 & 45.709 & 0.35 & 478.630 & 0.11 & 5011.872 & 0.1 \\
\hline 0.046 & 0.00 & 0.479 & 0.45 & 5.012 & 5.65 & 52.481 & 0.27 & 549.541 & 0.16 & 5754.399 & 0.1 \\
\hline 0.052 & 0.00 & 0.550 & 0.56 & 5.750 & 5.62 & 60.256 & 0.21 & 620.957 & 0.21 & 6606.934 & 0.1 \\
\hline 0.060 & 0.00 & 0.631 & 0.69 & 6.607 & 5.47 & 69.183 & 0.15 & 724.436 & 0.24 & 7585.776 & 0.1 \\
\hline 0.069 & 0.00 & 0.724 & 0.84 & 7.586 & 5.20 & 79.433 & 0.11 & 831.764 & 0.27 & 8709.636 & 0.1 \\
\hline 0.079 & 0.00 & 0.832 & 1.04 & 8.710 & 4.82 & 91.201 & 0.07 & 954.993 & 0.30 & 10000.000 & 0.1 \\
\hline 0.091 & 0.00 & 0.955 & 1.29 & 10.000 & 4.35 & 104.713 & 0.03 & 1096.478 & 0.33 & & \\
\hline 0.105 & 0.00 & 1.096 & 1.61 & 11.482 & 3.81 & 120.226 & 0.01 & 1258.925 & 0.35 & & \\
\hline
\end{tabular}


Table A-2: Medium plasticity clay data showing the particle size in microns with the percent volume of the particle size.

\begin{tabular}{|c|c|c|c|c|c|c|c|c|c|c|c|}
\hline $\begin{array}{l}\text { Size } \\
(\mu \mathrm{m})\end{array}$ & $\begin{array}{l}\text { Volume } \\
\qquad(\%)\end{array}$ & $\begin{array}{l}\text { Size } \\
(\mu \mathrm{m})\end{array}$ & $\begin{array}{l}\text { Volume } \\
\qquad(\%)\end{array}$ & $\begin{array}{l}\text { Size } \\
(\mu \mathrm{m})\end{array}$ & $\begin{array}{l}\text { Volume } \\
\qquad(\%)\end{array}$ & $\begin{array}{l}\text { Size } \\
(\mu \mathrm{m})\end{array}$ & $\begin{array}{l}\text { Volume } \\
\qquad(\%)\end{array}$ & $\begin{array}{l}\text { Size } \\
(\mu \mathrm{m})\end{array}$ & $\begin{array}{c}\text { Volume } \\
\qquad(\%)\end{array}$ & $\begin{array}{l}\text { Size } \\
(\mu \mathrm{m})\end{array}$ & $\begin{array}{c}\text { Volum } \\
(\%)\end{array}$ \\
\hline 0.010 & & 0.105 & & 1.096 & & 11.482 & & 120.226 & & 1258.925 & \\
\hline 0.011 & 0.00 & 0.120 & 0.00 & 1.259 & 1.98 & 13.183 & 3.26 & 138.038 & 0.00 & 1445.440 & 0. \\
\hline 0.013 & 0.00 & 1.380 & 0.00 & 1.445 & 2.41 & 15.136 & 2.71 & 158.489 & 0.00 & 1659.587 & 0. \\
\hline 0.015 & 0.00 & 0.158 & 0.00 & 1.660 & 2.88 & 17.378 & 2.20 & 181.970 & 0.00 & 1905.461 & 0. \\
\hline 0.017 & 0.00 & 0.182 & 0.00 & 1.905 & 3.38 & 19.953 & 1.74 & 208.930 & 0.00 & 2187.762 & 0.1 \\
\hline 0.020 & 0.00 & 0.209 & 0.00 & 2.188 & 3.86 & 22.909 & 1.35 & 239.883 & 0.00 & 2511.886 & 0.1 \\
\hline 0.023 & 0.00 & 0.240 & 0.00 & 2.512 & 4.33 & 26.303 & 1.04 & 275.423 & 0.00 & 2884.032 & 0.1 \\
\hline 0.026 & 0.00 & 0.275 & 0.02 & 2.884 & 4.74 & 30.200 & 0.79 & 316.228 & 0.00 & 3311.311 & 0.1 \\
\hline 0.030 & 0.00 & 0.316 & 0.13 & 3.311 & 5.10 & 34.674 & 0.60 & 363.078 & 0.00 & 3801.894 & 0.1 \\
\hline 0.035 & 0.00 & 0.363 & 0.25 & 3.802 & 5.37 & 39.811 & 0.46 & 416.869 & 0.04 & 4365.158 & 0.1 \\
\hline 0.040 & 0.00 & 0.417 & 0.35 & 4.365 & 5.56 & 45.709 & 0.35 & 478.630 & 0.11 & 5011.872 & 0.1 \\
\hline 0.046 & 0.00 & 0.479 & 0.45 & 5.012 & 5.65 & 52.481 & 0.27 & 549.541 & 0.16 & 5754.399 & 0.1 \\
\hline 0.052 & 0.00 & 0.550 & 0.56 & 5.750 & 5.62 & 60.256 & 0.21 & 620.957 & 0.21 & 6606.934 & 0.1 \\
\hline 0.060 & 0.00 & 0.631 & 0.69 & 6.607 & 5.47 & 69.183 & 0.15 & 724.436 & 0.24 & 7585.776 & 0.1 \\
\hline 0.069 & 0.00 & 0.724 & 0.84 & 7.586 & 5.20 & 79.433 & 0.11 & 831.764 & 0.27 & 8709.636 & 0.1 \\
\hline 0.079 & 0.00 & 0.832 & 1.04 & 8.710 & 4.82 & 91.201 & 0.07 & 954.993 & 0.30 & 10000.000 & 0.1 \\
\hline 0.091 & 0.00 & 0.955 & 1.29 & 10.000 & 4.35 & 104.713 & 0.03 & 1096.478 & 0.33 & & \\
\hline 0.105 & 0.00 & 1.096 & 1.61 & 11.482 & 3.81 & 120.226 & 0.01 & 1258.925 & 0.35 & & \\
\hline
\end{tabular}


Table A-3: High plasticity clay data showing the particle size in microns with the percent volume of the particle size.

\begin{tabular}{|c|c|c|c|c|c|c|c|c|c|c|c|}
\hline $\begin{array}{l}\text { Size } \\
(\mu \mathrm{m})\end{array}$ & $\begin{array}{c}\text { Volume } \\
(\%)\end{array}$ & $\begin{array}{l}\text { Size } \\
(\mu \mathrm{m})\end{array}$ & $\begin{array}{c}\text { Volume } \\
(\%)\end{array}$ & $\begin{array}{l}\text { Size } \\
(\mu \mathrm{m})\end{array}$ & $\begin{array}{c}\text { Volume } \\
(\%)\end{array}$ & $\begin{array}{l}\text { Size } \\
(\mu \mathrm{m})\end{array}$ & $\begin{array}{c}\text { Volume } \\
(\%)\end{array}$ & $\begin{array}{l}\text { Size } \\
(\mu \mathrm{m})\end{array}$ & $\begin{array}{c}\text { Volume } \\
\qquad(\%)\end{array}$ & $\begin{array}{l}\text { Size } \\
(\mu \mathrm{m})\end{array}$ & $\begin{array}{c}\text { Volum } \\
(\%)\end{array}$ \\
\hline 0.010 & & 0.105 & & 1.096 & & 11.482 & & 120.226 & & 1258.925 & \\
\hline 0.011 & 0.00 & 0.120 & 0.00 & 1.259 & 2.07 & 13.183 & 3.24 & 138.038 & 0.00 & 1445.440 & 0.1 \\
\hline 0.013 & 0.00 & 1.380 & 0.00 & 1.445 & 2.55 & 15.136 & 2.64 & 158.489 & 0.00 & 1659.587 & 0.1 \\
\hline 0.015 & 0.00 & 0.158 & 0.00 & 1.660 & 3.05 & 17.378 & 2.08 & 181.970 & 0.00 & 1905.461 & 0.1 \\
\hline 0.017 & 0.00 & 0.182 & 0.00 & 1.905 & 0.58 & 19.953 & 1.59 & 208.930 & 0.00 & 2187.762 & 0.1 \\
\hline 0.020 & 0.00 & 0.209 & 0.00 & 2.188 & 4.10 & 22.909 & 1.19 & 239.883 & 0.00 & 2511.886 & 0.1 \\
\hline 0.023 & 0.00 & 0.240 & 0.00 & 2.512 & 4.58 & 26.303 & 0.88 & 275.423 & 0.00 & 2884.032 & 0.1 \\
\hline 0.026 & 0.00 & 0.275 & 0.01 & 2.884 & 5.00 & 30.200 & 0.65 & 316.228 & 0.00 & 3311.311 & 0.1 \\
\hline 0.030 & 0.00 & 0.316 & 0.08 & 3.311 & 5.35 & 34.674 & 0.49 & 363.078 & 0.02 & 3801.894 & 0.1 \\
\hline 0.035 & 0.00 & 0.363 & 0.20 & 3.802 & 5.61 & 39.811 & 0.38 & 416.869 & 0.00 & 4365.158 & 0.1 \\
\hline 0.040 & 0.00 & 0.417 & 0.30 & 4.365 & 5.76 & 45.709 & 0.31 & 478.630 & 0.00 & 5011.872 & 0.1 \\
\hline 0.046 & 0.00 & 0.479 & 0.40 & 5.012 & 0.80 & 52.481 & 0.25 & 549.541 & 0.00 & 5754.399 & 0.1 \\
\hline 0.052 & 0.00 & 0.550 & 0.52 & 5.750 & 5.73 & 60.256 & 0.19 & 620.957 & 0.00 & 6606.934 & 0.1 \\
\hline 0.060 & 0.00 & 0.631 & 0.66 & 6.607 & 5.53 & 69.183 & 0.14 & 724.436 & 0.00 & 7585.776 & 0.1 \\
\hline 0.069 & 0.00 & 0.724 & 0.83 & 7.586 & 5.21 & 79.433 & 0.07 & 831.764 & 0.00 & 8709.636 & 0.1 \\
\hline 0.079 & 0.00 & 0.832 & 1.04 & 8.710 & 4.79 & 91.201 & 0.01 & 954.993 & 0.00 & 10000.000 & 0.1 \\
\hline 0.091 & 0.00 & 0.955 & 1.32 & 10.000 & 4.29 & 104.713 & 0.00 & 1096.478 & 0.00 & & \\
\hline 0.105 & 0.00 & 1.096 & 1.66 & 11.482 & 3.74 & 120.226 & 0.00 & 1258.925 & 0.00 & & \\
\hline
\end{tabular}


APPENDIX B

RESULTS OF THE ATTERBERG LIMIT TESTS 


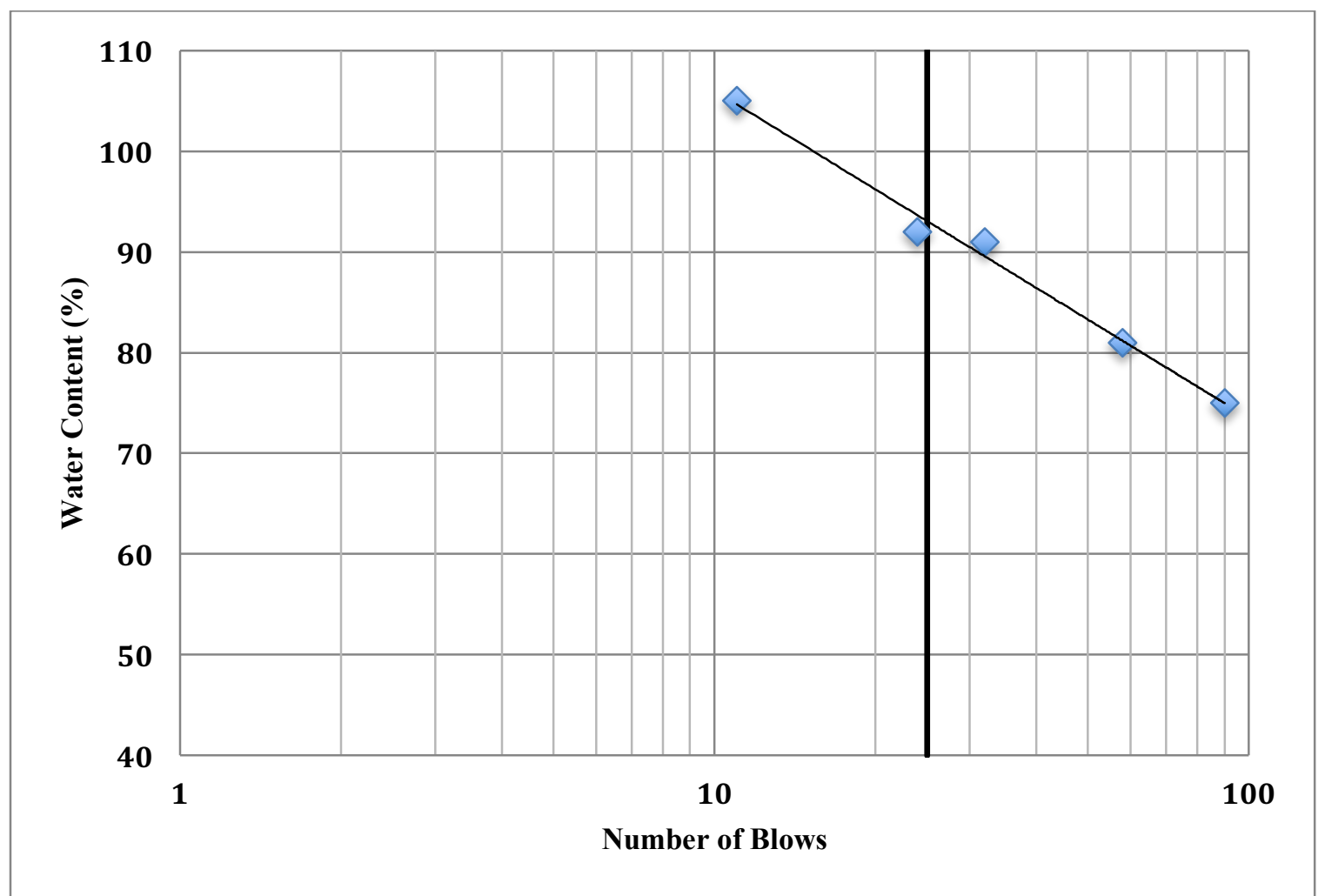

Figure B-1: Flow curve for the low plasticity clay (CL). 


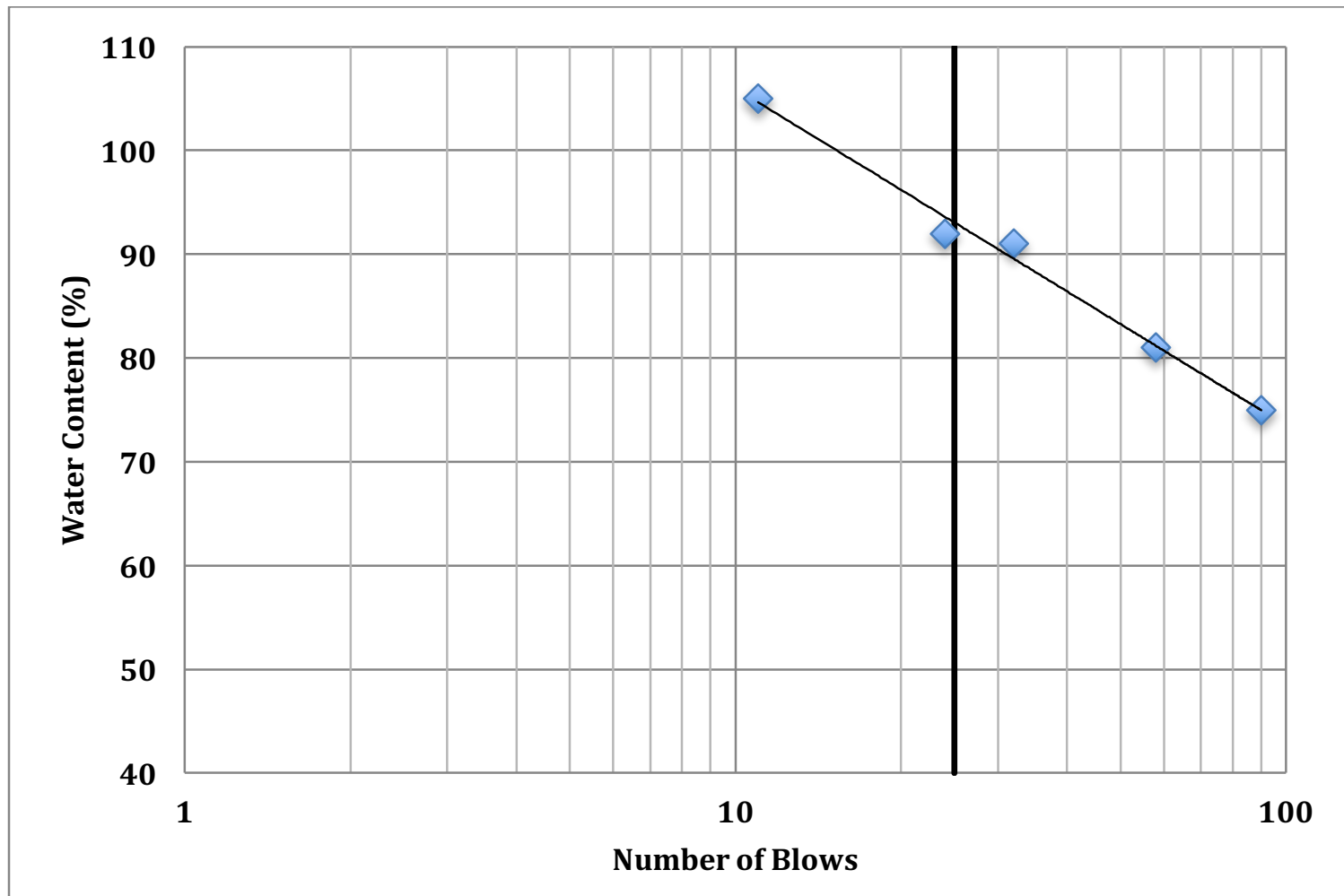

Figure B-2: Flow curve for the medium plasticity clay. 


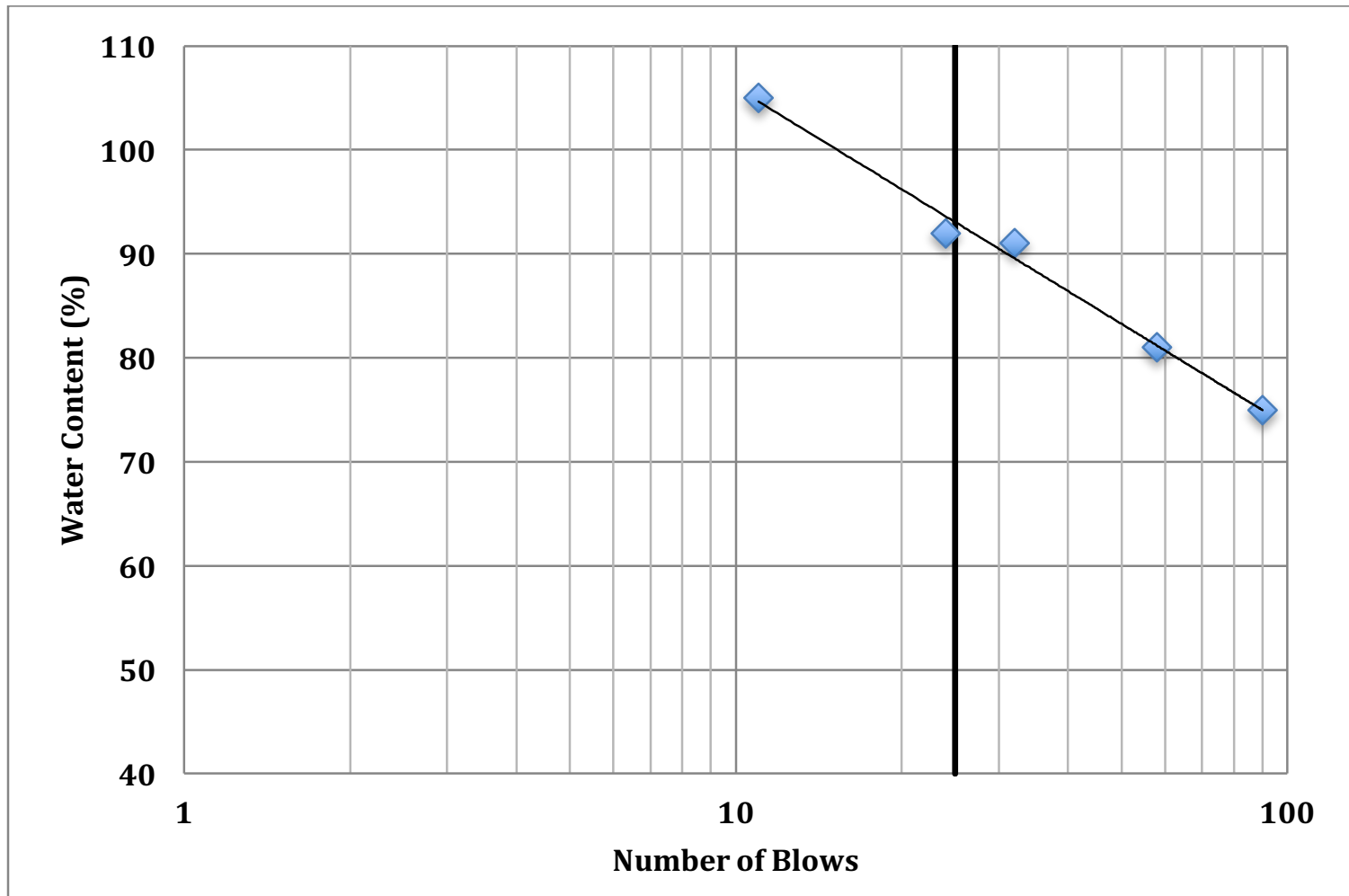

Figure B-3: Flow curve for the high plasticity clay $(\mathrm{CH})$. 
APPENDIX C

COMPACTION TEST DATA 


\begin{tabular}{|c|c|c|c|c|c|c|c|c|c|c|c|c|c|}
\hline Sample & \multicolumn{13}{|c|}{ Standard Proctor Low Plasticity (CL) Sample } \\
\hline Water Content & $8.0 \%$ & $12.0 \%$ & $16.0 \%$ & $18.0 \%$ & $19.0 \%$ & $20.0 \%$ & $20.0 \%$ & $21.0 \%$ & $23.0 \%$ & $24.0 \%$ & $24.0 \%$ & $26.0 \%$ & $28.0 \%$ \\
\hline weight of soil (g) & 1505 & 1625 & 1700 & 1762 & 1806 & 1819 & 1836 & 1883 & 1892 & 1888 & 1863 & 1822 & 1810 \\
\hline weight of soil (lb) & 3.32 & 3.58 & 3.75 & 3.88 & 3.98 & 4.01 & 4.05 & 4.15 & 4.17 & 4.16 & 4.11 & 4.02 & 3.99 \\
\hline wet unit weight $\left(\mathrm{lb} / \mathrm{ft}^{\wedge} 3\right)$ & 100.54 & 108.56 & 113.57 & 117.71 & 120.65 & 121.52 & 122.66 & 125.79 & 126.40 & 126.13 & 124.46 & 121.72 & 120.92 \\
\hline dry unit weight $(\mathrm{lb} / \mathrm{ft} \wedge 3)$ & 91.40 & 95.23 & 97.90 & 99.76 & 101.47 & 101.60 & 102.21 & 103.96 & 103.60 & 102.54 & 100.37 & 96.60 & 94.47 \\
\hline Actual Water content $(\%)$ & $10.0 \%$ & $14.0 \%$ & $16.0 \%$ & $18.0 \%$ & $18.9 \%$ & $19.6 \%$ & $20.0 \%$ & $21.0 \%$ & $22.0 \%$ & $23.0 \%$ & $24.0 \%$ & $26.0 \%$ & $28.0 \%$ \\
\hline Total V & 3.32 & 3.58 & 3.75 & 3.88 & 3.98 & 4.01 & 4.05 & 4.15 & 4.17 & 4.16 & 4.11 & 4.02 & 3.99 \\
\hline Weig & 3.02 & 3.14 & 3.23 & 3.29 & 3.35 & 3.35 & 3.37 & 3.43 & 3.42 & 3.38 & 3.31 & 3.19 & 3.12 \\
\hline Weig & 0.30 & 0.44 & 0.52 & 0.59 & 0.63 & 0.66 & 0.67 & 0.72 & 0.75 & 0.78 & 0.79 & 0.83 & 0.87 \\
\hline Volume of Water & 0.0048 & 0.0071 & 0.0083 & 0.0095 & 0.0101 & 0.0105 & 0.0108 & 0.0115 & 0.0121 & 0.0125 & 0.0127 & 0.0133 & 0.0140 \\
\hline Volume of Solid & 0.0179 & 0.0187 & 0.0192 & 0.0195 & 0.0199 & 0.0199 & 0.0200 & 0.0204 & 0.0203 & 0.0201 & 0.0197 & 0.0189 & 0.0185 \\
\hline Volum & 0.0151 & 0.0143 & 0.0138 & 0.0135 & 0.0131 & 0.0131 & 0.0130 & 0.0126 & 0.0127 & 0.0129 & 0.0133 & 0.0141 & 0.0145 \\
\hline Volum & 0.010 & 0.007 & 0.006 & 0.004 & 0.003 & 0.003 & 0.002 & 0.001 & 0.001 & 0.000 & 0.001 & 0.001 & 0.001 \\
\hline Total Volume (Vt) & 0.033 & 0.033 & 0.033 & 0.033 & 0.033 & 0.033 & 0.033 & 0.033 & 0.033 & 0.033 & 0.033 & 0.033 & 0.033 \\
\hline & 0.84 & 0.77 & 0.72 & 0.69 & 0.66 & 0.66 & 0.65 & 0.62 & 0.63 & 0.64 & 0.68 & 0.74 & 0.78 \\
\hline Porosity (n) & $46 \%$ & $43 \%$ & $42 \%$ & $41 \%$ & $40 \%$ & $40 \%$ & $39 \%$ & $38 \%$ & $39 \%$ & $39 \%$ & $40 \%$ & $43 \%$ & $44 \%$ \\
\hline Max Dry Den & & & & & & & 103 & & & & & & \\
\hline Optimum Water Content & & & & & & & $21 \%$ & & & & & & \\
\hline
\end{tabular}




\begin{tabular}{|l|rrrrrrrr|}
\hline Sample & \multicolumn{7}{|c|}{ Standard Proctor Medium Plasticity $(\mathrm{CH})$} & Sample $(\mathrm{CL}+20 \%)$ \\
\hline Water Content & $14 \%$ & $19 \%$ & $22 \%$ & $23 \%$ & $25 \%$ & $27 \%$ & $29 \%$ & $31 \%$ \\
\hline weight of soil $(\mathrm{g})$ & 1520 & 1623 & 1700 & 1720 & 1765 & 1791 & 1785 & 1780 \\
weight of soil $(\mathrm{lb})$ & 3.35 & 3.58 & 3.75 & 3.79 & 3.89 & 3.95 & 3.94 & 3.92 \\
wet unit weight $(\mathrm{lb} / \mathrm{ft} \wedge 3)$ & 101.54 & 108.43 & 113.57 & 114.91 & 117.91 & 119.65 & 119.25 & 118.91 \\
dry unit weight $\left(\mathrm{lb} / \mathrm{ft}^{\wedge} 3\right)$ & 89.07 & 91.34 & 93.09 & 93.65 & 95.09 & 94.43 & 92.44 & 90.77 \\
Actual Water content (\%) & $14 \%$ & $19 \%$ & $22 \%$ & $23 \%$ & $24 \%$ & $27 \%$ & $29 \%$ & $31 \%$ \\
Total Weight $(\mathrm{Wt})$ & 3.35 & 3.58 & 3.75 & 3.79 & 3.89 & 3.95 & 3.94 & 3.92 \\
Weight of Solids (Ws) & 2.94 & 3.01 & 3.07 & 3.09 & 3.14 & 3.12 & 3.05 & 3.00 \\
Weight of Water (Ww) & 0.41 & 0.56 & 0.68 & 0.70 & 0.75 & 0.83 & 0.88 & 0.93 \\
Volume of Water (Vw) & 0.0066 & 0.0090 & 0.0108 & 0.0112 & 0.0121 & 0.0133 & 0.0142 & 0.0149 \\
Volume of Solids (Vs) & 0.0175 & 0.0180 & 0.0183 & 0.0184 & 0.0187 & 0.0186 & 0.0182 & 0.0178 \\
Volume of Voids (Vv) & 0.0155 & 0.0150 & 0.0147 & 0.0146 & 0.0143 & 0.0144 & 0.0148 & 0.0152 \\
Volume of Air $(\mathrm{Va})$ & 0.009 & 0.006 & 0.004 & 0.003 & 0.002 & 0.001 & 0.001 & 0.000 \\
Total Volume (Vt) & 0.033 & 0.033 & 0.033 & 0.033 & 0.033 & 0.033 & 0.033 & 0.033 \\
void ratio (e) & 0.88 & 0.84 & 0.80 & 0.79 & 0.77 & 0.78 & 0.82 & 0.85 \\
Porosity (n) & $47 \%$ & $46 \%$ & $45 \%$ & $44 \%$ & $43 \%$ & $44 \%$ & $45 \%$ & $46 \%$ \\
Max Dry Density (pcf) & & & & 94.5 & & & & \\
Optimum Water Content & & & & $26 \%$ & & & & \\
\hline
\end{tabular}




\begin{tabular}{|c|c|c|c|c|c|c|c|c|c|}
\hline Sample & \multicolumn{9}{|c|}{ Standard Proctor High Plasticity $\mathrm{CH}$ Sample $(\mathrm{CL}+40 \%)$} \\
\hline Water Content & $12 \%$ & $16 \%$ & $20 \%$ & $24 \%$ & $25 \%$ & $26 \%$ & $28 \%$ & $30 \%$ & $32 \%$ \\
\hline weight of soil (g) & 1417 & 1493 & 1579 & 1652 & 1670 & 1686 & 1729 & 1734 & 1748 \\
\hline weight of soil (lb) & 3.12 & 3.29 & 3.48 & 3.64 & 3.68 & 3.72 & 3.81 & 3.82 & 3.85 \\
\hline wet unit weight $\left(\mathrm{lb} / \mathrm{ft}^{\wedge} 3\right)$ & 94.66 & 99.74 & 105.49 & 110.36 & 111.57 & 112.63 & 115.51 & 115.84 & 116.78 \\
\hline dry unit weight (lb/ft^3) & 84.52 & 85.98 & 87.91 & 89.00 & 89.25 & 89.39 & 89.26 & 88.43 & 88.00 \\
\hline Actual Water content $(\%)$ & $12 \%$ & $16 \%$ & $20 \%$ & $24 \%$ & $25 \%$ & $26 \%$ & $29 \%$ & $31 \%$ & $33 \%$ \\
\hline Total Weight (Wt) & 3.12 & 3.29 & 3.48 & 3.64 & 3.68 & 3.72 & 3.81 & 3.82 & 3.85 \\
\hline Weight of Solids (Ws) & 2.79 & 2.84 & 2.90 & 2.94 & 2.95 & 2.95 & 2.95 & 2.92 & 2.90 \\
\hline Weight of Water (Ww) & 0.33 & 0.45 & 0.58 & 0.70 & 0.74 & 0.77 & 0.87 & 0.90 & 0.95 \\
\hline Volume of Water (Vw) & 0.0054 & 0.0073 & 0.0093 & 0.0113 & 0.0118 & 0.0123 & 0.0139 & 0.0145 & 0.0152 \\
\hline Volume of Solids (Vs) & 0.0167 & 0.0170 & 0.0173 & 0.0176 & 0.0176 & 0.0176 & 0.0176 & 0.0175 & 0.0174 \\
\hline Volume of Voids (Vv) & 0.0163 & 0.0160 & 0.0157 & 0.0154 & 0.0154 & 0.0154 & 0.0154 & 0.0155 & 0.0156 \\
\hline Volume of Air (Va) & 0.011 & 0.009 & 0.006 & 0.004 & 0.004 & 0.003 & 0.002 & 0.001 & 0.000 \\
\hline Total Volume (Vt) & 0.033 & 0.033 & 0.033 & 0.033 & 0.033 & 0.033 & 0.033 & 0.033 & 0.033 \\
\hline void ratio $(e)$ & 0.98 & 0.94 & 0.90 & 0.88 & 0.87 & 0.87 & 0.87 & 0.89 & 0.90 \\
\hline Porosity (n) & $49 \%$ & $49 \%$ & $47 \%$ & $47 \%$ & $47 \%$ & $47 \%$ & $47 \%$ & $47 \%$ & $47 \%$ \\
\hline Max Dry Density (pcf) & \multirow{2}{*}{\multicolumn{9}{|c|}{$\begin{array}{c}89.50 \\
27 \%\end{array}$}} \\
\hline Optimum Water Content & & & & & & & & & \\
\hline
\end{tabular}


APPENDIX D

UNCONFINED COMPRESSION TEST DATA 
Sample: Low Plasticity Clay (CL)

Water Content: 9\%

Time to Fail: $10 \mathrm{~min}$

Failure Load: $613 \mathrm{lbs}$

$q_{u}=48.1 \mathrm{psi}$

Deformation: 0.18 in

Mode of Failure: Brittle

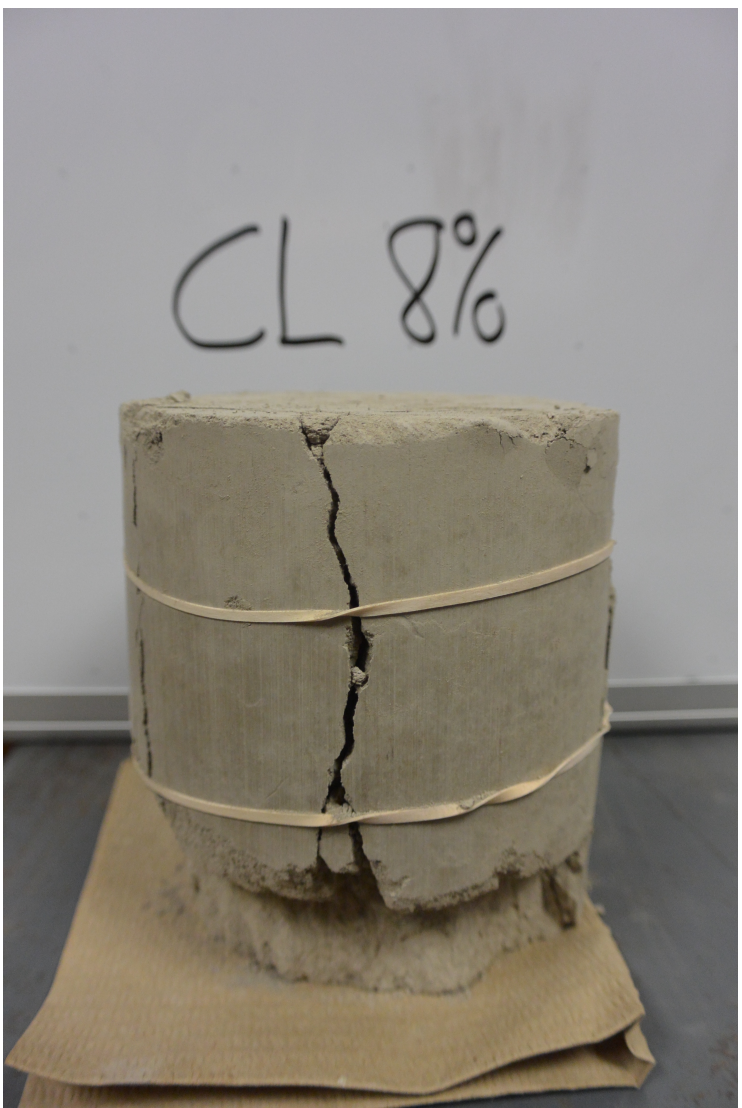

Failed Sample 
Sample: Low Plasticity Clay (CL)

Water Content: $12 \%$

Time to Fail: $10 \mathrm{~min}$

Failure Load: $593 \mathrm{lbs}$

$q_{u}=47.21 \mathrm{psi}$

Deformation: 0.18 in

Mode of Failure: Brittle

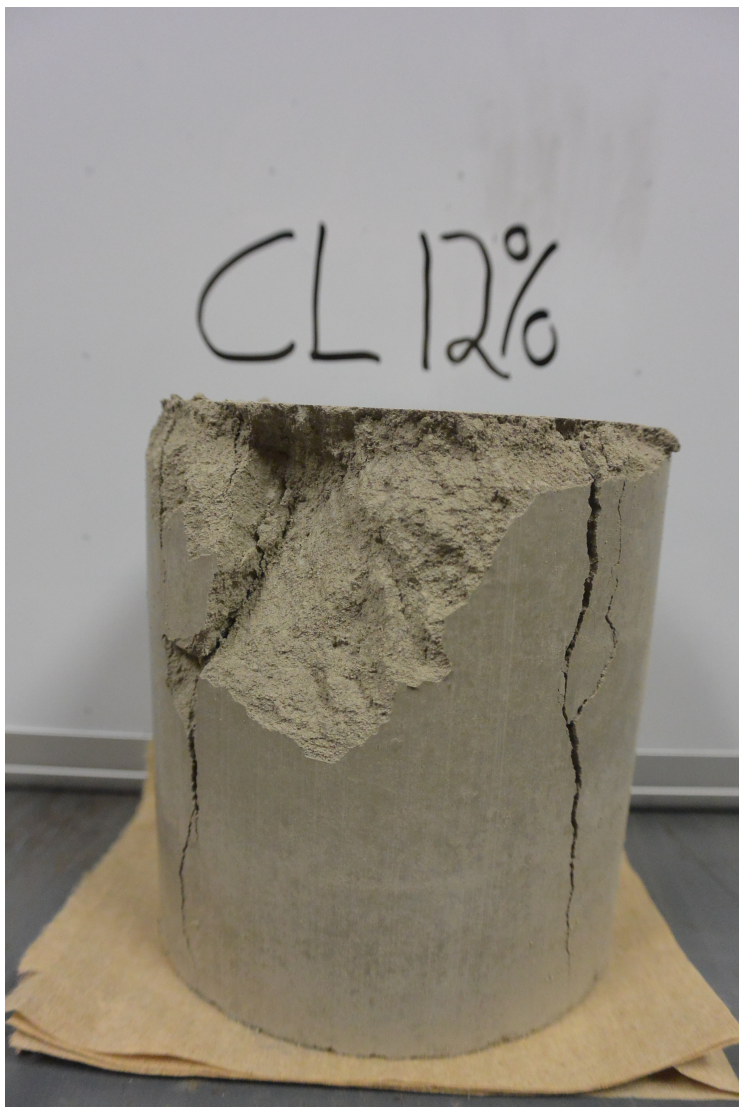

Failed Sample 
Sample: Low Plasticity Clay (CL)

Water Content: 16\%

Time to Fail: $8 \mathrm{~min}$

Failure Load: $653 \mathrm{lbs}$

$q_{u}=51.9 \mathrm{psi}$

Deformation: 0.18 in

Mode of Failure: Brittle

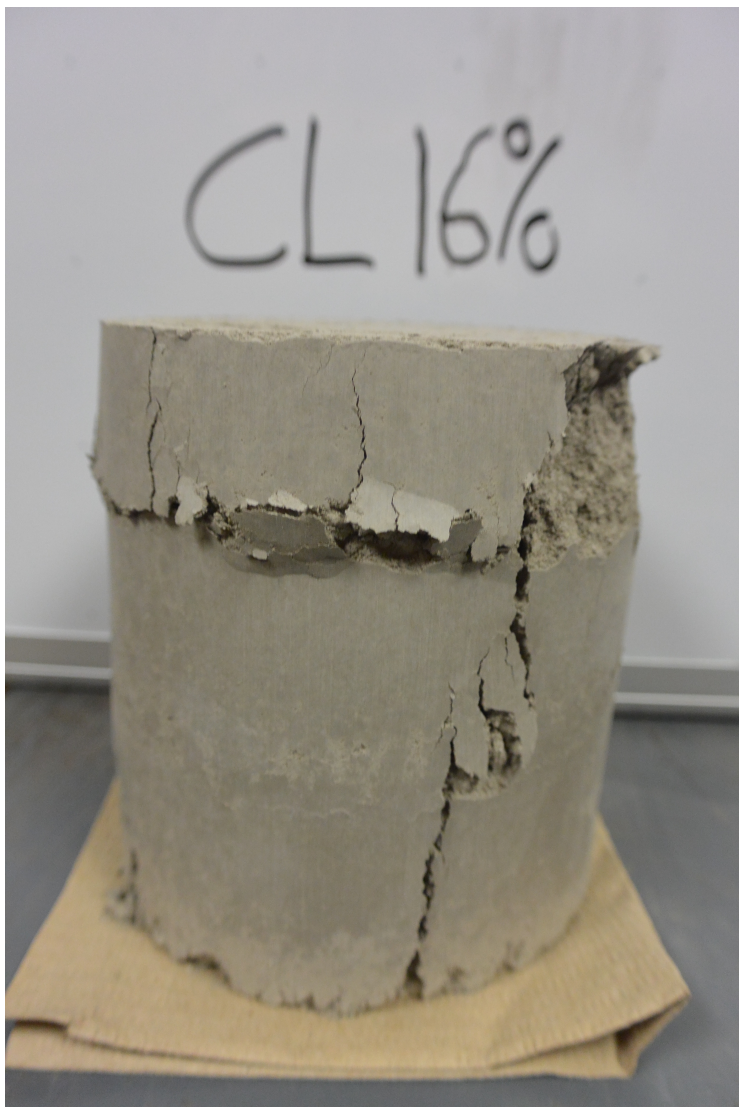

Failed Sample 
Sample: Low Plasticity Clay (CL)

Water Content: $18 \%$

Time to Fail: $10 \mathrm{~min}$

Failure Load: $791 \mathrm{lbs}$

$q_{u}=62.9 \mathrm{psi}$

Deformation: 0.30 in

Mode of Failure: Brittle

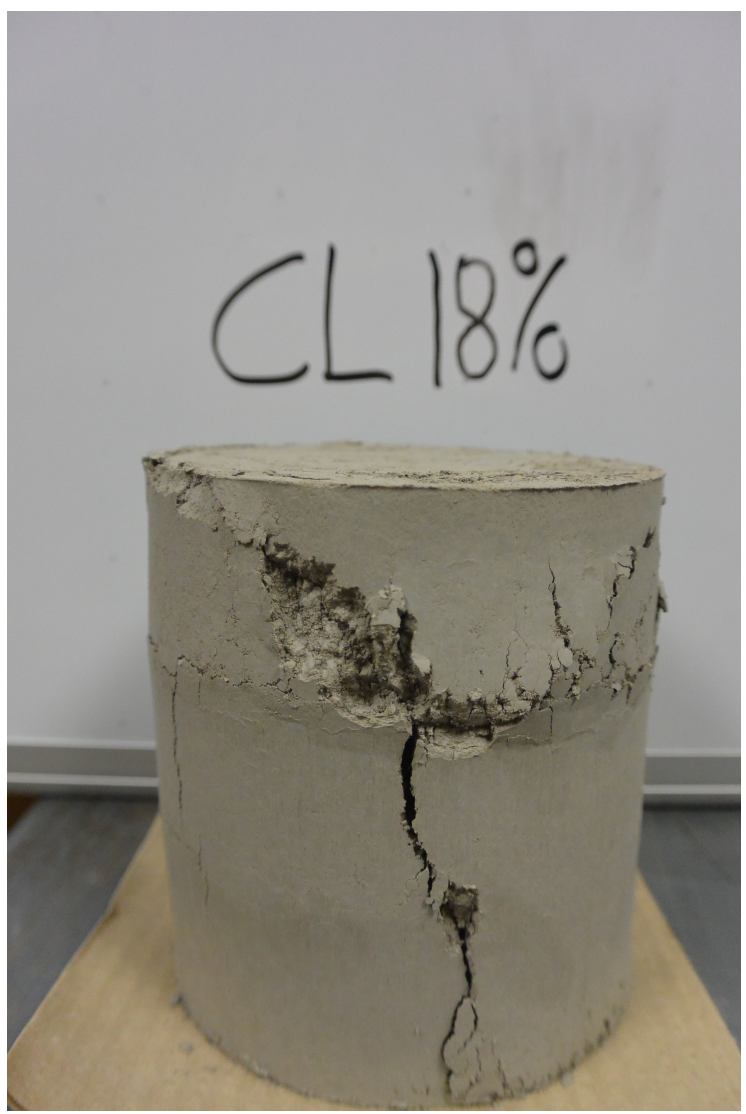

Failed Sample 
Sample: Low Plasticity Clay (CL)

Water Content: 19\%

Time to Fail: $10 \mathrm{~min}$

Failure Load: $831 \mathrm{lbs}$

$q_{u}=66.1 \mathrm{psi}$

Deformation: 0.23 in

Mode of Failure: Brittle

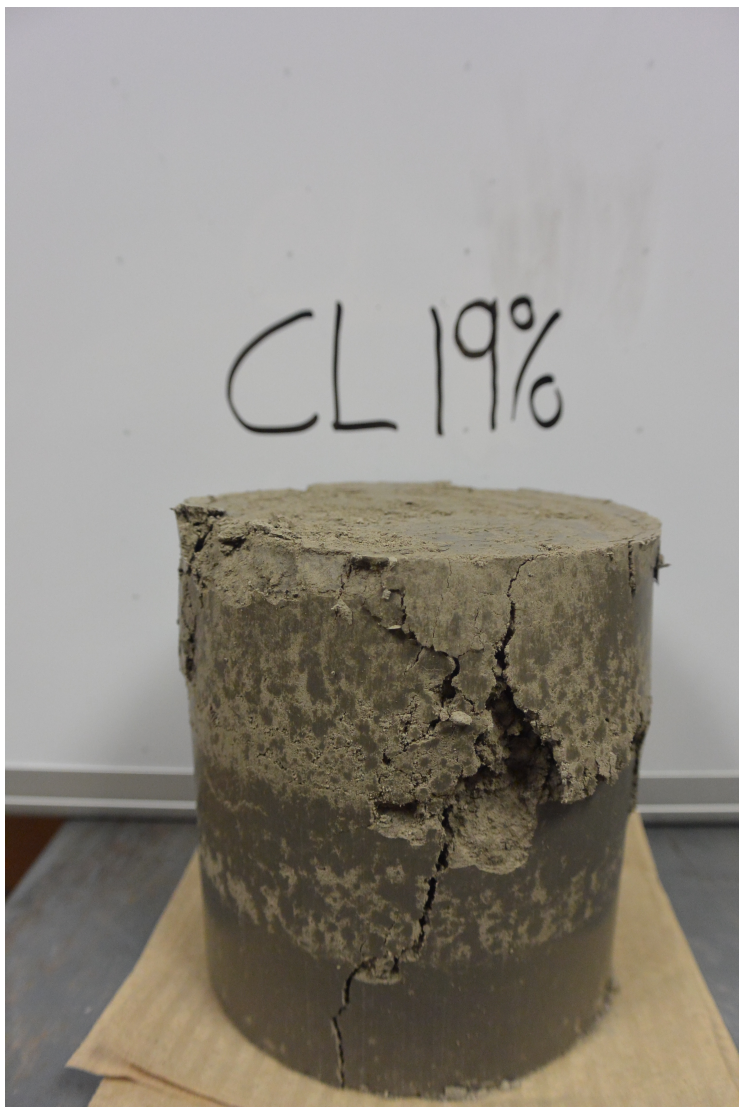

Failed Sample 
Sample: Low Plasticity Clay (CL)

Water Content: $20 \%$

Time to Fail: $11 \mathrm{~min}$

Failure Load: $613 \mathrm{lbs}$

$q_{u}=48.8 \mathrm{psi}$

Deformation: 0.70 in

Mode of Failure: Semi-Plastic

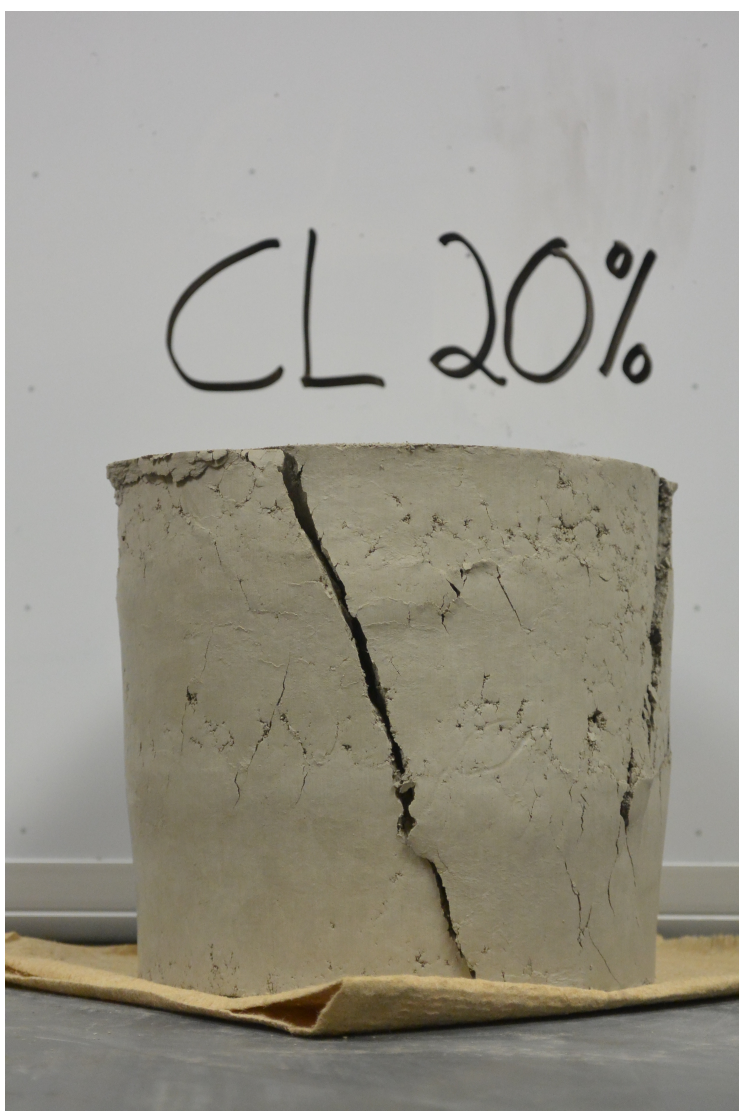

Failed Sample 
Sample: Low Plasticity Clay (CL)

Water Content: $24 \%$

Time to Fail: $12 \mathrm{~min}$

Failure Load: $593 \mathrm{lbs}$

$q_{u}=47.2 \mathrm{psi}$

Deformation: 1.0 in

Mode of Failure: Plastic

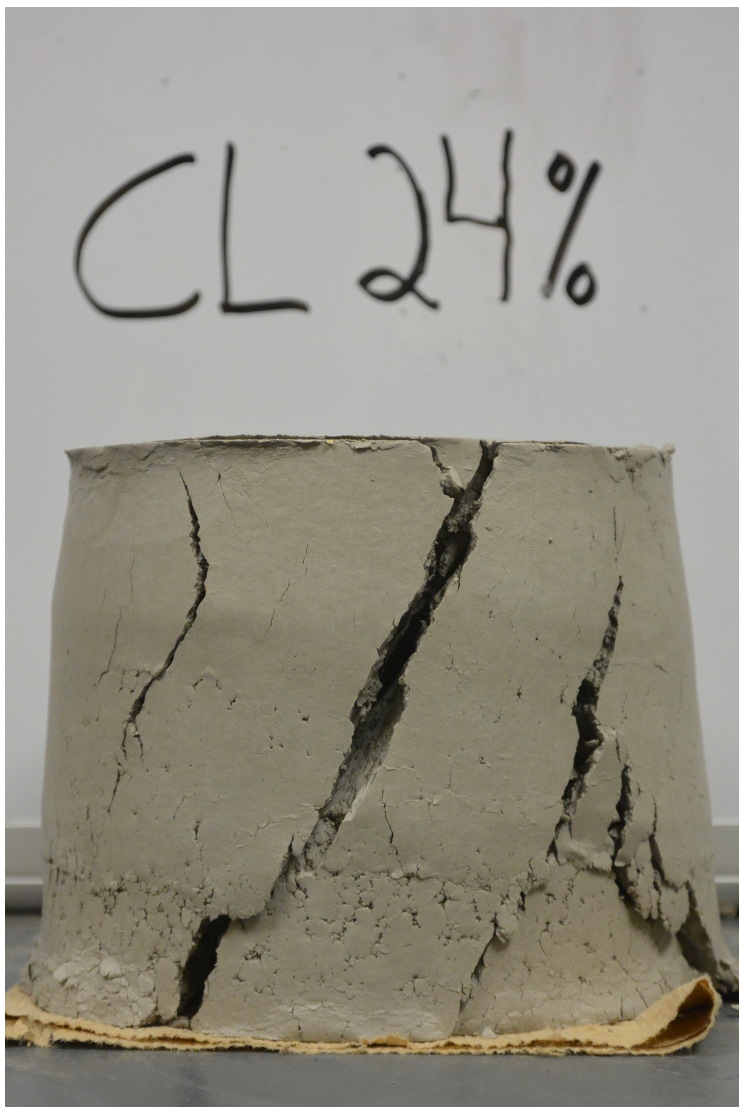

Failed Sample 
Sample: Low Plasticity Clay (CL)

Water Content: $28 \%$

Time to Fail: $12 \mathrm{~min}$

Failure Load: 198 lbs

$q_{u}=15.7 \mathrm{psi}$

Deformation: 1.0 in

Mode of Failure: Plastic

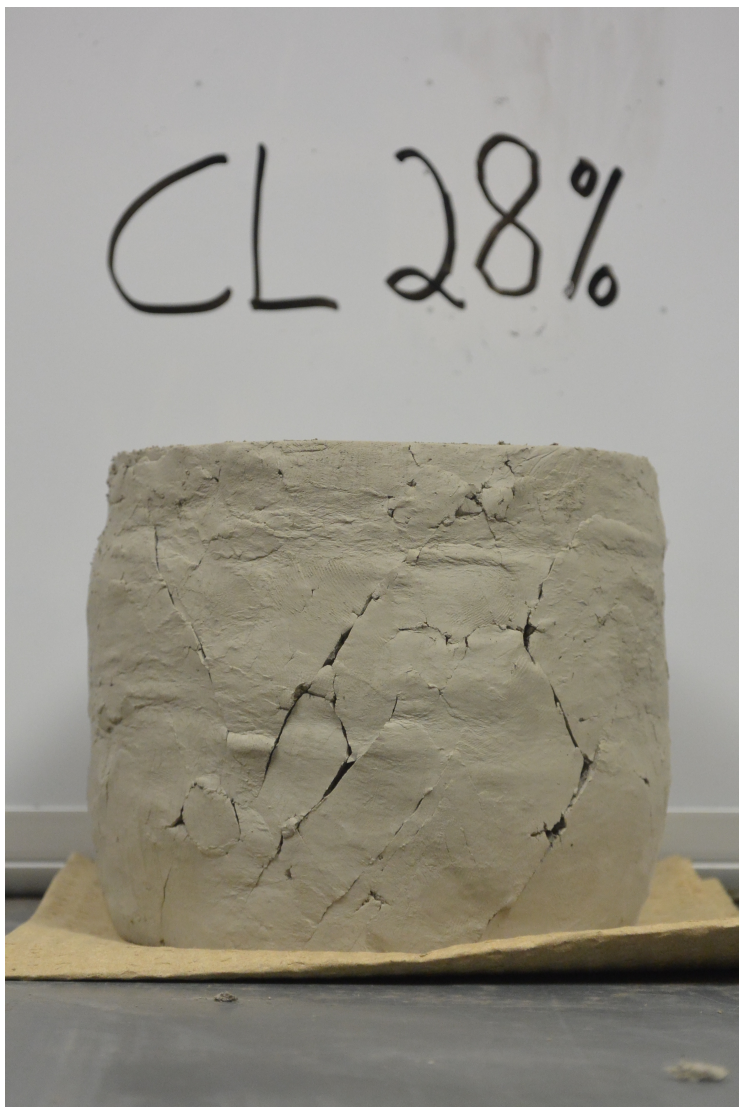

Failed Sample 
Sample: Medium Plasticity Clay (CL-CH)

Water Content: $14 \%$

Time to Fail: $7 \mathrm{~min}$

Failure Load: $653 \mathrm{lbs}$

$q_{u}=51.9 \mathrm{psi}$

Deformation: 0.16 in

Mode of Failure: Brittle

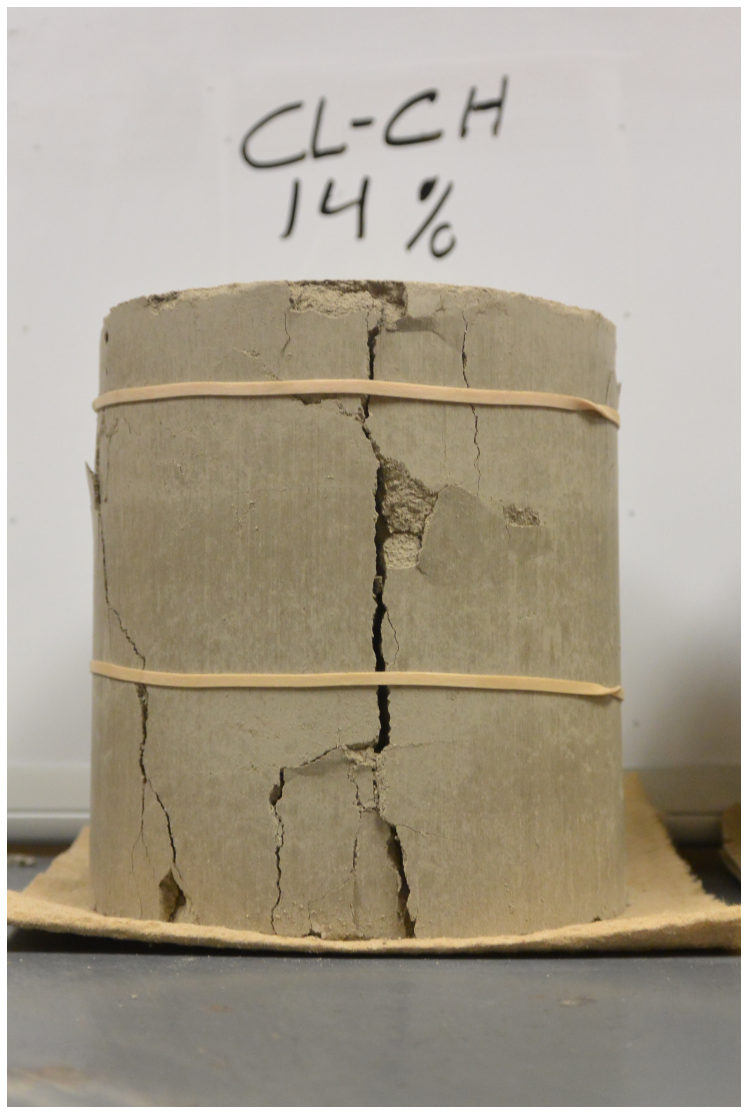

Failed Sample 
Sample: Medium Plasticity Clay (CL-CH)

Water Content: $19 \%$

Time to Fail: $7 \mathrm{~min}$

Failure Load: $712 \mathrm{lbs}$

$q_{u}=56.6 \mathrm{psi}$

Deformation: 0.16 in

Mode of Failure: Brittle

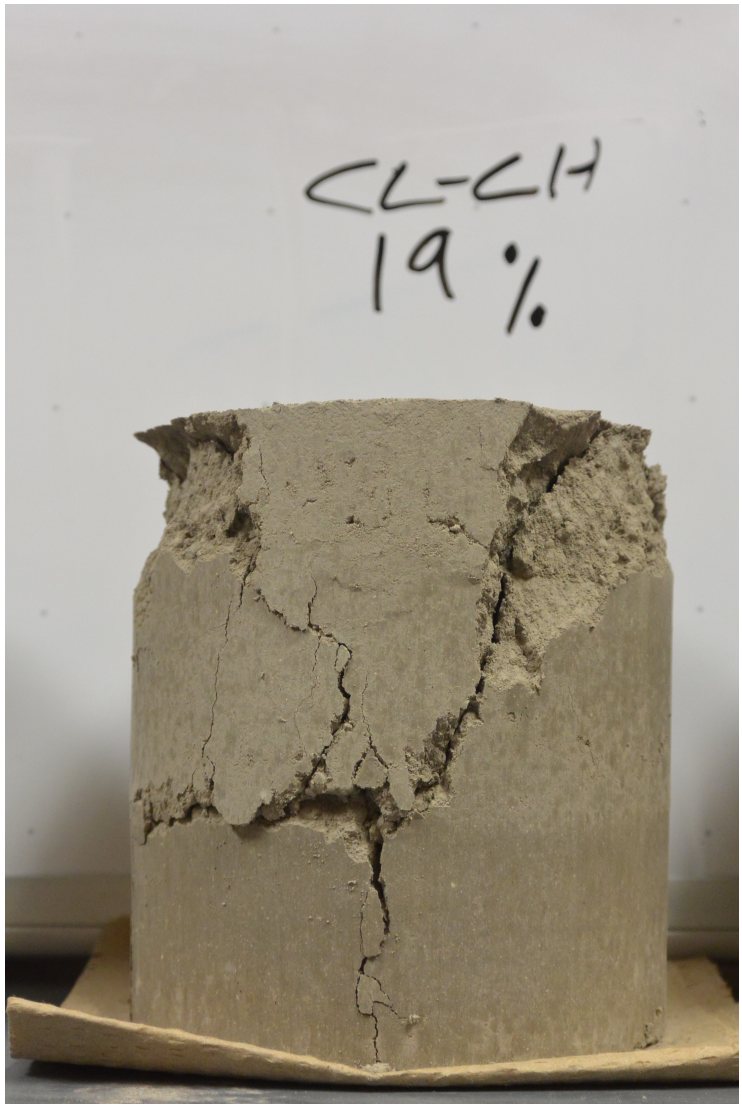

Failed Sample 
Sample: Medium Plasticity Clay (CL-CH)

Water Content: $23 \%$

Time to Fail: $8 \mathrm{~min}$

Failure Load: $890 \mathrm{lbs}$

$q_{u}=70.8 \mathrm{psi}$

Deformation: 0.30 in

Mode of Failure: Brittle

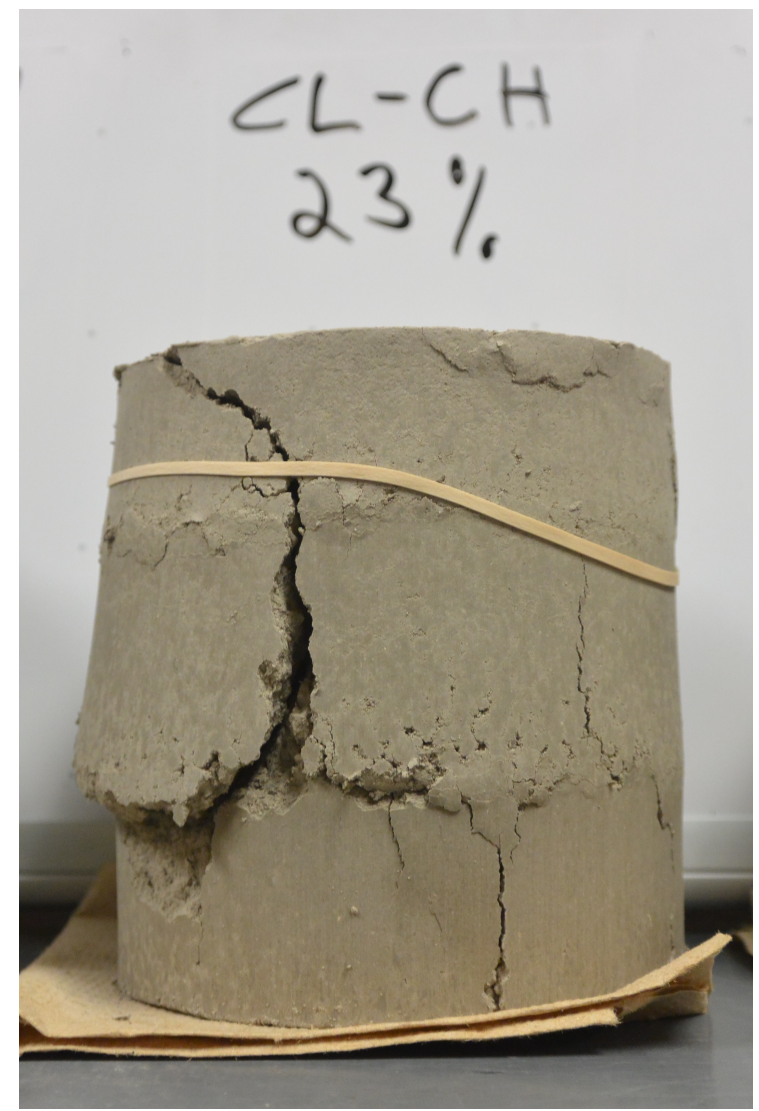

Failed Sample 
Sample: Medium Plasticity Clay (CL-CH)

Water Content: $27 \%$

Time to Fail: $10 \mathrm{~min}$

Failure Load: $732 \mathrm{lbs}$

$q_{u}=58.2 \mathrm{psi}$

Deformation: 0.50 in

Mode of Failure: Brittle

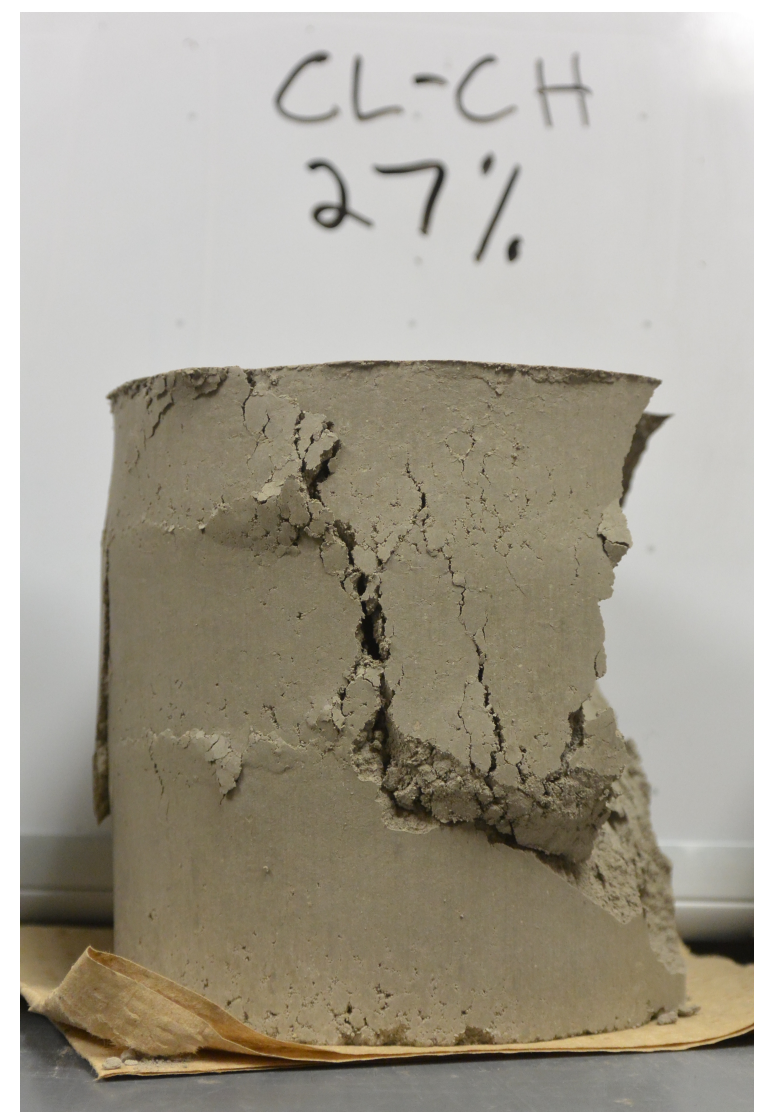

Failed Sample 
Sample: Medium Plasticity Clay (CL-CH)

Water Content: $31 \%$

Time to Fail: $10 \mathrm{~min}$

Failure Load: $277 \mathrm{lbs}$

$q_{u}=22 \mathrm{psi}$

Deformation: 1.0 in

Mode of Failure: Plastic

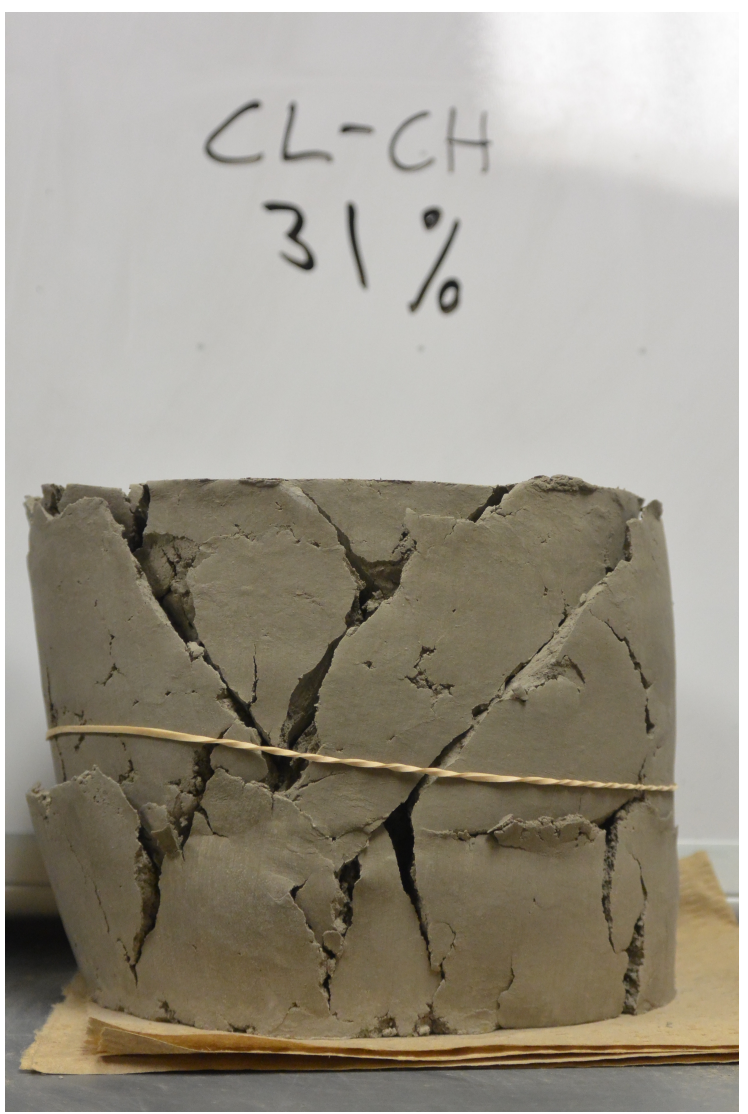

Failed Sample 
Sample: High Plasticity Clay $(\mathrm{CH})$

Water Content: $12 \%$

Time to Fail: $5 \mathrm{~min}$

Failure Load: $475 \mathrm{lbs}$

$q_{u}=37.8 \mathrm{psi}$

Deformation: 0.18 in

Mode of Failure: Brittle

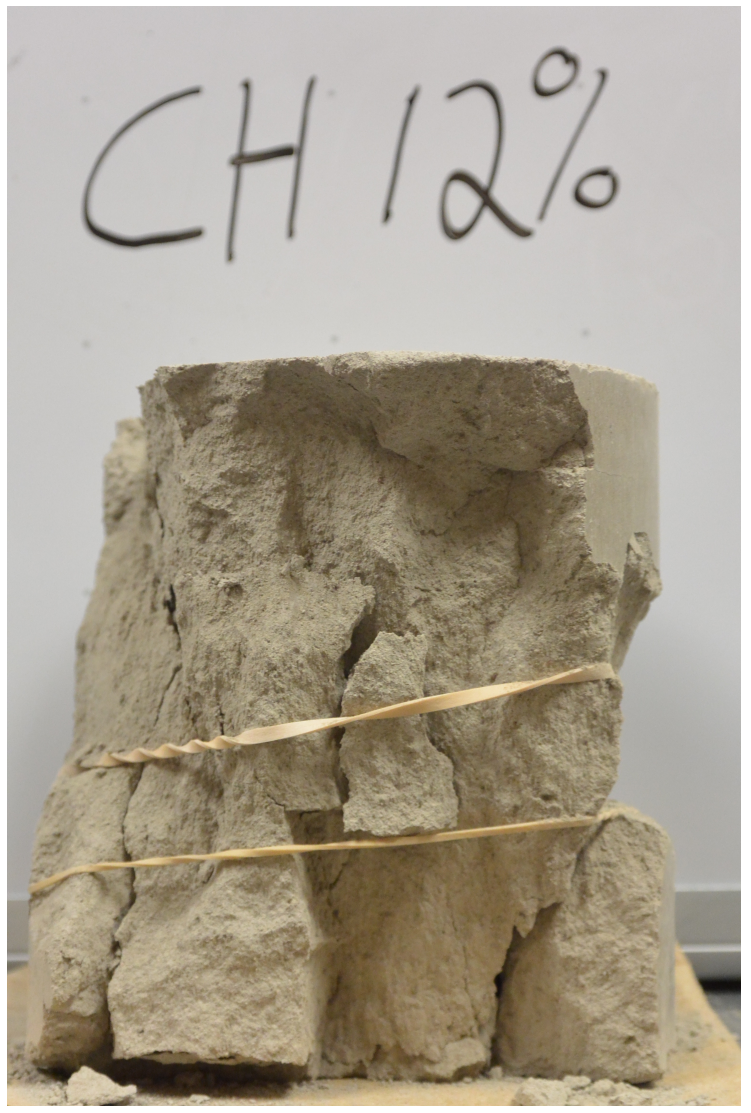

Failed Sample 
Sample: High Plasticity Clay $(\mathrm{CH})$

Water Content: 16\%

Time to Fail: $9 \mathrm{~min}$

Failure Load: $692 \mathrm{lbs}$

$q_{u}=55 \mathrm{psi}$

Deformation: 0.18 in

Mode of Failure: Brittle

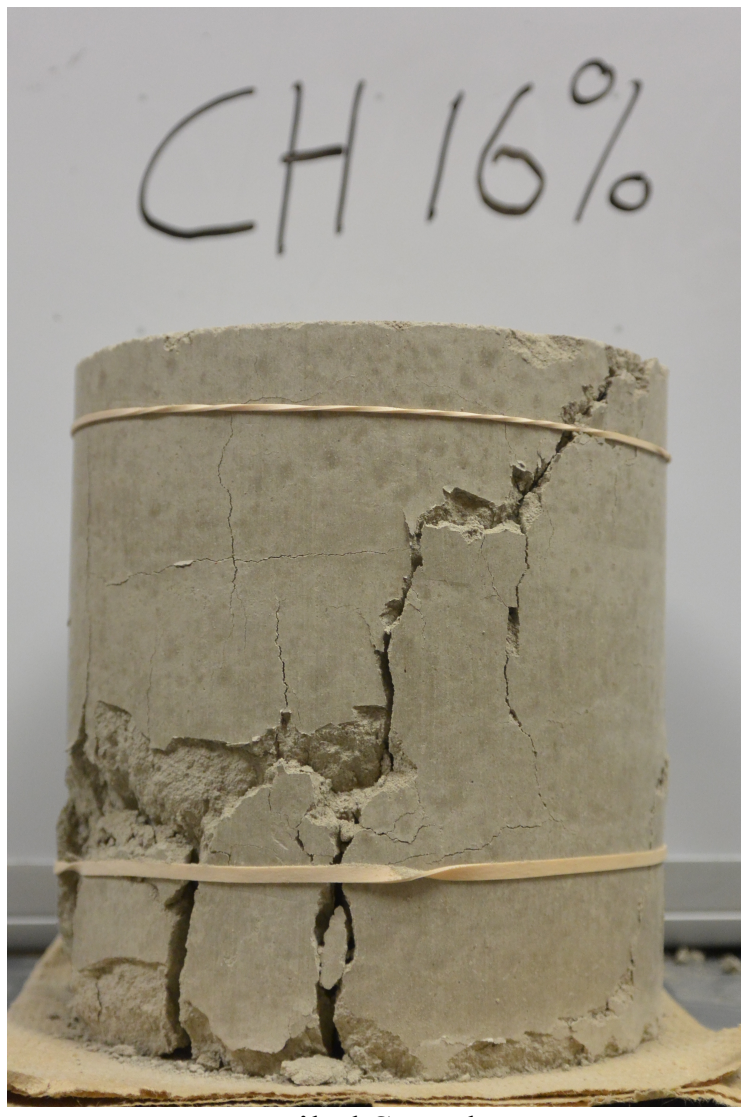

Failed Sample 
Sample: High Plasticity Clay $(\mathrm{CH})$

Water Content: $20 \%$

Time to Fail: $7 \mathrm{~min}$

Failure Load: $771 \mathrm{lbs}$

$q_{u}=61.3 \mathrm{psi}$

Deformation: 0.18 in

Mode of Failure: Brittle

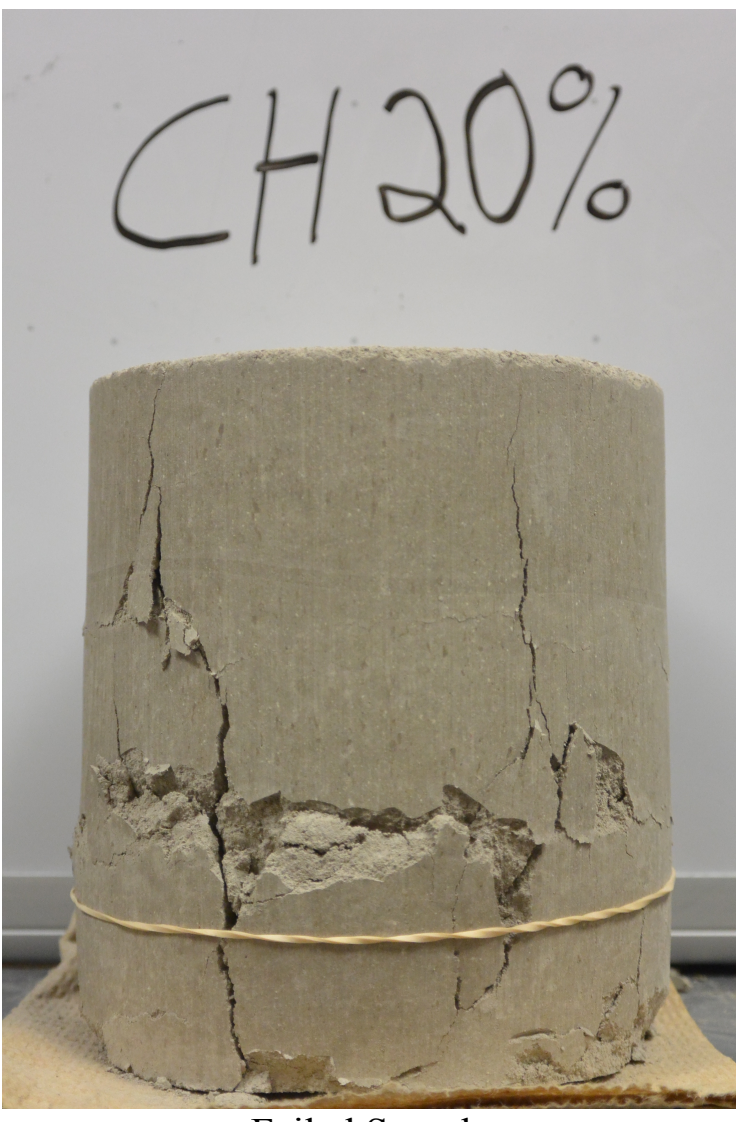

Failed Sample 
Sample: High Plasticity Clay $(\mathrm{CH})$

Water Content: $24 \%$

Time to Fail: $8 \mathrm{~min}$

Failure Load: $850 \mathrm{lbs}$

$q_{u}=67.6 \mathrm{psi}$

Deformation: 0.29 in

Mode of Failure: Brittle

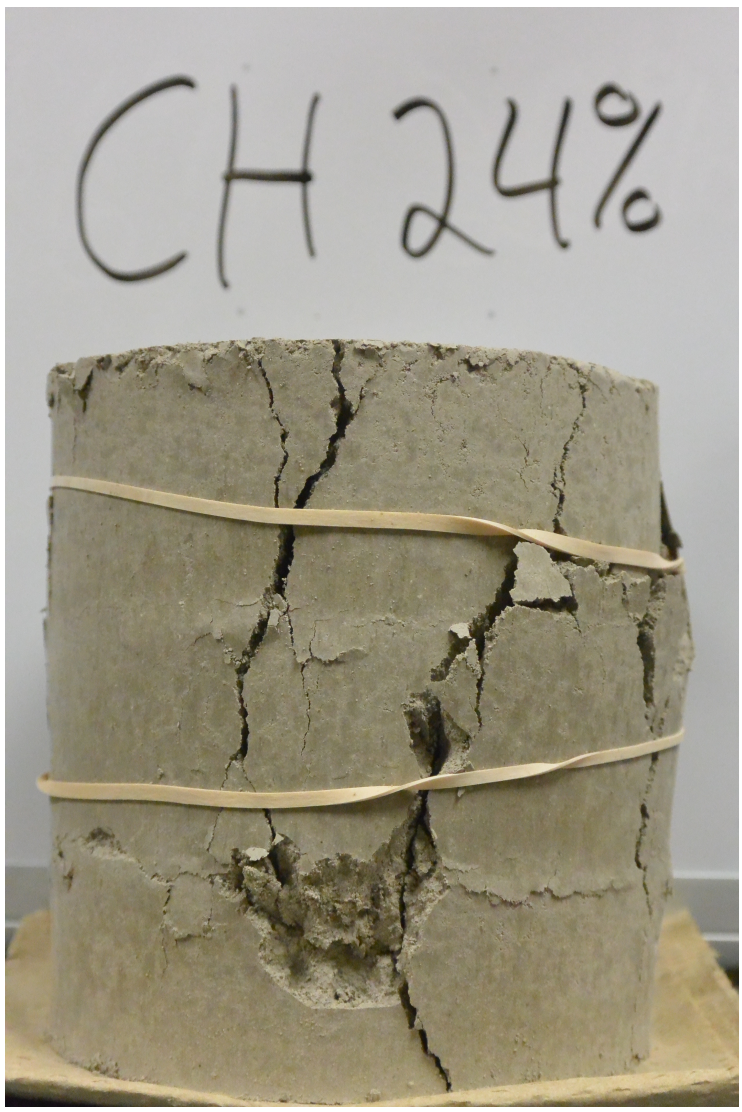

Failed Sample 
Sample: High Plasticity Clay $(\mathrm{CH})$

Water Content: $26 \%$

Time to Fail: $10 \mathrm{~min}$

Failure Load: $791 \mathrm{lbs}$

$q_{u}=62.9 \mathrm{psi}$

Deformation: 0.35 in

Mode of Failure: Brittle

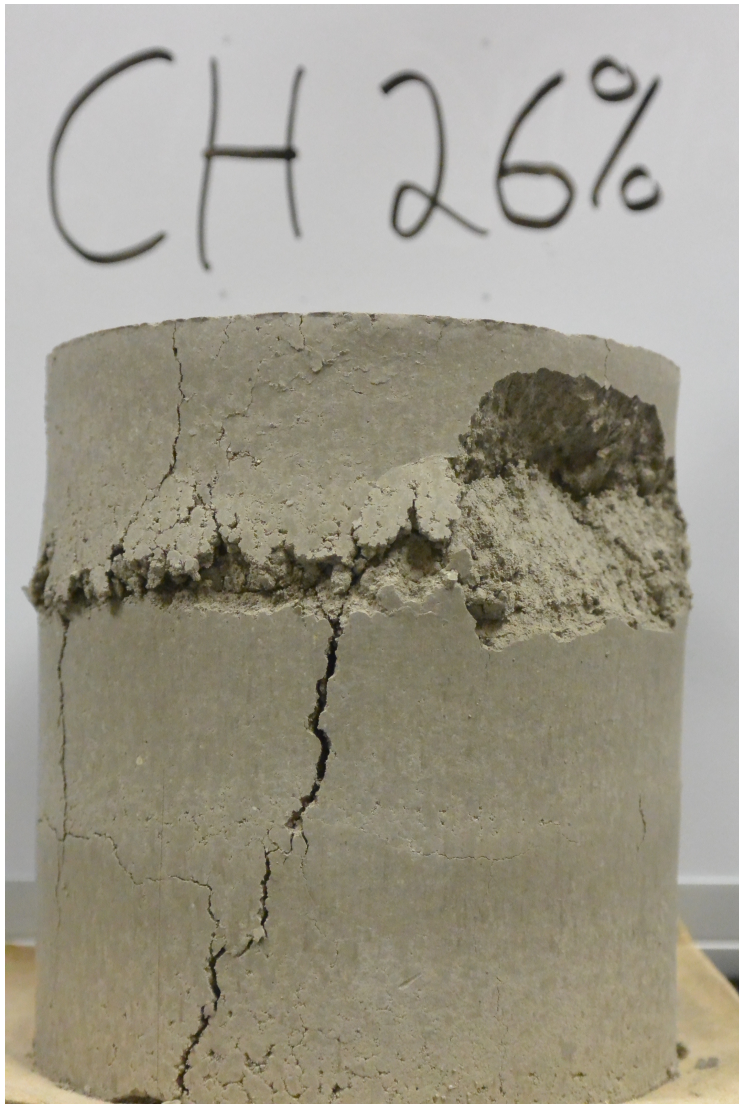

Failed Sample 
Sample: High Plasticity Clay $(\mathrm{CH})$

Water Content: $28 \%$

Time to Fail: $10 \mathrm{~min}$

Failure Load: $692 \mathrm{lbs}$

$q_{u}=55 \mathrm{psi}$

Deformation: 0.49 in

Mode of Failure: Brittle

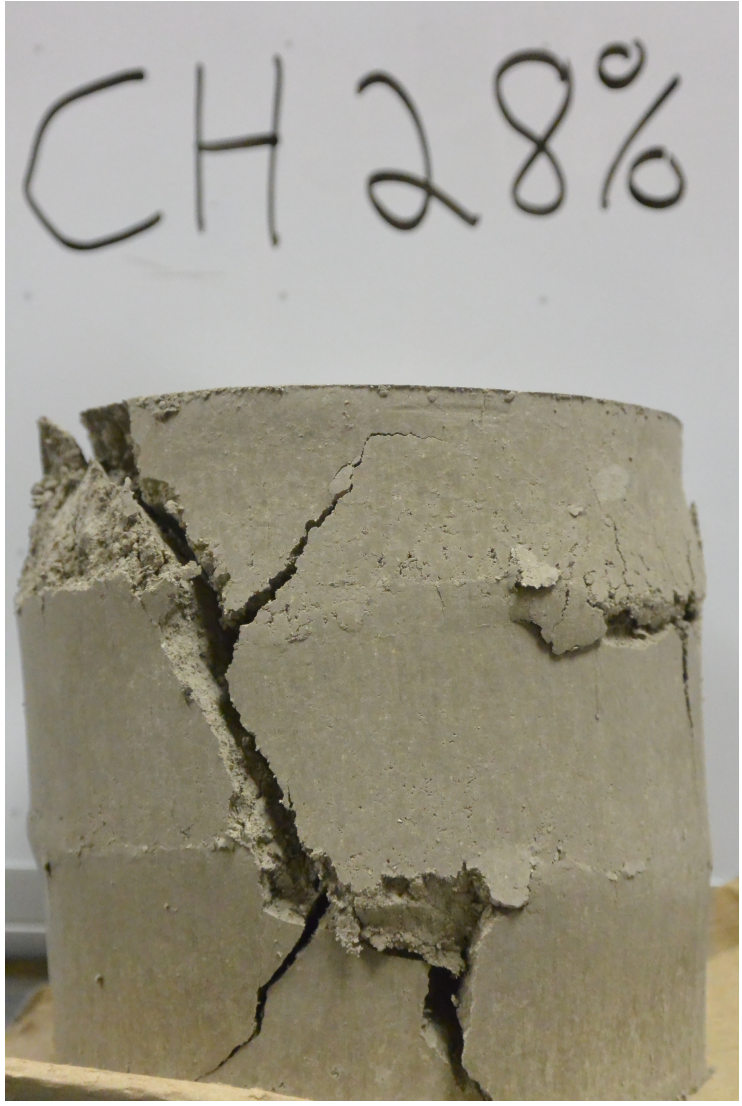

Failed Sample 
Sample: High Plasticity Clay $(\mathrm{CH})$

Water Content: $30 \%$

Time to Fail: $10 \mathrm{~min}$

Failure Load: $593 \mathrm{lbs}$

$q_{u}=47.2 \mathrm{psi}$

Deformation: $0.45 \mathrm{in}$

Mode of Failure: Brittle

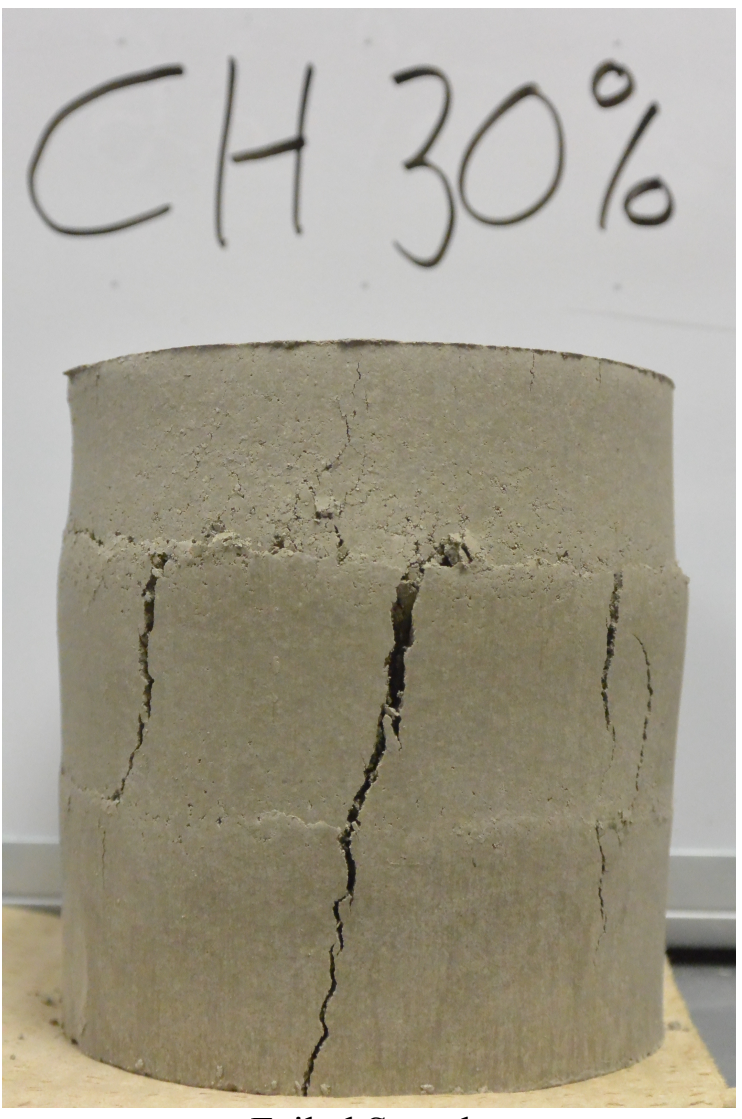

Failed Sample 
Sample: High Plasticity Clay $(\mathrm{CH})$

Water Content: $32 \%$

Time to Fail: $10 \mathrm{~min}$

Failure Load: $455 \mathrm{lbs}$

$q_{u}=36.2 \mathrm{psi}$

Deformation: 1.0 in

Mode of Failure: Plastic

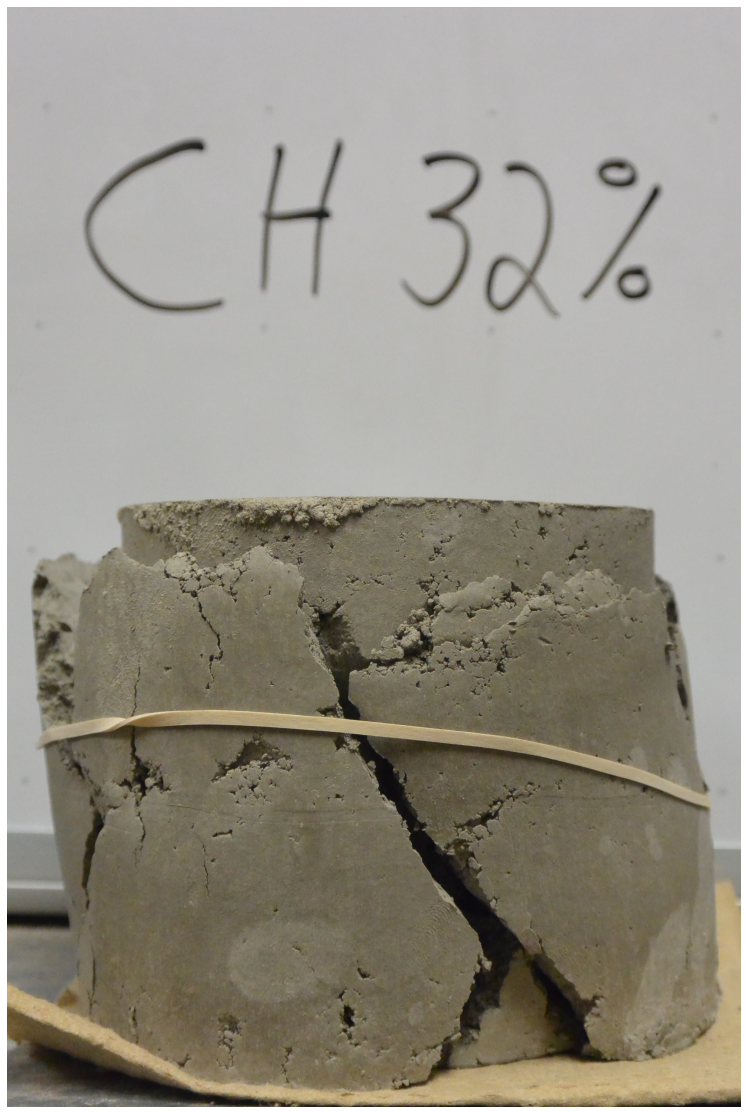

Failed Sample 


\section{APPENDIX E}

DIRECT SHEAR TEST DATA 
Sample: Low Plasticity Clay

Water Content: $18 \%$

Applied Load: 25 lbs, 50 lbs, 75lbs

Peak Shear Load: 58.9 lbs, 102.3 lbs, 97.1 lbs

Table E-1

\begin{tabular}{|c|c|c|c|}
\hline Normal Load: & $25 \mathrm{lbs}$. & $50 \mathrm{lbs}$. & $75 \mathrm{lbs}$. \\
\hline Displacement (0.001 in.) & $\underline{\text { Force (lbs.) }}$ & $\underline{\text { Force }(\mathrm{lbs} .)}$ & $\underline{\text { Force }(\mathrm{lbs} .)}$ \\
\hline 10 & 44.2 & 54.0 & 55.6 \\
\hline 20 & 57.6 & 80.1 & 81.8 \\
\hline 30 & 58.9 & 91.6 & 94.5 \\
\hline 40 & 53.6 & 97.8 & 97.1 \\
\hline 50 & 42.9 & 101.0 & 96.5 \\
\hline 60 & 37.3 & 102.3 & 94.8 \\
\hline 70 & 32.7 & 99.1 & 93.2 \\
\hline 80 & 29.5 & 98.4 & 91.2 \\
\hline 90 & 27.8 & 96.5 & 90.9 \\
\hline 100 & 26.2 & 60.5 & 91.6 \\
\hline 110 & 24.6 & 55.0 & 91.6 \\
\hline 120 & 23.6 & 51.0 & 91.6 \\
\hline 130 & 22.6 & 47.4 & 91.6 \\
\hline 140 & 21.9 & 45.8 & 89.9 \\
\hline 150 & 21.0 & 43.8 & 86.7 \\
\hline 160 & 20.0 & 41.2 & 84.7 \\
\hline 170 & 19.7 & 39.6 & 82.7 \\
\hline 180 & 19.0 & 37.6 & 80.1 \\
\hline & & & \\
\hline
\end{tabular}




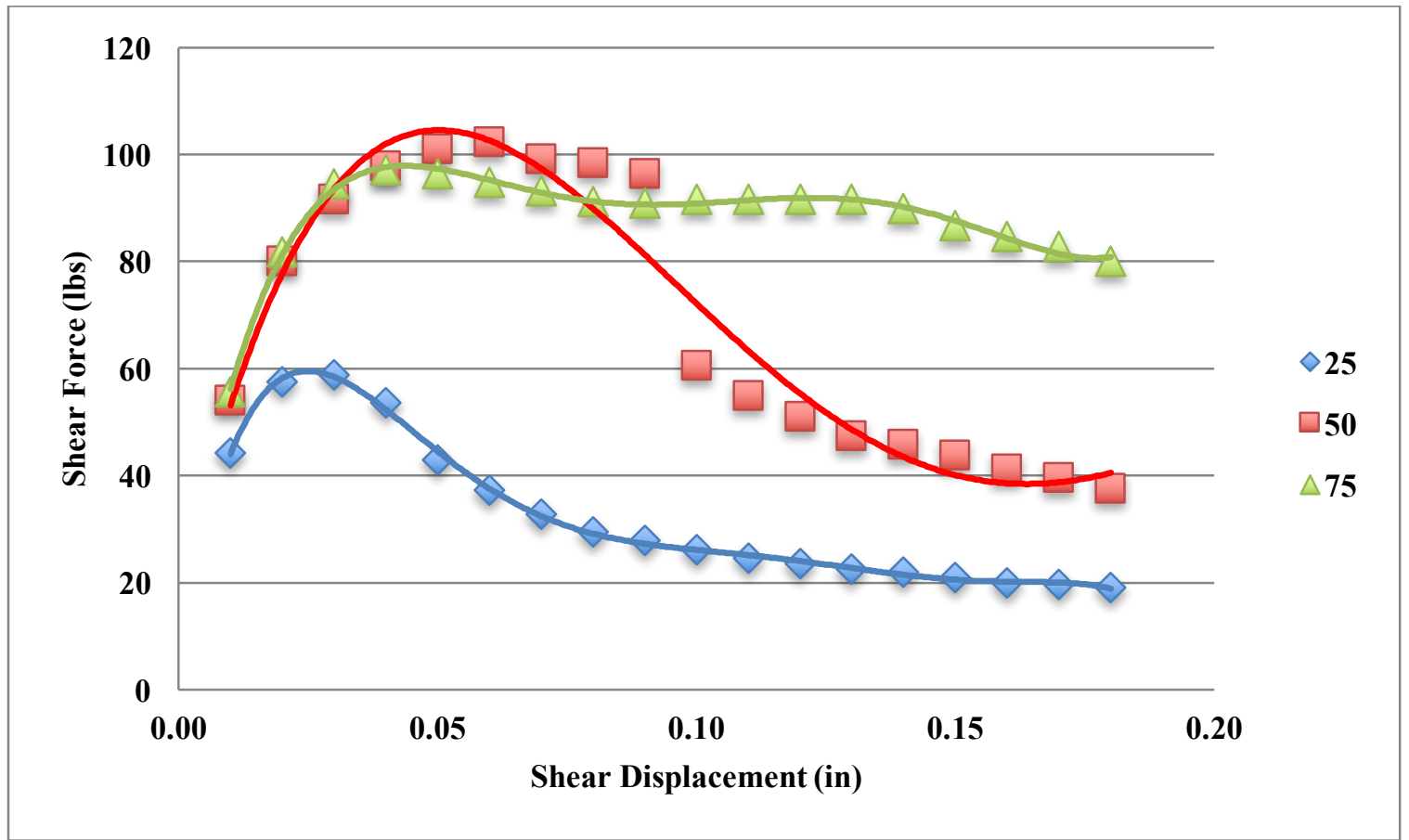

Figure E-1: Stress-strain plots for the low plasticity clay at $18 \%$ water content.

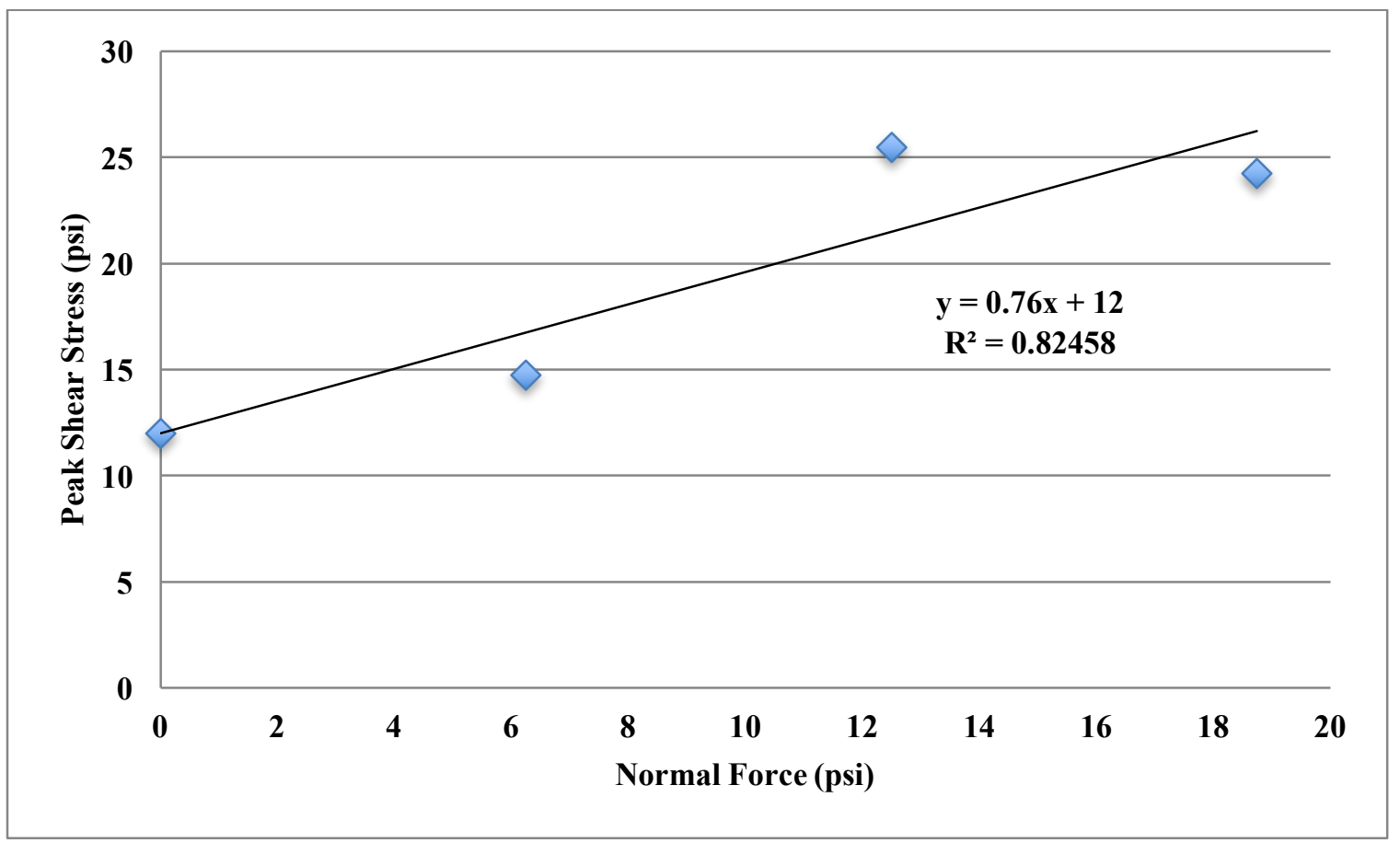

Figure E-2: Mohr Envelope for the low plasticity clay at 18\% water content. 
Sample: Low Plasticity Clay

Water Content: 19\%

Applied Load: 25 lbs, 50 lbs, 75lbs

Peak Shear Load: 67 lbs, 95.5 lbs, 113.8 lbs

Table E-2

\begin{tabular}{|c|c|c|c|}
\hline Normal Load: & $25 \mathrm{lbs}$. & 50 lbs. & $75 \mathrm{lbs}$. \\
\hline Displacement (0.001 in.) & Force (lbs.) & Force (lbs.) & Force (lbs.) \\
\hline 10 & 49.1 & 58.9 & 64.4 \\
\hline 20 & 63.5 & 79.1 & 91.6 \\
\hline 30 & 63.8 & 86.7 & 104.6 \\
\hline 40 & 64.4 & 88.9 & 108.9 \\
\hline 50 & 64.8 & 90.6 & 110.8 \\
\hline 60 & 65.4 & 90.9 & 112.5 \\
\hline 70 & 67.0 & 92.9 & 112.5 \\
\hline 80 & 67.0 & 93.5 & 112.5 \\
\hline 90 & 67.0 & 93.5 & 113.5 \\
\hline 100 & 65.1 & 94.8 & 113.8 \\
\hline 110 & 59.5 & 95.5 & 104.6 \\
\hline 120 & 50.7 & 94.5 & 89.9 \\
\hline 130 & 44.5 & 93.8 & 79.5 \\
\hline 140 & 39.9 & 93.8 & 72.6 \\
\hline 150 & 37.6 & 93.8 & 63.8 \\
\hline 160 & 35.7 & 91.9 & 56.6 \\
\hline 170 & 33.7 & 88.9 & 52.3 \\
\hline 180 & 32.1 & 84.7 & 49.1 \\
\hline
\end{tabular}




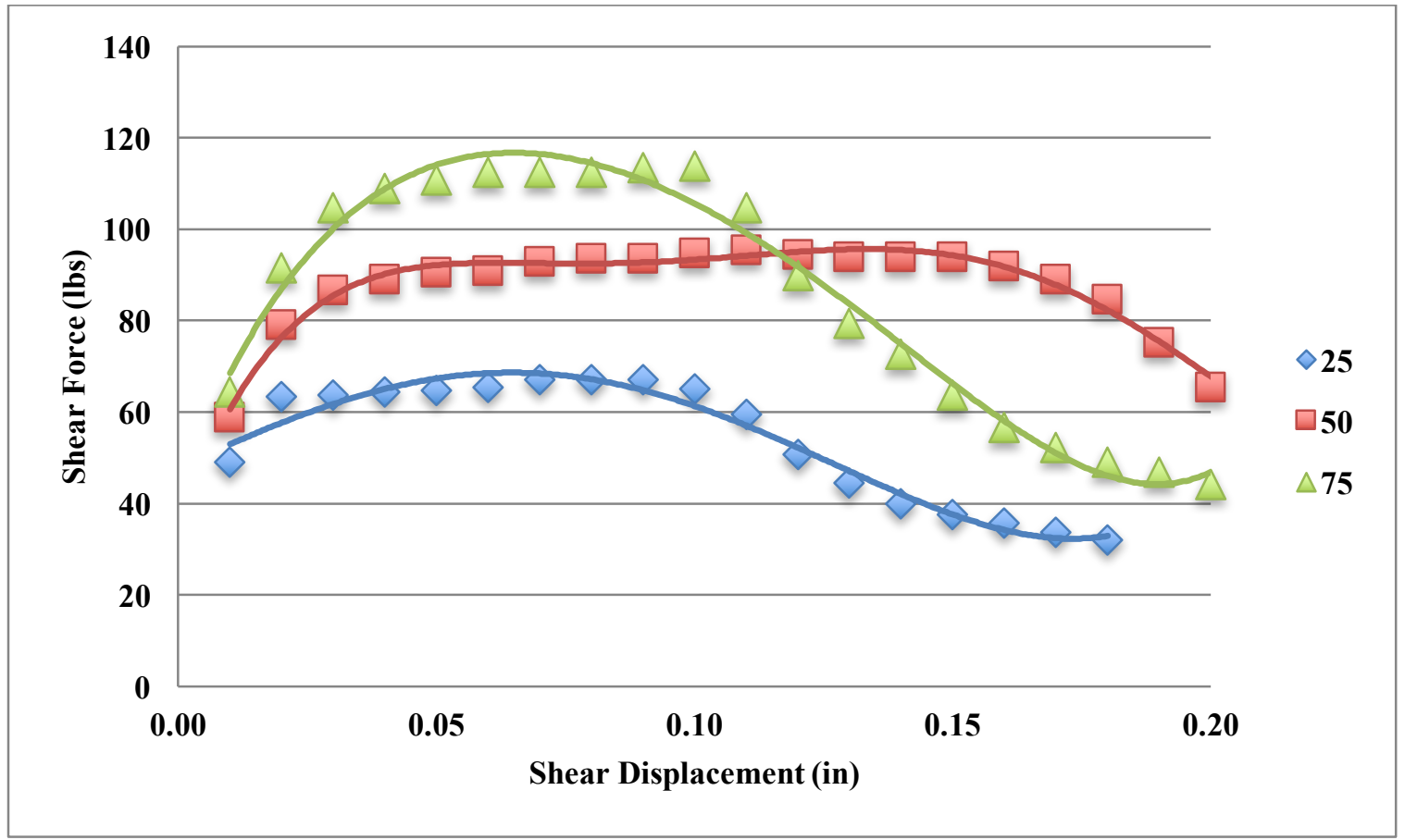

Figure E-3: Stress-strain plots for the low plasticity clay at 19\% water content.

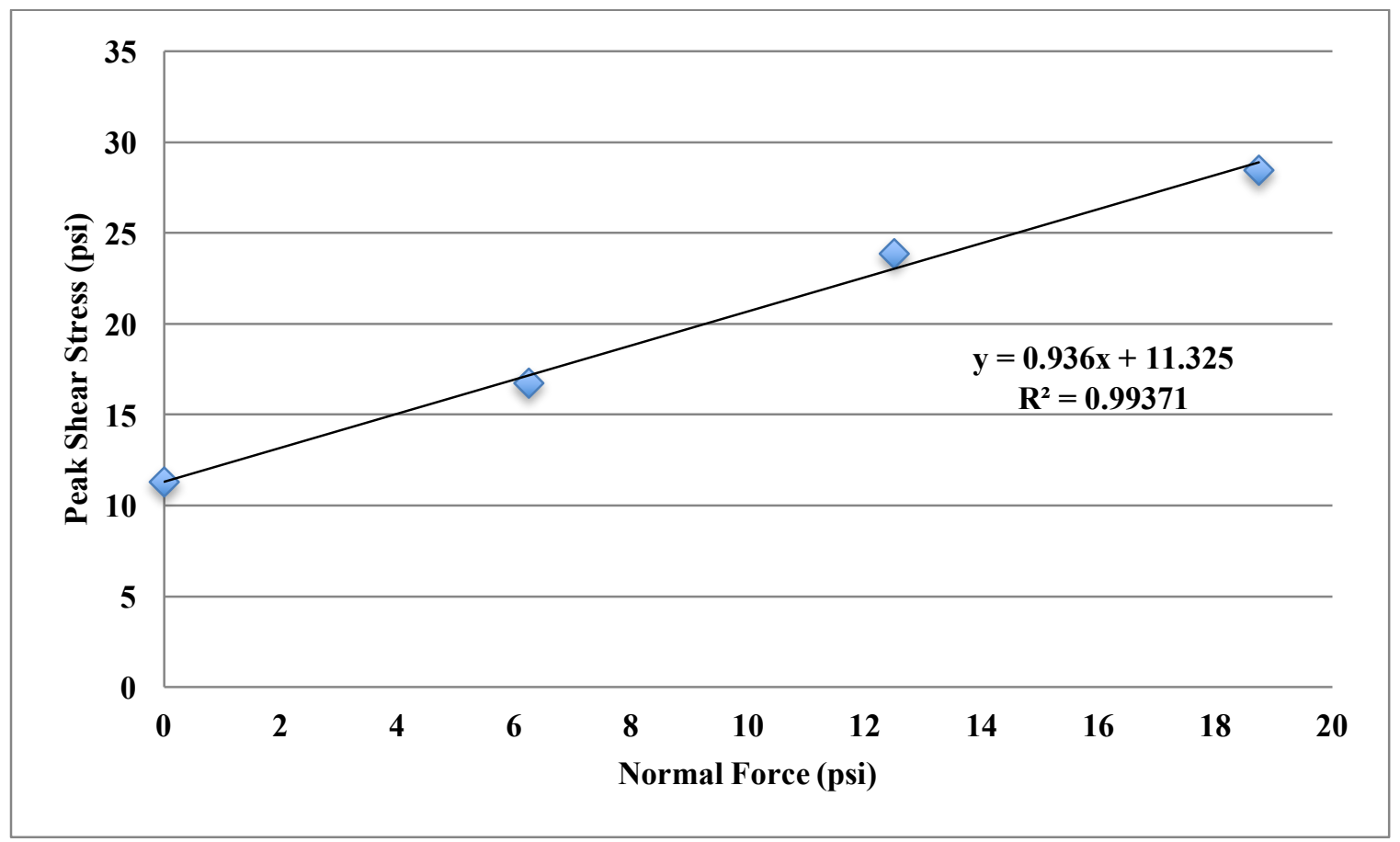

Figure E-4: Mohr Envelope for the low plasticity clay at 19\% water content. 
Sample: Low Plasticity Clay

Water Content: $20 \%$

Applied Load: 25 lbs, 50 lbs, 75lbs

Peak Shear Load: 70 lbs, 87.3 lbs, 102 lbs

Table E-3

\begin{tabular}{|c|c|c|c|}
\hline Normal Load: & $25 \mathrm{lbs}$. & $50 \mathrm{lbs}$. & $75 \mathrm{lbs}$. \\
\hline Displacement (0.001 in.) & Force (lbs.) & Force (lbs.) & Force (lbs.) \\
\hline 10 & 57.2 & 52.3 & 74.6 \\
\hline 20 & 62.8 & 71.3 & 94.8 \\
\hline 30 & 67.0 & 83.1 & 102.3 \\
\hline 40 & 68.7 & 87.3 & 102.0 \\
\hline 50 & 69.7 & 87.3 & 101.4 \\
\hline 60 & 69.7 & 86.7 & 100.1 \\
\hline 70 & 69.7 & 84.7 & 98.4 \\
\hline 80 & 70.0 & 83.4 & 97.4 \\
\hline 90 & 69.7 & 79.5 & 96.8 \\
\hline 100 & 68.7 & 77.2 & 94.5 \\
\hline 110 & 68.7 & 75.5 & 91.6 \\
\hline 120 & 62.5 & 73.6 & 88.9 \\
\hline 130 & 58.2 & 71.6 & 86.3 \\
\hline 140 & 54.0 & 68.7 & 83.4 \\
\hline 150 & 49.7 & 64.4 & 81.1 \\
\hline 160 & 44.8 & 58.2 & 79.8 \\
\hline 170 & 42.5 & 54.3 & 78.5 \\
\hline 180 & 39.9 & 51.7 & 77.8 \\
\hline 190 & 38.3 & 49.7 & 77.8 \\
\hline 200 & 37.3 & 48.4 & 77.5 \\
\hline
\end{tabular}




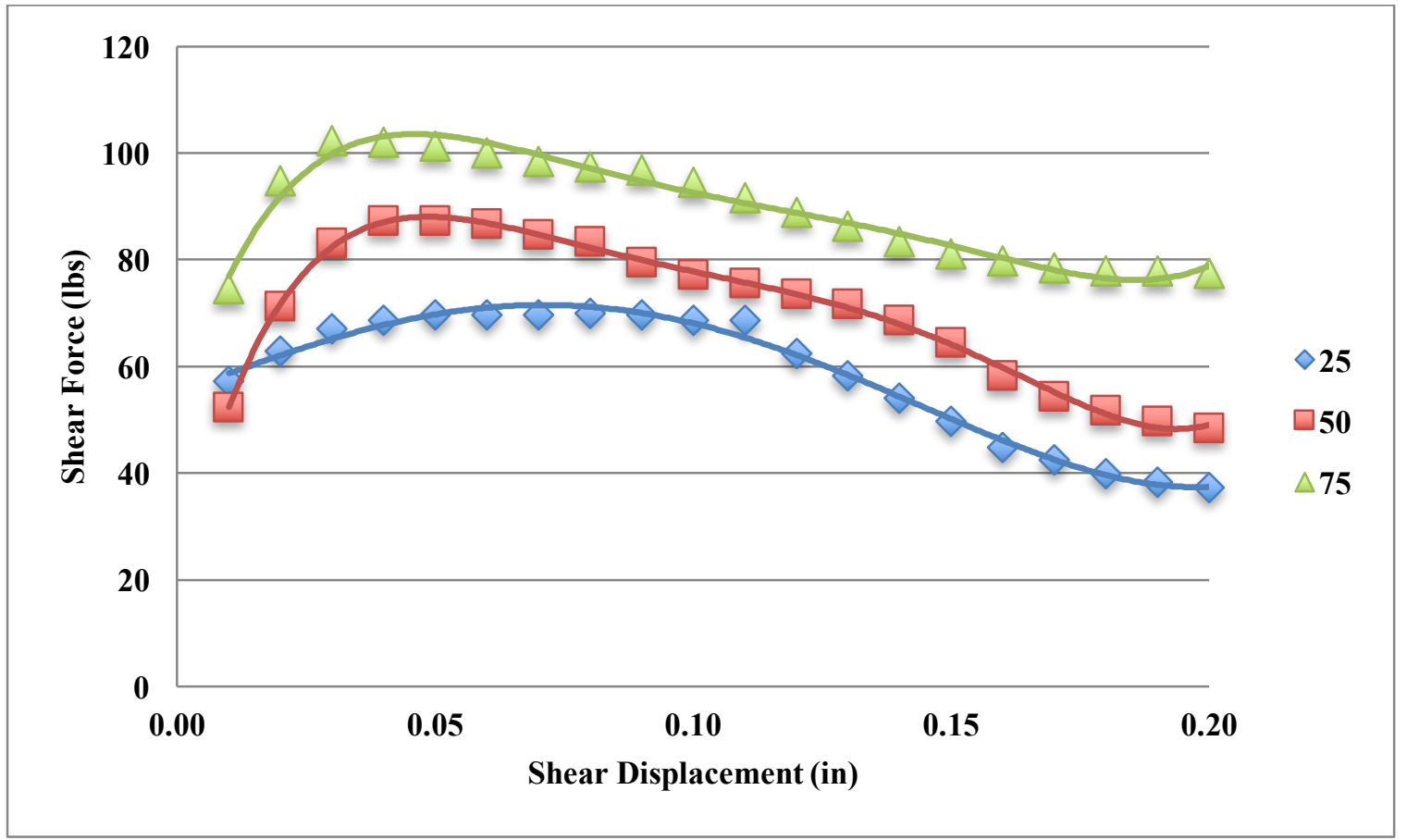

Figure E-5: Stress-strain plots for the low plasticity clay at $20 \%$ water content.

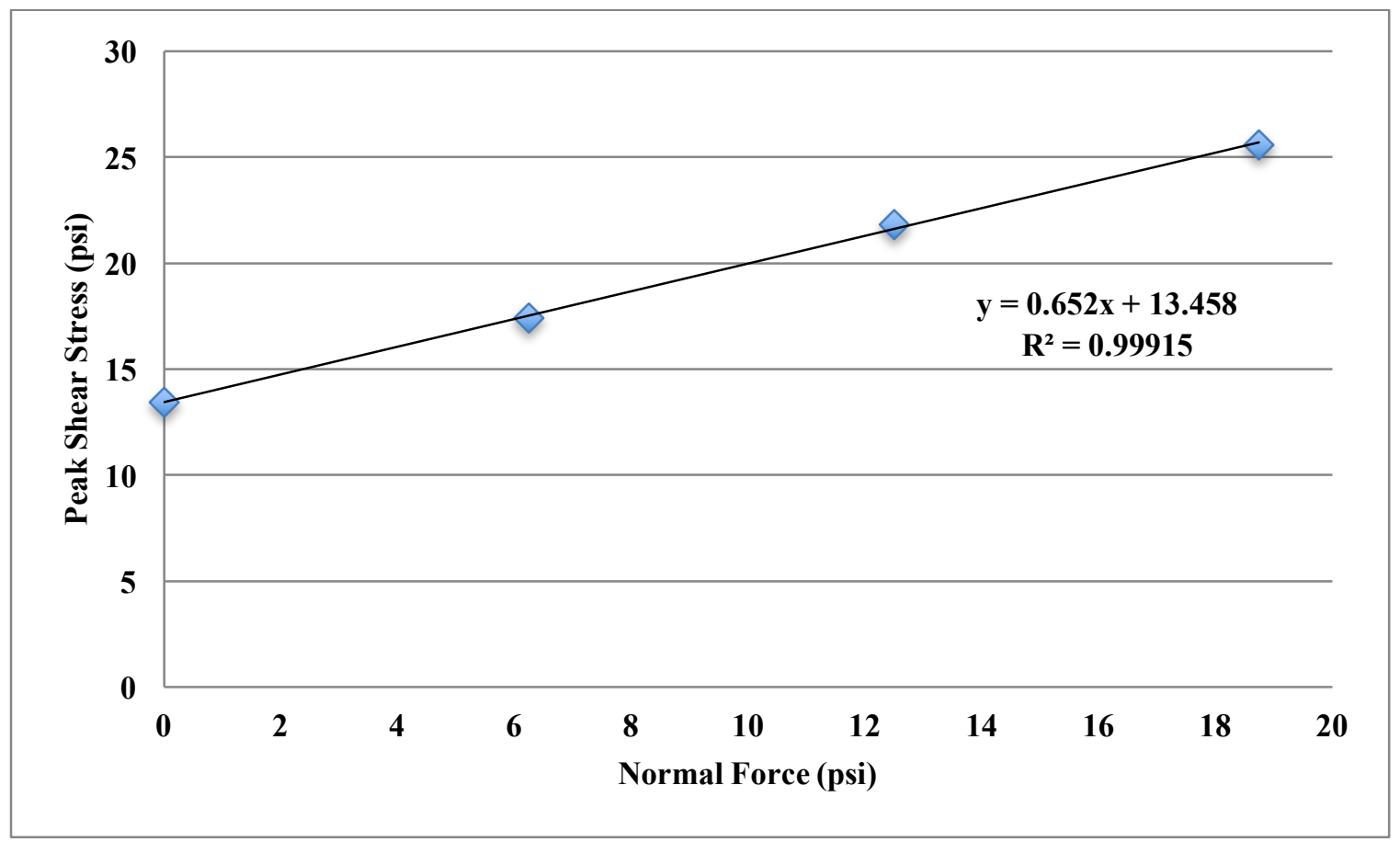

Figure E-6: Mohr Envelope for the low plasticity clay at 20\% water content. 
Sample: Medium Plasticity Clay

Water Content: $28 \%$

Applied Load: 25 lbs, 50 lbs, $75 \mathrm{lbs}$

Peak Shear Load: 46.8 lbs, 44.5 lbs, 57.6 lbs

Table E-4

\begin{tabular}{|c|c|c|c|}
\hline Normal Load: & 25 lbs. & 50 lbs. & 75 lbs. \\
\hline Displacement (0.001 in.) & Force (lbs.) & Force (lbs.) & Force (lbs.) \\
\hline 10 & 21.6 & 23.9 & 36.7 \\
\hline 20 & 29.8 & 30.8 & 45.8 \\
\hline 30 & 35.3 & 34.7 & 49.7 \\
\hline 40 & 39.3 & 37.6 & 54.6 \\
\hline 50 & 40.9 & 39.9 & 56.3 \\
\hline 60 & 41.6 & 40.9 & 57.2 \\
\hline 70 & 43.5 & 41.9 & 57.6 \\
\hline 80 & 45.2 & 43.2 & 56.6 \\
\hline 90 & 46.1 & 44.5 & 54.0 \\
\hline 100 & 46.5 & 44.5 & 51.4 \\
\hline 110 & 46.8 & 43.8 & 49.4 \\
\hline 120 & 46.5 & 43.5 & 47.4 \\
\hline 130 & 45.2 & 43.5 & 43.5 \\
\hline 140 & 44.8 & 43.5 & 40.6 \\
\hline 150 & 44.8 & 43.5 & 38.3 \\
\hline 160 & 44.8 & 43.5 & 36.3 \\
\hline
\end{tabular}




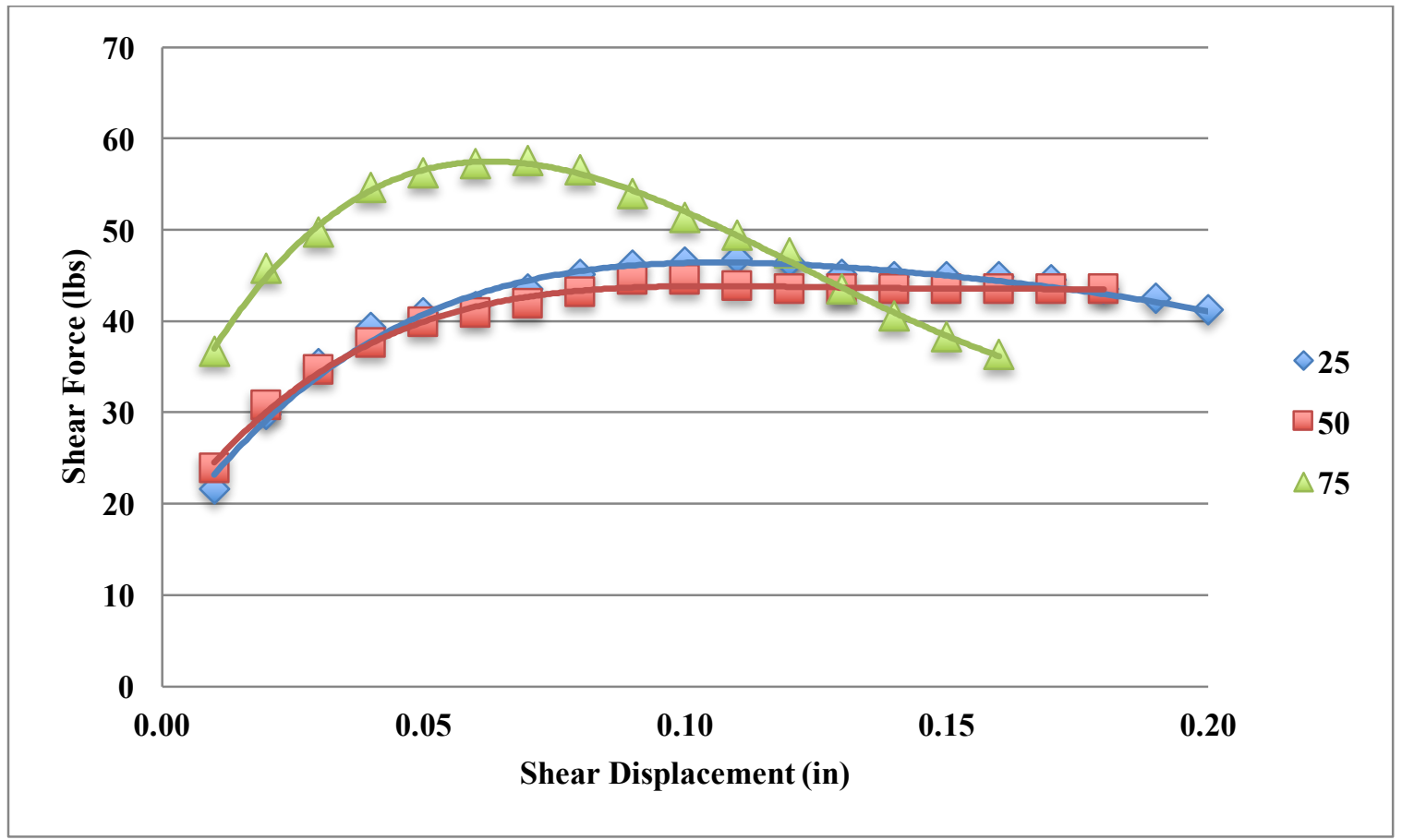

Figure E-7: Stress-strain plots for the medium plasticity clay at $28 \%$ water content.

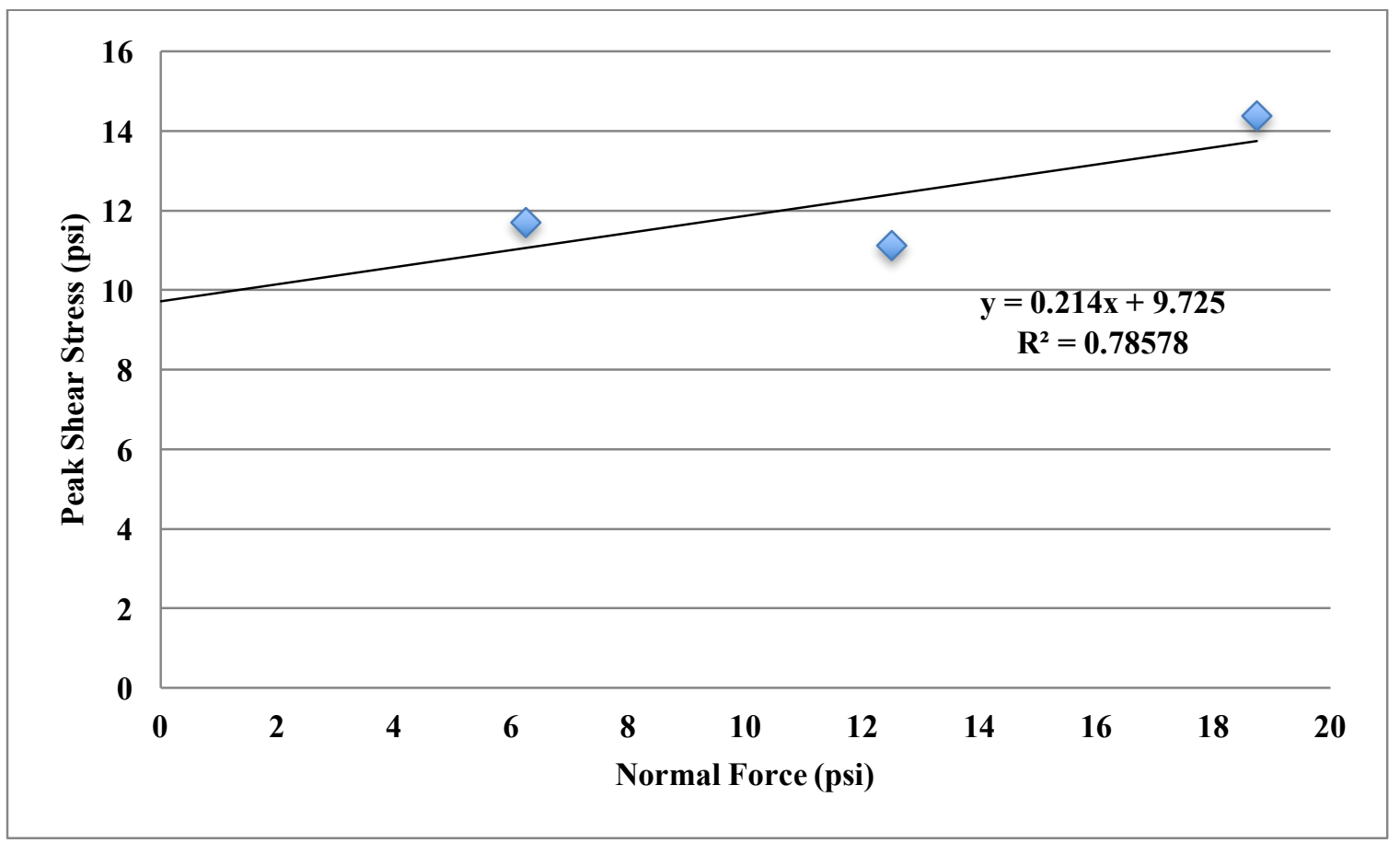

Figure E-8: Mohr Envelope for the medium plasticity clay at 28\% water content. 
Sample: Medium Plasticity Clay

Water Content: 29\%

Applied Load: 25 lbs, 50 lbs, $75 \mathrm{lbs}$

Peak Shear Load: $33.7 \mathrm{lbs}, 41.2 \mathrm{lbs}, 43.5 \mathrm{lbs}$

Table E-5

\begin{tabular}{|c|c|c|c|}
\hline Normal Load: & 25 lbs. & 50 lbs. & 75 lbs. \\
\hline Displacement (0.001 in.) & Force (lbs.) & Force (lbs.) & Force (lbs.) \\
\hline 10 & 16.7 & 21.3 & 21.6 \\
\hline 20 & 20.3 & 29.1 & 28.8 \\
\hline 30 & 23.9 & 33.4 & 33.1 \\
\hline 40 & 26.9 & 36.7 & 35.3 \\
\hline 50 & 29.1 & 38.0 & 37.3 \\
\hline 60 & 30.8 & 39.3 & 39.6 \\
\hline 70 & 32.4 & 40.6 & 40.9 \\
\hline 80 & 33.4 & 41.2 & 42.2 \\
\hline 90 & 33.7 & 41.2 & 43.2 \\
\hline 100 & 33.7 & 40.9 & 43.5 \\
\hline 110 & 33.1 & 39.9 & 43.5 \\
\hline 120 & 32.1 & 37.6 & 43.5 \\
\hline 130 & 31.8 & 36.0 & 43.2 \\
\hline 140 & 29.5 & 34.4 & 42.9 \\
\hline 150 & 26.9 & 32.7 & 42.5 \\
\hline 160 & 25.2 & 31.8 & 41.9 \\
\hline 170 & 23.9 & 30.8 & 41.6 \\
\hline 180 & 22.6 & 29.5 & 40.6 \\
\hline 190 & 21.3 & 28.5 & 39.3 \\
\hline 200 & 20.0 & 27.8 & 37.6 \\
\hline
\end{tabular}




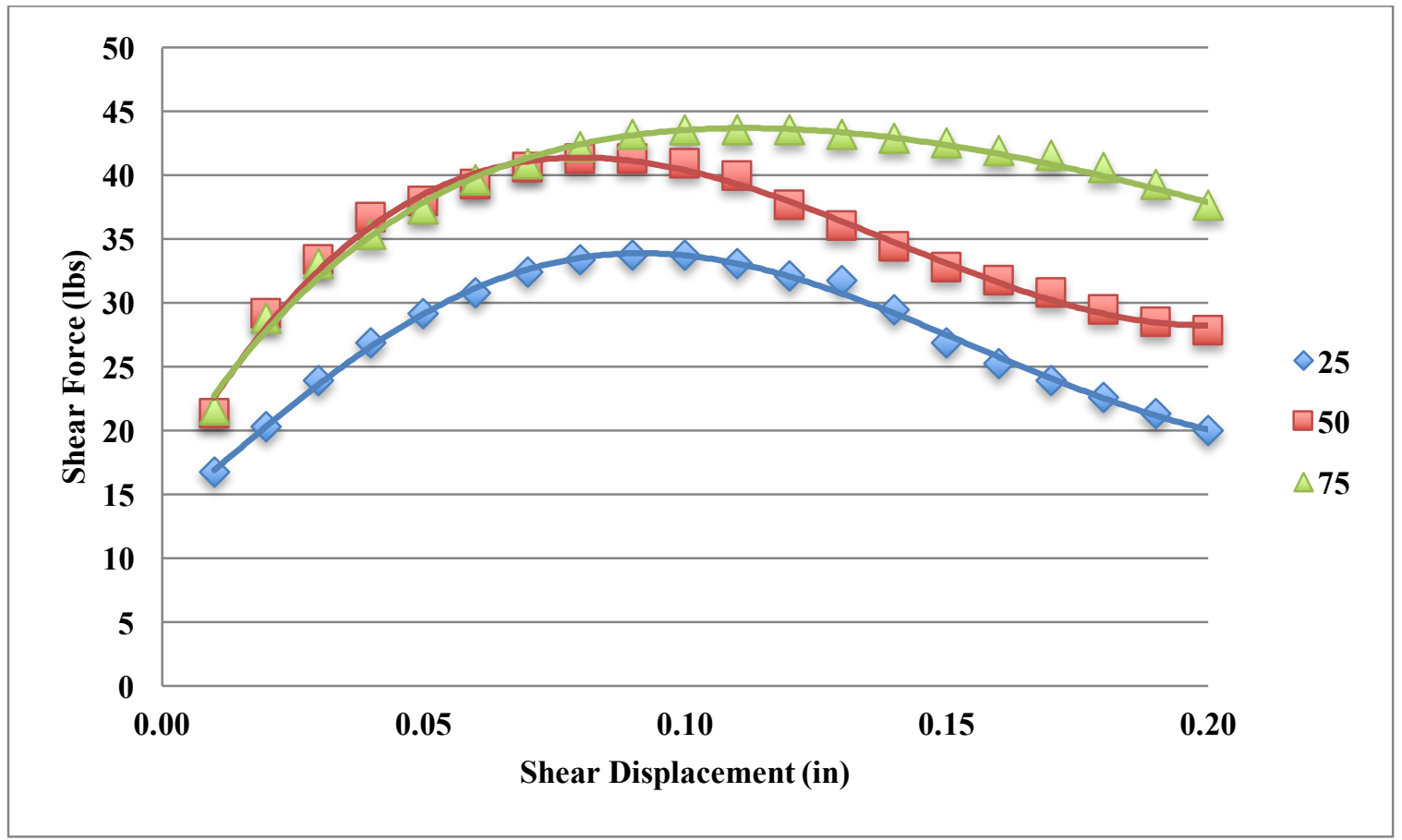

Figure E-9: Stress-strain plots for the medium plasticity clay at 29\% water content.

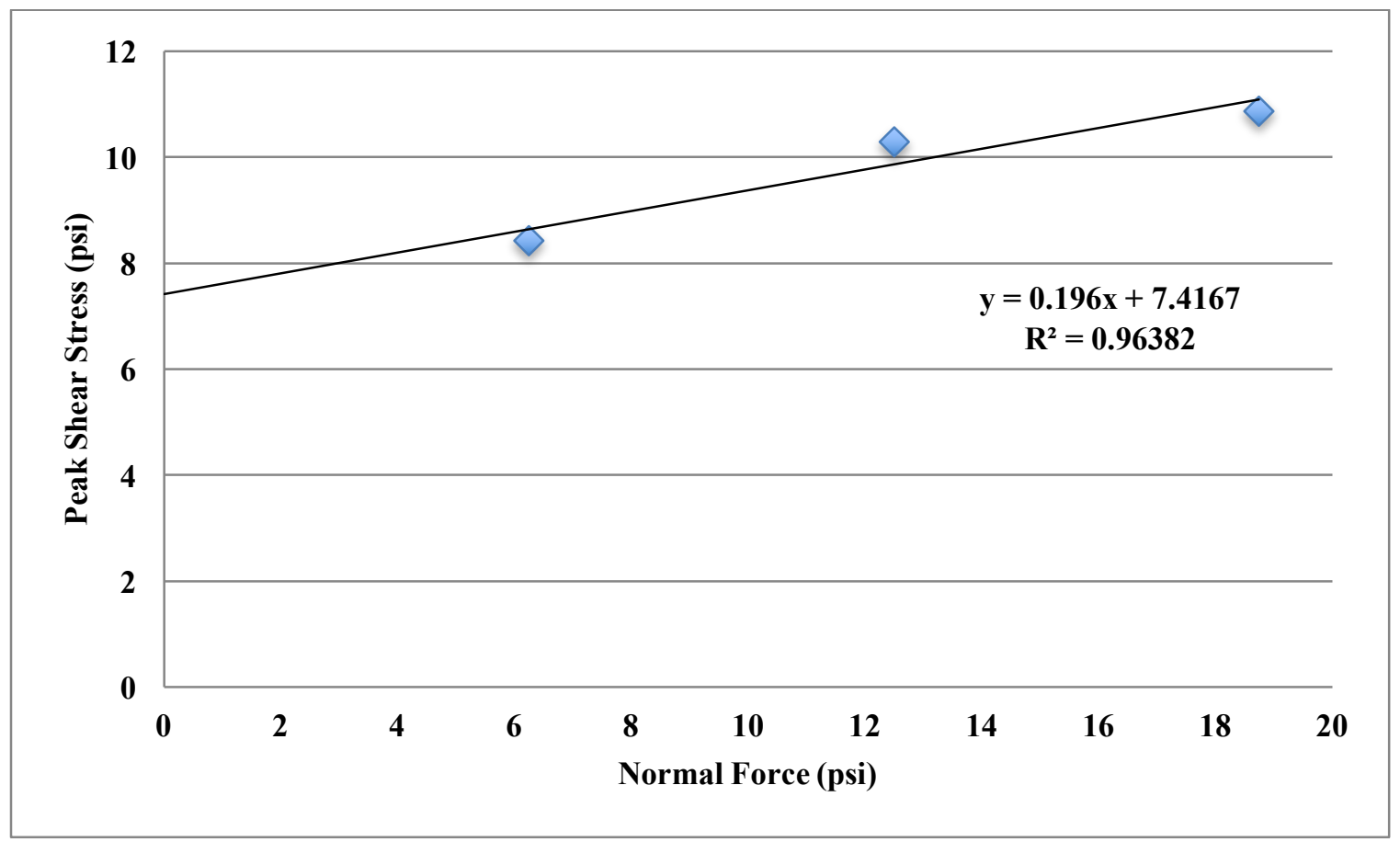

Figure E-10: Mohr Envelope for the medium plasticity clay at 29\% water content. 
Sample: Medium Plasticity Clay

Water Content: 30\%

Applied Load: 25 lbs, 50 lbs, $75 \mathrm{lbs}$

Peak Shear Load: 34.4 lbs, 38 lbs, 40.3 lbs

Table E-6

\begin{tabular}{|c|c|c|c|}
\hline Normal Load: & $25 \mathrm{lbs}$. & $50 \mathrm{lbs}$. & $75 \mathrm{lbs}$. \\
\hline Displacement (0.001 in.) & Force (lbs.) & Force (lbs.) & Force (lbs.) \\
\hline 10 & 21.0 & 14.8 & 22.9 \\
\hline 20 & 26.2 & 19.7 & 29.5 \\
\hline 30 & 29.5 & 23.6 & 34.0 \\
\hline 40 & 32.4 & 26.9 & 36.3 \\
\hline 50 & 34.0 & 30.1 & 38.3 \\
\hline 60 & 34.4 & 32.1 & 39.9 \\
\hline 70 & 34.0 & 34.0 & 40.3 \\
\hline 80 & 33.4 & 36.0 & 39.9 \\
\hline 90 & 32.7 & 37.0 & 39.6 \\
\hline 100 & 32.7 & 37.6 & 38.9 \\
\hline 110 & 32.4 & 38.0 & 38.0 \\
\hline 120 & 31.4 & 37.6 & 37.0 \\
\hline 130 & 30.4 & 35.7 & 35.7 \\
\hline 140 & 29.5 & 34.7 & 34.4 \\
\hline 150 & 28.8 & 33.4 & 33.4 \\
\hline 160 & 28.2 & 32.4 & 32.4 \\
\hline 170 & 27.5 & 31.1 & 31.1 \\
\hline 180 & 26.5 & 29.5 & 30.4 \\
\hline 190 & 25.5 & 28.8 & 29.5 \\
\hline 200 & 24.9 & 28.2 & 29.1 \\
\hline
\end{tabular}




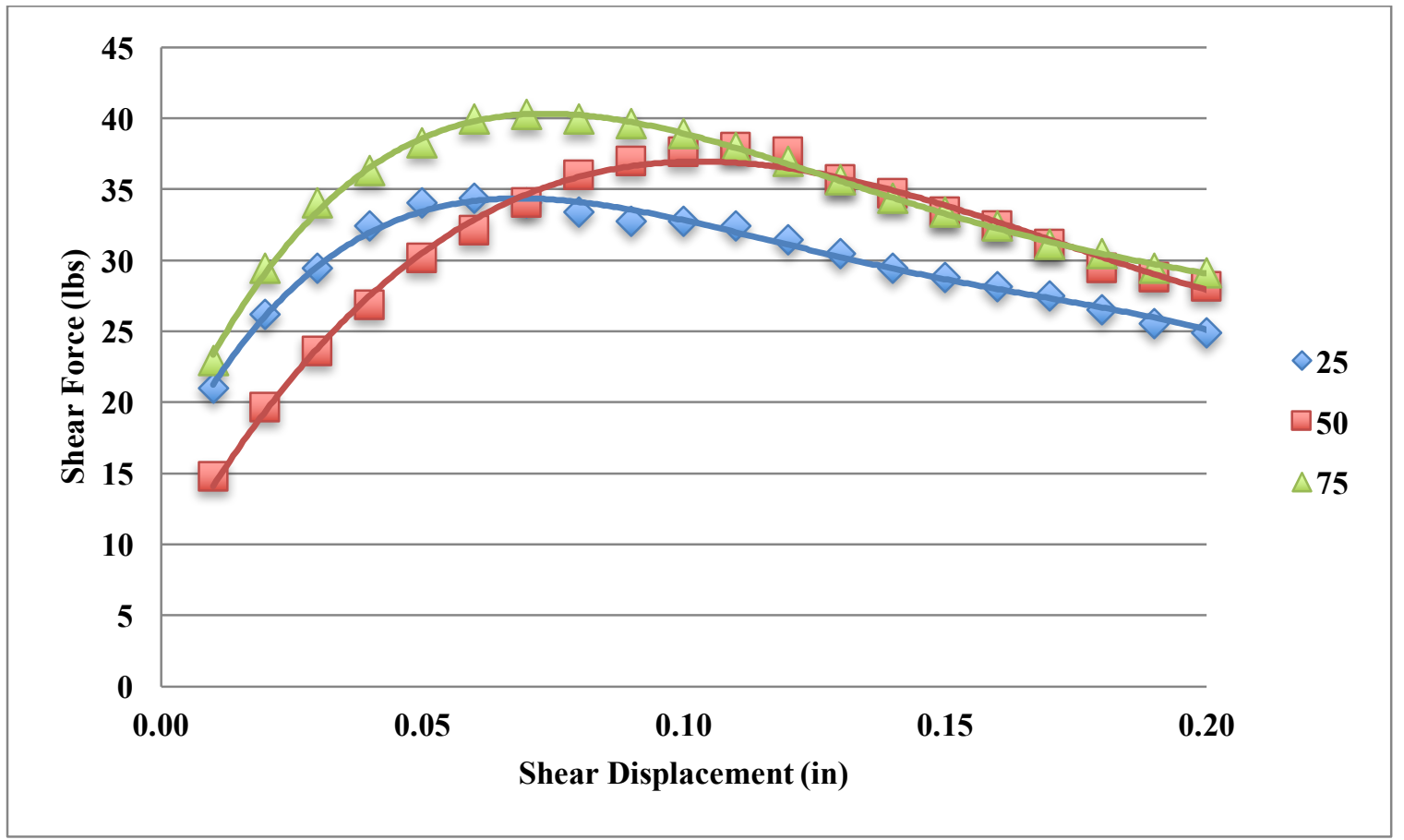

Figure E-11: Stress-strain plots for the medium plasticity clay at 30\% water content.

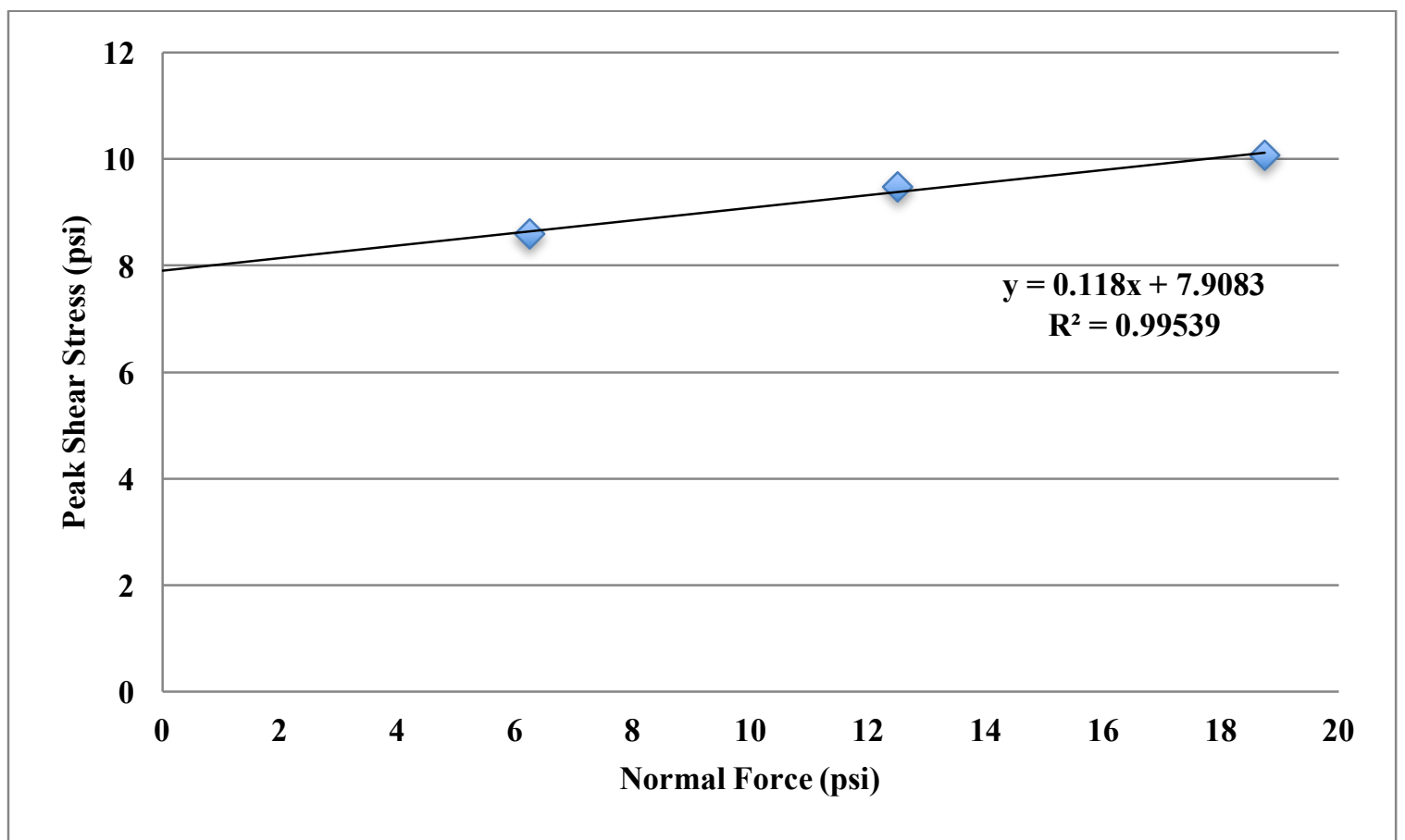

Figure E-12: Mohr envelope for the medium plasticity clay at $30 \%$ water content. 
Sample: Medium Plasticity Clay

Water Content: 31\%

Applied Load: 25 lbs, 50 lbs, 75lbs

Peak Shear Load: 34.7 lbs, 45.5 lbs, 45.8 lbs

Table E-7

\begin{tabular}{|c|c|c|c|}
\hline Normal Load: & $25 \mathrm{lbs}$. & $50 \mathrm{lbs}$. & $75 \mathrm{lbs}$. \\
\hline Displacement (0.001 in.) & Force (lbs.) & Force (lbs.) & Force (lbs.) \\
\hline 10 & 20.3 & 27.8 & 22.9 \\
\hline 20 & 26.5 & 35.7 & 30.8 \\
\hline 30 & 29.8 & 40.9 & 36.0 \\
\hline 40 & 32.7 & 43.2 & 39.3 \\
\hline 50 & 34.0 & 44.8 & 42.5 \\
\hline 60 & 34.7 & 45.5 & 44.5 \\
\hline 70 & 34.7 & 45.2 & 45.8 \\
\hline 80 & 33.7 & 44.2 & 45.8 \\
\hline 90 & 32.4 & 42.9 & 45.8 \\
\hline 100 & 30.8 & 41.2 & 45.5 \\
\hline 110 & 29.5 & 39.3 & 45.2 \\
\hline 120 & 26.5 & 37.3 & 44.2 \\
\hline 130 & 24.2 & 34.0 & 42.9 \\
\hline 140 & 22.3 & 33.4 & 41.6 \\
\hline 150 & 20.6 & 33.4 & 40.9 \\
\hline 160 & 19.3 & 33.4 & 40.9 \\
\hline 170 & 18.0 & 33.4 & 40.9 \\
\hline 180 & 16.7 & 33.4 & 40.9 \\
\hline
\end{tabular}




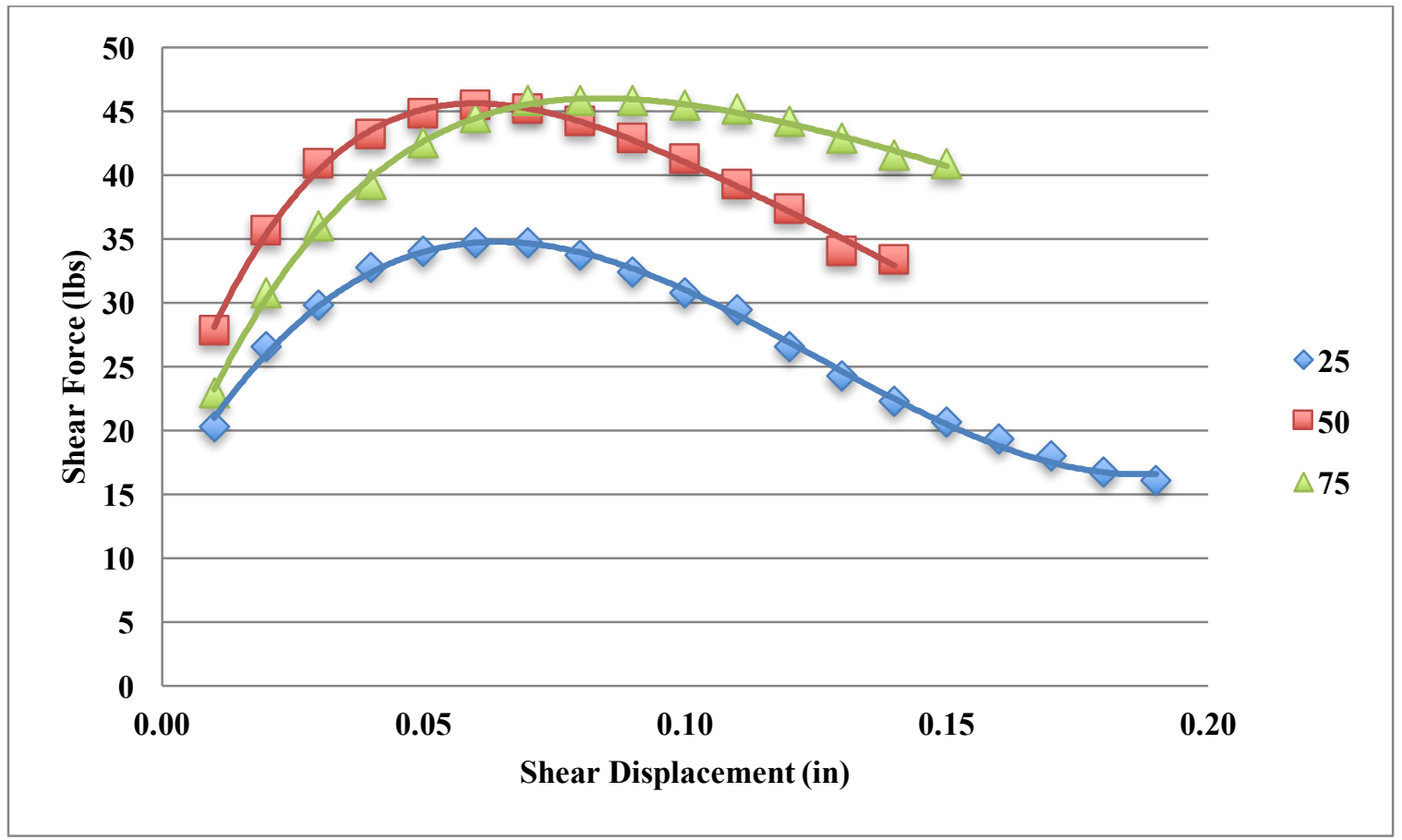

Figure E-13: Stress-strain plots for the medium plasticity clay at $31 \%$ water content.

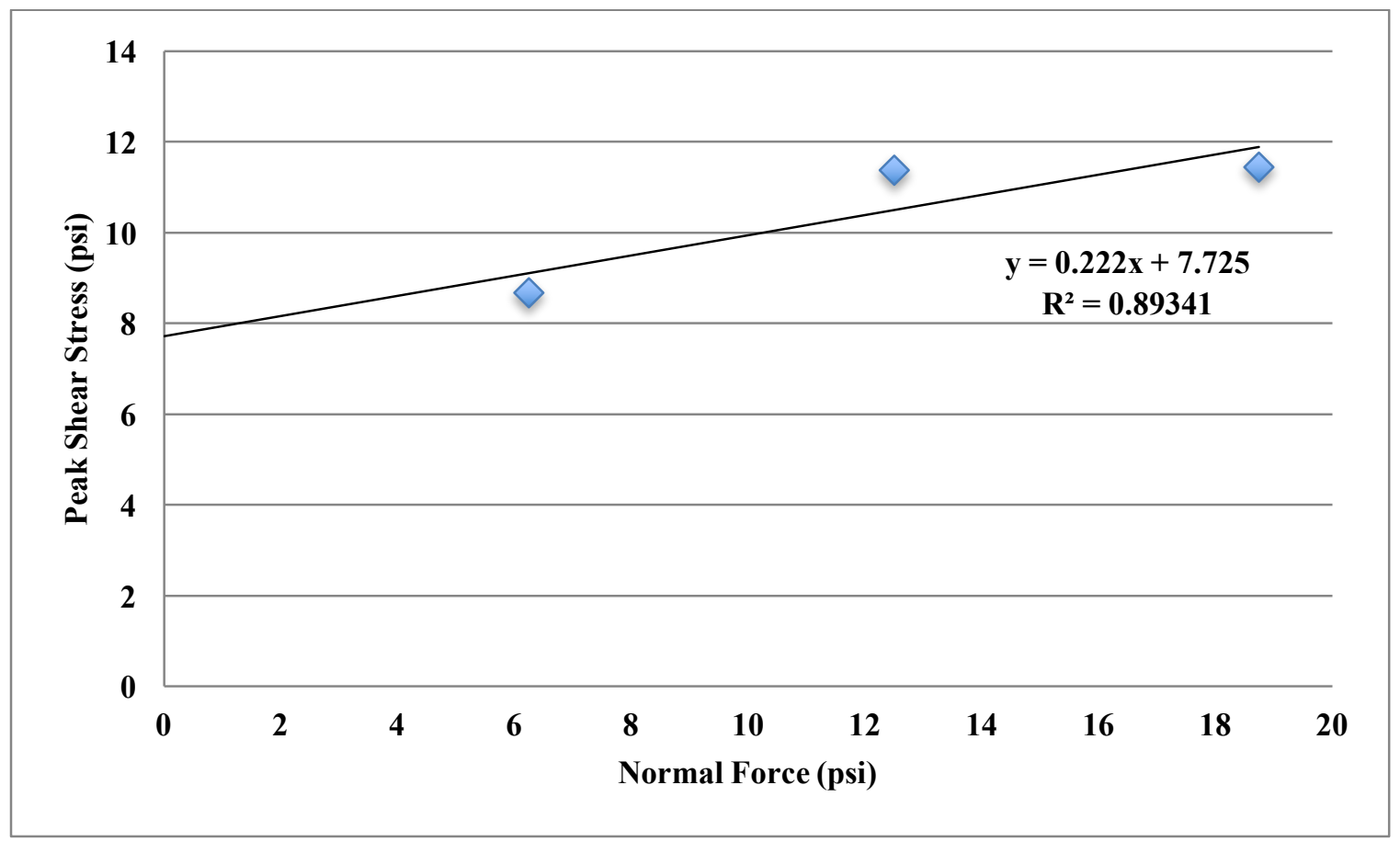

Figure E-14: Mohr Envelope for the medium plasticity clay at 31\% water content. 
Sample: High Plasticity Clay

Water Content: $28 \%$

Applied Load: 25 lbs, 50 lbs, 75lbs

Peak Shear Load: 72 lbs, 86.7 lbs, 102.7 lbs

Table E-8

\begin{tabular}{|c|c|c|c|}
\hline Normal Load: & $25 \mathrm{lbs}$. & $50 \mathrm{lbs}$. & $75 \mathrm{lbs}$. \\
\hline Displacement (0.001 in.) & Force (lbs.) & Force (lbs.) & Force (lbs.) \\
\hline 10 & 56.3 & 47.4 & 49.7 \\
\hline 20 & 65.4 & 69.3 & 71.3 \\
\hline 30 & 67.0 & 83.4 & 86.7 \\
\hline 40 & 69.3 & 85.0 & 96.5 \\
\hline 50 & 72.0 & 85.3 & 100.1 \\
\hline 60 & 65.7 & 86.7 & 102.3 \\
\hline 70 & 60.8 & 85.0 & 102.7 \\
\hline 80 & 55.6 & 83.4 & 102.7 \\
\hline 90 & 49.1 & 80.1 & 101.4 \\
\hline 100 & 44.2 & 79.5 & 95.8 \\
\hline 110 & 40.3 & 78.2 & 92.5 \\
\hline 120 & 35.3 & 76.2 & 89.9 \\
\hline 130 & 32.7 & 73.6 & 87.6 \\
\hline 140 & 32.7 & 70.3 & 85.0 \\
\hline 150 & 32.7 & 66.1 & 81.8 \\
\hline
\end{tabular}




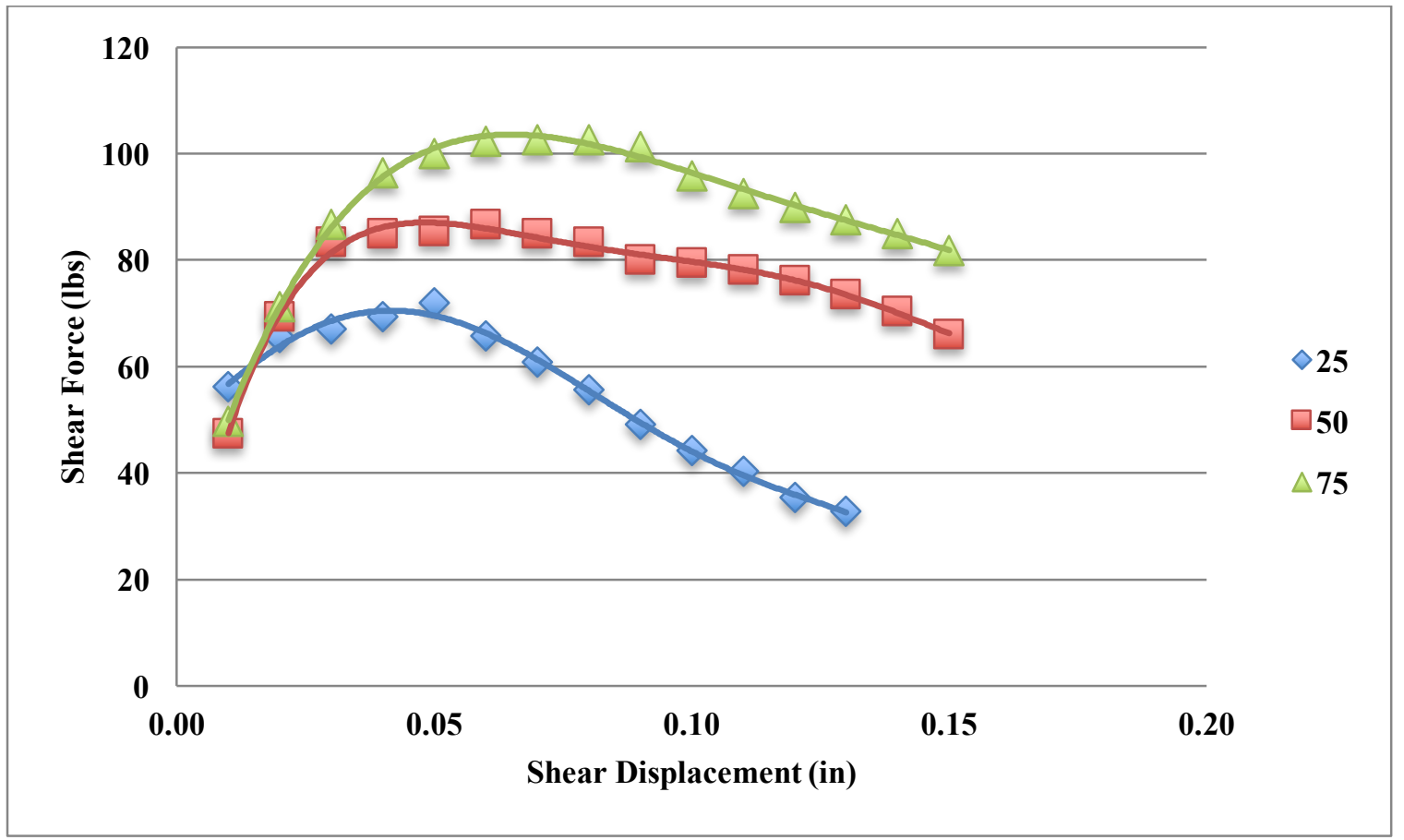

Figure E-15: Stress-strain plots for the high plasticity clay at $28 \%$ water content.

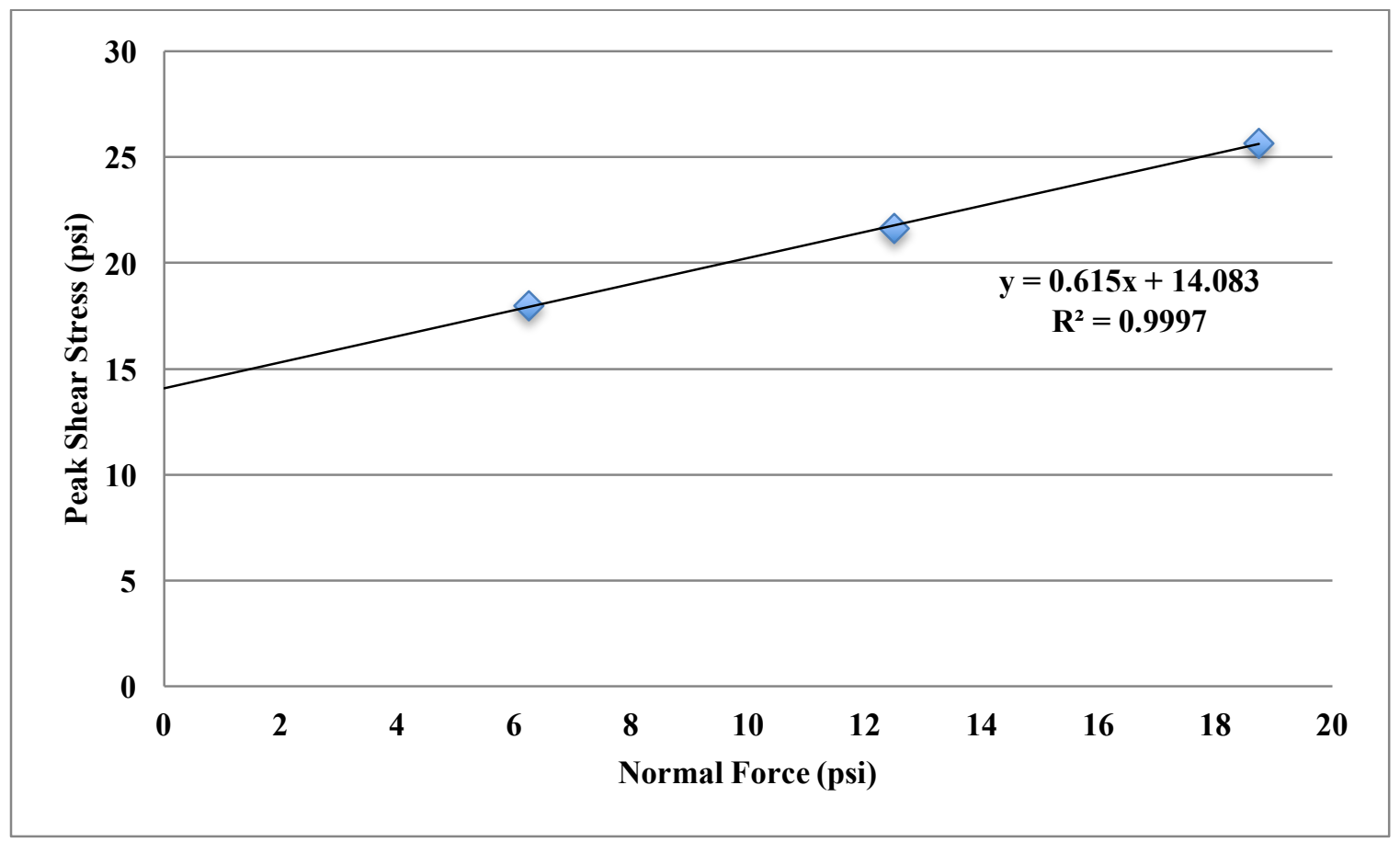

Figure E-16: Mohr Envelope for the high plasticity clay at 28\% water content. 
Sample: High Plasticity Clay

Water Content: $29 \%$

Applied Load: 25 lbs, 50 lbs, 75lbs

Peak Shear Load: 70.3 lbs, 87.0 lbs, 104.3 lbs

Table E-9

\begin{tabular}{|c|c|c|c|}
\hline Normal Load: & $25 \mathrm{lbs}$. & 50 lbs. & $75 \mathrm{lbs}$. \\
\hline Displacement (0.001 in.) & Force (lbs.) & Force (lbs.) & Force (lbs.) \\
\hline 10 & 47.4 & 52.0 & 62.5 \\
\hline 20 & 61.2 & 71.0 & 78.8 \\
\hline 30 & 69.3 & 83.4 & 92.5 \\
\hline 40 & 70.3 & 87.0 & 100.7 \\
\hline 50 & 67.0 & 84.7 & 104.3 \\
\hline 60 & 63.1 & 83.4 & 100.7 \\
\hline 70 & 60.5 & 81.8 & 100.1 \\
\hline 80 & 56.3 & 80.1 & 100.1 \\
\hline 90 & 52.7 & 80.1 & 99.4 \\
\hline 100 & 48.1 & 80.1 & 95.2 \\
\hline 110 & 44.2 & 80.1 & 88.3 \\
\hline 120 & 38.3 & 80.1 & 84.0 \\
\hline 130 & 31.1 & 80.1 & 80.1 \\
\hline 140 & 27.5 & 80.1 & 74.6 \\
\hline 150 & 26.5 & 79.6 & 72.0 \\
\hline 160 & 26.2 & 79.8 & 71.3 \\
\hline 170 & 26.2 & 80.0 & 70.6 \\
\hline 180 & 26.2 & 79.9 & 69.3 \\
\hline 190 & 26.2 & 79.9 & 69.3 \\
\hline
\end{tabular}




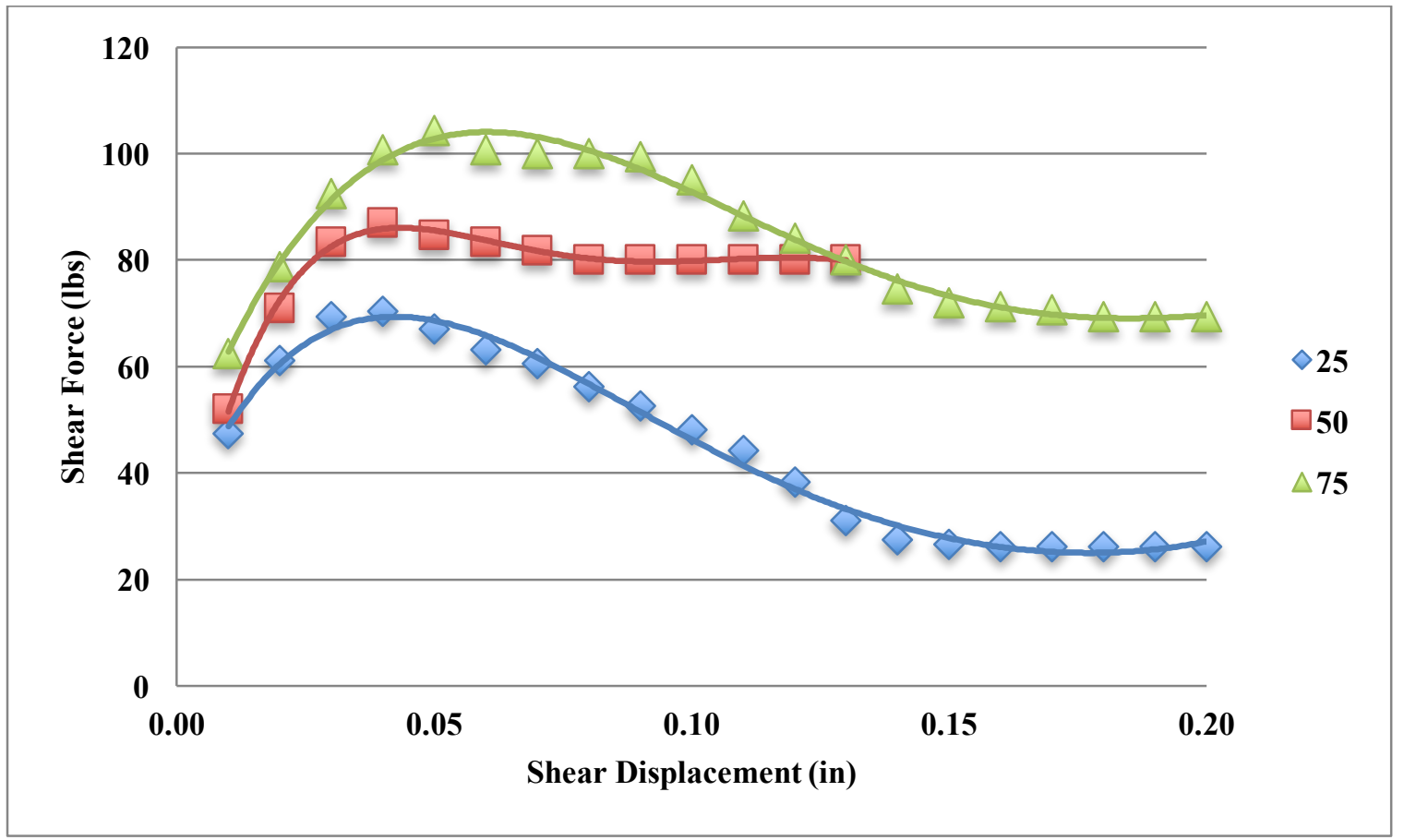

Figure E-17: Stress-strain plots for the high plasticity clay at 29\% water content.

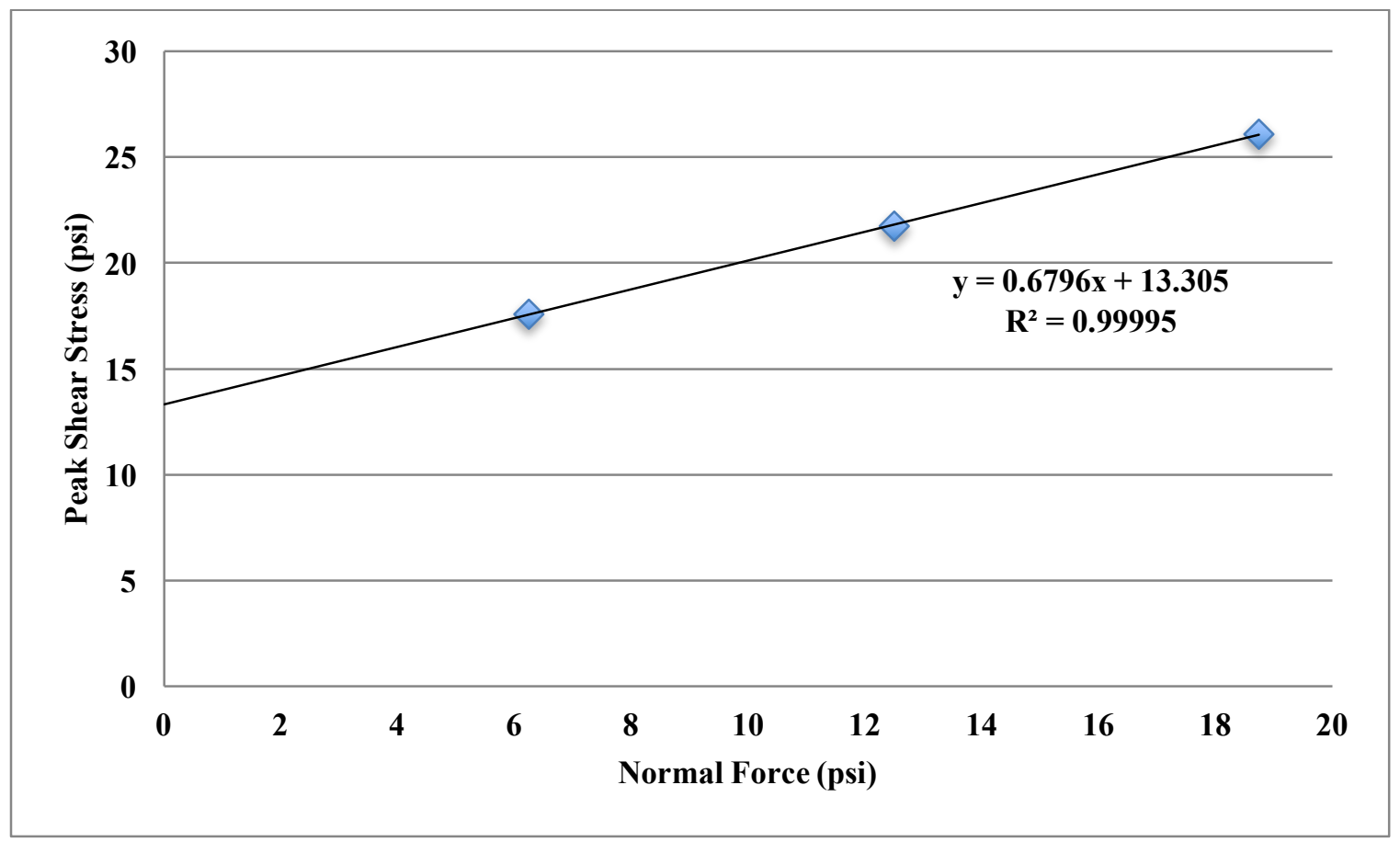

Figure E-18: Mohr envelope for the high plasticity clay at 29\% water content. 
Sample: High Plasticity Clay

Water Content: 30\%

Applied Load: 25 lbs, 50 lbs, 75lbs

Peak Shear Load: 83.4 lbs, 87 lbs, 106.6 lbs

Table E-10

\begin{tabular}{|c|c|c|c|}
\hline Normal Load: & $25 \mathrm{lbs}$. & $50 \mathrm{lbs}$. & 75 lbs. \\
\hline Displacement (0.001 in.) & Force (lbs.) & Force (lbs.) & Force (lbs.) \\
\hline 10 & 55.6 & 54.0 & 56.3 \\
\hline 20 & 73.6 & 72.3 & 76.9 \\
\hline 30 & 83.4 & 80.8 & 90.6 \\
\hline 40 & 75.9 & 83.4 & 100.1 \\
\hline 50 & 75.2 & 86.7 & 105.3 \\
\hline 60 & 71.3 & 87.0 & 106.6 \\
\hline 70 & 57.2 & 85.0 & 104.0 \\
\hline 80 & 51.0 & 80.4 & 100.1 \\
\hline 90 & 47.4 & 75.2 & 93.8 \\
\hline 100 & 44.5 & 72.0 & 87.6 \\
\hline 110 & 41.9 & 69.0 & 81.4 \\
\hline 120 & 37.6 & 66.1 & 75.2 \\
\hline 130 & 35.7 & 61.8 & 55.6 \\
\hline 140 & 34.4 & 58.2 & 47.4 \\
\hline 150 & 33.1 & 53.6 & 42.5 \\
\hline 160 & 32.1 & 52.3 & 38.6 \\
\hline 170 & 27.8 & 52.0 & 36.7 \\
\hline 180 & 27.5 & 52.0 & 34.4 \\
\hline 190 & 29.5 & 52.0 & 32.7 \\
\hline 200 & 29.5 & 52.0 & 32.4 \\
\hline
\end{tabular}




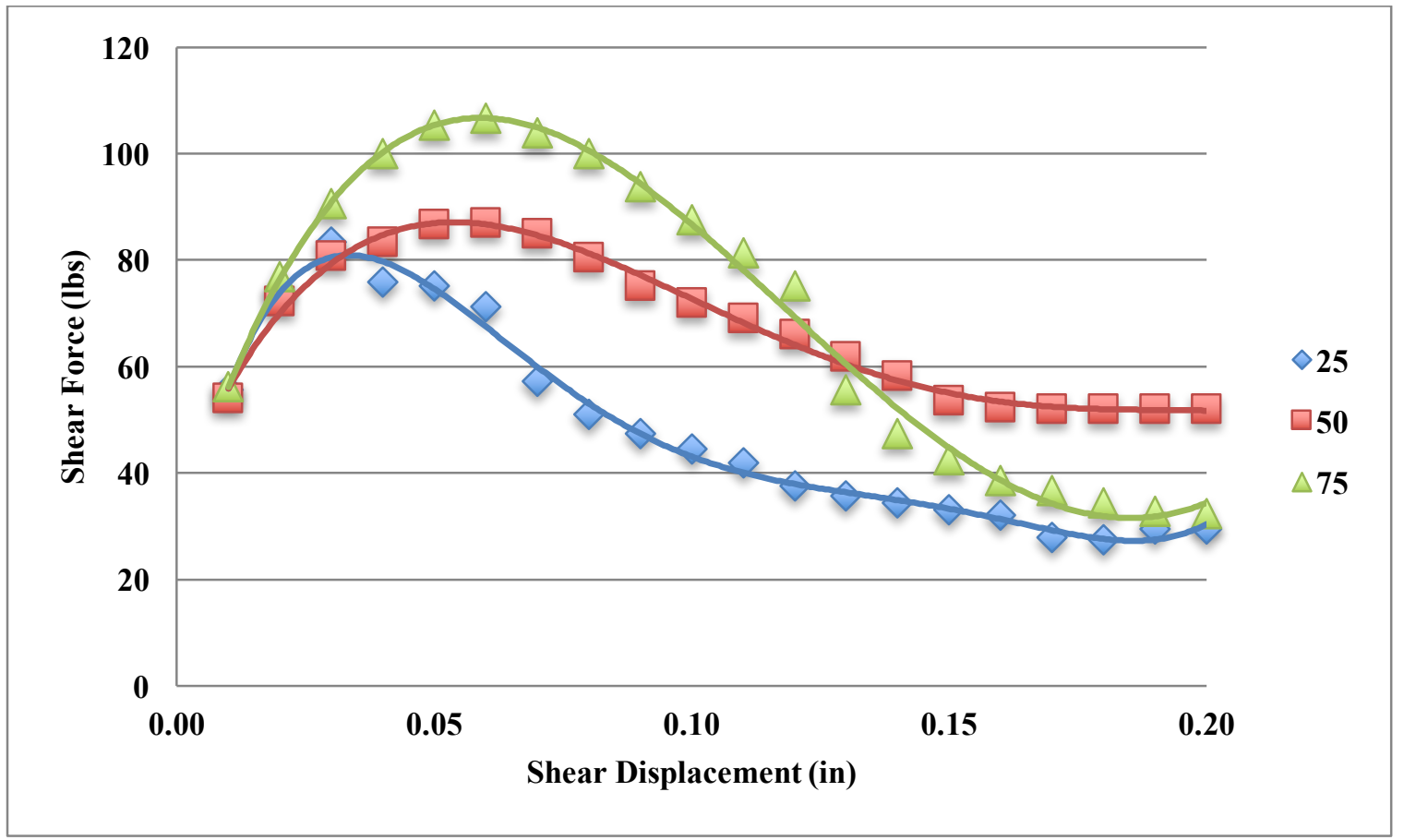

Figure E-19: Stress-strain plots for the high plasticity clay at 30\% water content.

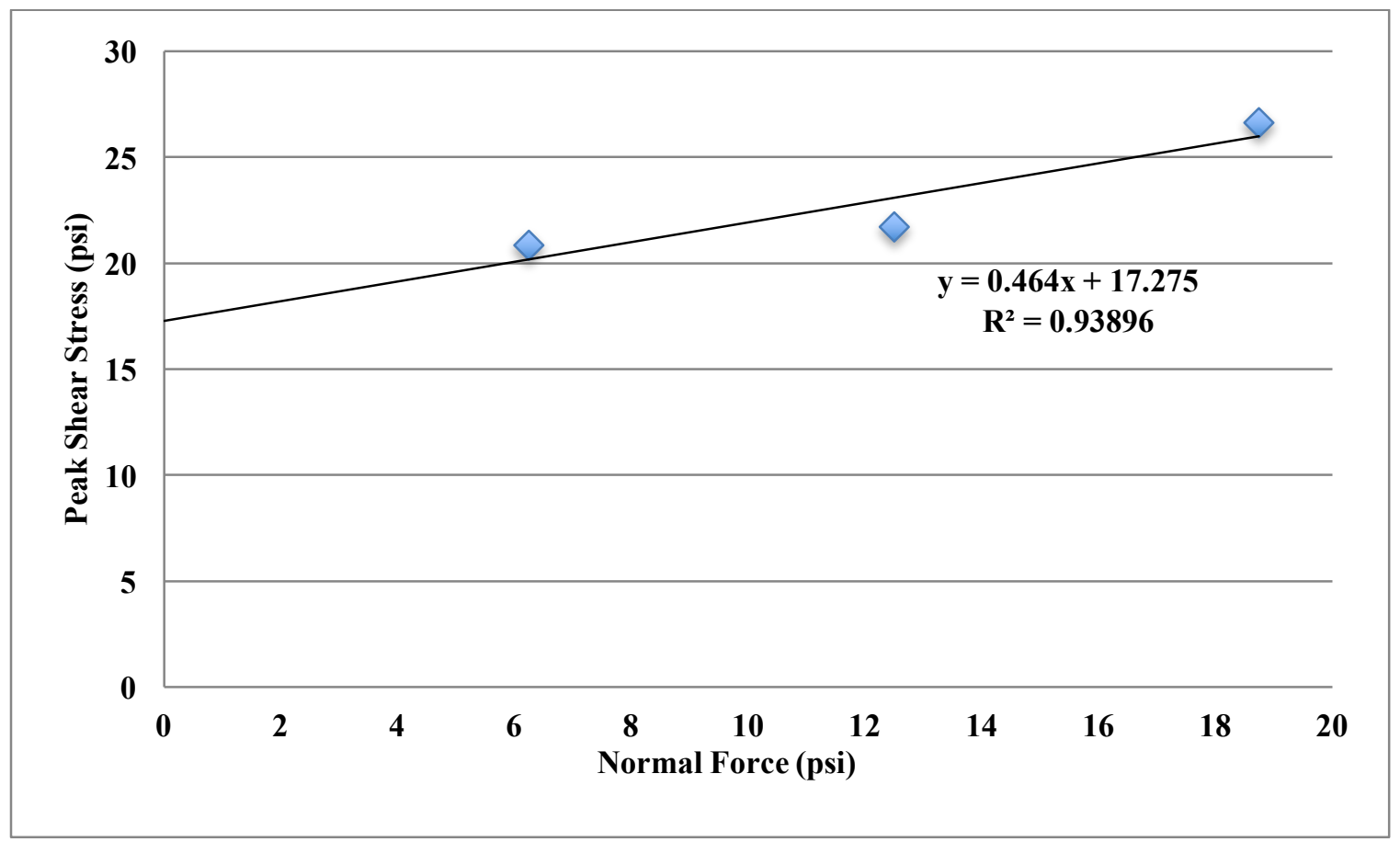

Figure E-20: Mohr envelope for the high plasticity clay at 30\% water content. 
Sample: High Plasticity Clay

Water Content: $32 \%$

Applied Load: 25 lbs, 50 lbs, 75lbs

Peak Shear Load: 50.4 lbs, 62.1 lbs, 75.5 lbs

Table E-11

\begin{tabular}{|c|c|c|c|}
\hline Normal Load: & 25 lbs. & 50 lbs. & 75 lbs. \\
\hline Displacement (0.001 in.) & Force (lbs.) & Force (lbs.) & Force (lbs.) \\
\hline 10 & 29.5 & 33.7 & 40.9 \\
\hline 20 & 36.0 & 45.8 & 54.0 \\
\hline 30 & 40.9 & 52.0 & 62.1 \\
\hline 40 & 45.8 & 55.6 & 66.4 \\
\hline 50 & 49.1 & 58.9 & 70.0 \\
\hline 60 & 50.4 & 60.5 & 72.9 \\
\hline 70 & 47.4 & 62.1 & 74.2 \\
\hline 80 & 41.6 & 61.2 & 75.2 \\
\hline 90 & 35.7 & 57.2 & 75.5 \\
\hline 100 & 32.1 & 53.3 & 74.9 \\
\hline 110 & 29.8 & 50.7 & 73.3 \\
\hline 120 & 27.8 & 49.1 & 71.0 \\
\hline 130 & 26.5 & 49.1 & 68.4 \\
\hline 140 & 25.9 & 49.1 & 66.4 \\
\hline 150 & 25.5 & 49.1 & 64.8 \\
\hline 160 & 25.5 & 49.1 & 62.8 \\
\hline 170 & 25.5 & 49.1 & 62.8 \\
\hline
\end{tabular}




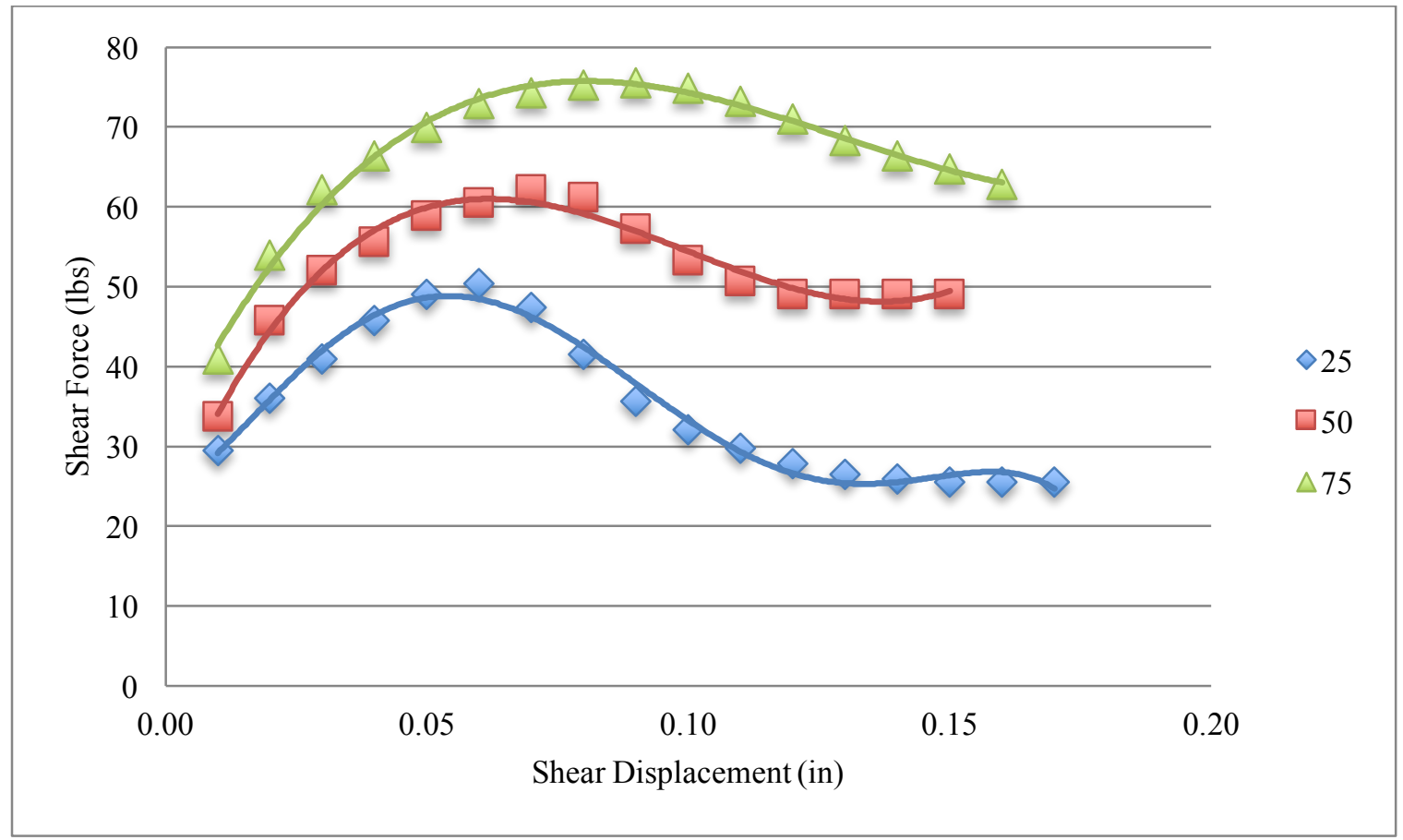

Figure E-21: Stress-strain plots for the high plasticity clay at $32 \%$ water content.

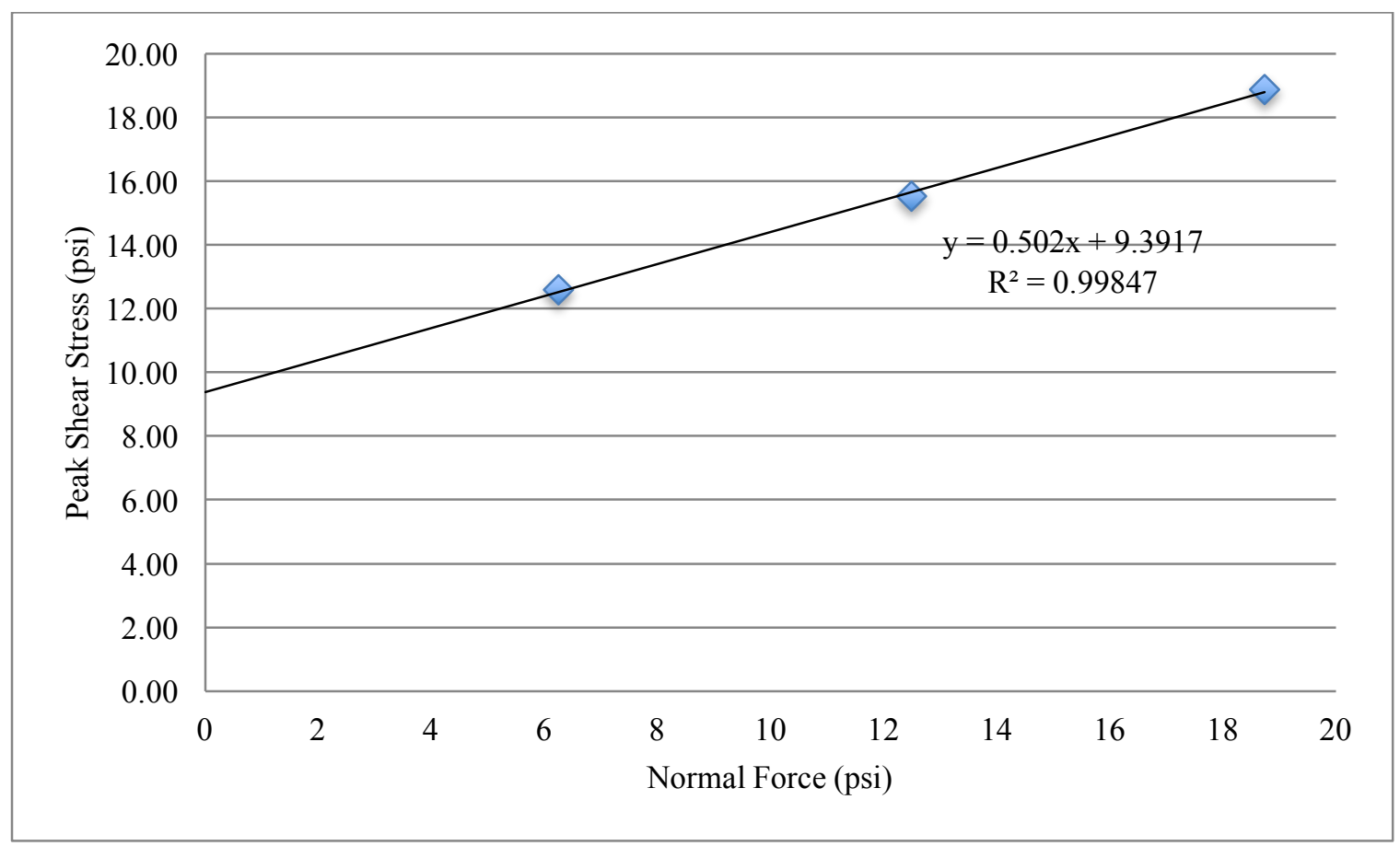

Figure E-22: Mohr envelope for the high plasticity clay at 32\% water content. 